\title{
A POPULATION-BASED STUDY OF FACTORS AFFECTING ACCESS TO RADIOTHERAPY FOR ENDOMETRIAL CANCER IN ONTARIO
}

by

Timothy Paul Hanna

A thesis submitted to the Department of Community Health and Epidemiology

In conformity with the requirements for

the degree of Masters of Science

Queen's University

Kingston, Ontario, Canada

(July, 2009)

Copyright @Timothy Paul Hanna, 2009 


\begin{abstract}
Aims: To describe use of post-operative radiation for endometrial cancer in Ontario. To identify system-related and patient-related factors affecting access to this treatment.

Materials and Methods: We performed a retrospective population-based cohort study of patients with surgically resected endometrial cancer in the Canadian province of Ontario between 19922003. Patients with evidence of incurable cancer at diagnosis or previous cancer diagnosis were excluded. We used multiple logistic regression to assess patient and system factors affecting radiation use. We controlled for disease-related and treatment-related factors: histology, surgical staging, type of hysterectomy and peritoneal biopsy. We applied a mixed model to account for clustering of data by operating hospital.
\end{abstract}

Results: 9,411 women comprised the study cohort. The median age was 63 years. $26.2 \%$ received adjuvant radiation. The proportion of patients receiving radiation varied between cancer centre catchment areas from $18.0 \%$ to $34.3 \%$ (median 26.3\%). In multivariate analysis, older patients were more likely to receive radiation up to the age of $80(\mathrm{p}<.0001)$. Patients who lived further from regional cancer centres were less likely to receive radiation $(\mathrm{p}=.0210)$. Patients who had their surgery during longer prevailing wait times at regional cancer centres were less likely to receive radiation $(\mathrm{p}=.0441)$. There was a 2.7 -fold variation in the odds of radiation use between cancer centre catchments $(\mathrm{p}<.0001)$. Management at a comprehensive gynecologic oncology centre was associated with use of radiation for patients who had surgical staging of lymph nodes. Year of diagnosis and neighborhood income quintile did not significantly affect the use of radiation. Conclusions: There is wide variation in use of radiation for endometrial cancer in Ontario. There is evidence that system factors unrelated to patient's needs affect use of adjuvant radiation for endometrial cancer in Ontario. Age is a key patient-related factor affecting radiation use. 


\section{Co-Authorship}

This thesis presents the work of Timothy Hanna in collaboration with his supervisors, Dr. William J. Mackillop, Dr. Harriet Richardson and Dr. Paul Peng.

Manuscript 1. A Population-Based Study of Factors Affecting Access to Radiotherapy for

Endometrial Cancer in Ontario. The research concept was developed by TP Hanna with input from WJ Mackillop, H Richardson, P Groome, L Levesque and P Peng. Methodology was developed by TP Hanna, WJ Mackillop and H Richardson. Data linkage and statistical analysis was performed by TP Hanna. Some SAS program code was written by others and modified by TP Hanna for use in parts of the analysis. Code from Gavin Lee and J. Zhang-Salomons was used in developing the concept of most responsible cancer centre. Derivation of hospital type used code from Weidong Kong identifying hospital amalgamations and name changes. Data interpretation was performed by TP Hanna with guidance from WJ Mackillop, H Richardson and P Peng. The manuscript was written by TP Hanna with supervision and input from WJ Mackillop, P Peng and H Richardson.

The other components of the thesis (i.e. Introduction, Literature Review, Main findings and Conclusions and Appendices) were the work of Timothy Hanna with feedback and suggestions from Dr. WJ Mackillop, Dr. P Peng and Dr. H Richardson. The conceptual framework relating access to care to medical decision making reflects the work of Timothy Hanna, Dr. D FeldmanStewart and Dr. WJ Mackillop. 


\section{Dedication}

For my dear wife and friend Jeanette, thank-you for all of your love, support and encouragement.

\section{Acknowledgements}

W Picket, W King, T Dyer, S Keller, JP Voroney, Duncan Hunter, K Aaronson, C de Metz, M Brundage, P Groome, J Queenan, Bev Shortt, Miu Lam, Grad Students, Weidong Kong, Grace Miao, Hugh Walker, P Bryson, B Rosen, Teri Stuckless and of course my thesis supervisors WJ Mackillop and H Richardson and P Peng for sharing their knowledge, experience, time and wisdom as they guided me through this project. 


\section{Table of Contents}

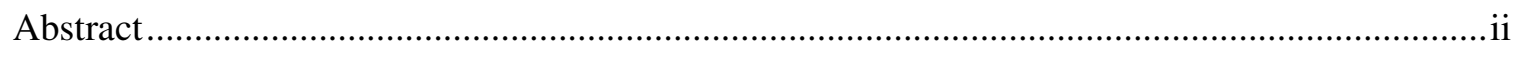

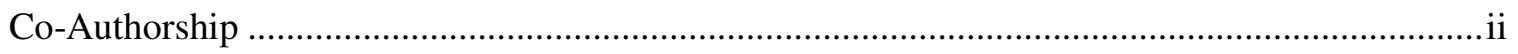

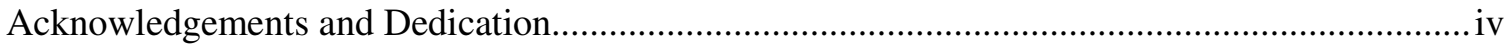

Chapter 1 General Introduction and Literature Review ............................................................ 1

Chapter 2 Methodologic Considerations: Choice and Characterization of Explanatory Variables

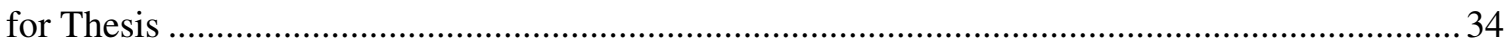

Chapter 3 Paper 1- For Submission to Clinical Oncology ............................................................. 52

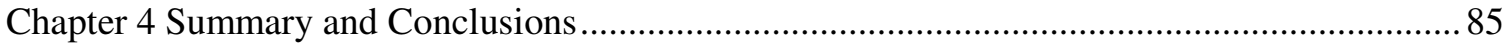

Appendix 1 Percent Missing Values in Data Set........................................... 98

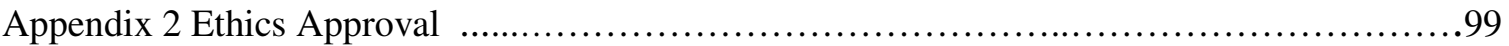




\section{List of Figures}

\section{Chapter 1}

Figure 1. Lymph nodes sampled during surgical staging .................................

Figure 2. Types of radiation for endometrial cancer..................................

Figure 3. Conceptual framework: relationship of access to care and medical decision

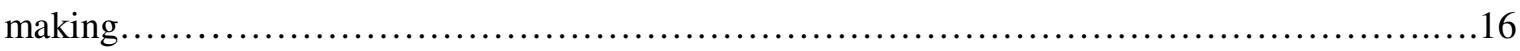

\section{Chapter 2}

Figure 1. Number of operating hospitals with given proportions of endometrial cancer patients

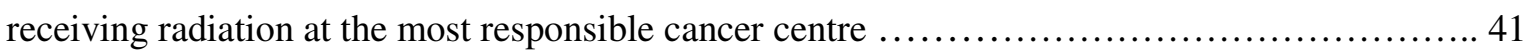

Figure 2. Most responsible cancer centre by county for endometrial cancer patients in Ontario ...42

\section{Chapter 3}

Figure 1. Data linkage relationships for Endometrial Cancer Database....................... 74

Figure 2. Adjuvant radiation for endometrial cancer by operating hospital....................79

Figure 3. Proportion of patients receiving adjuvant radiation for endometrial cancer in Ontario by

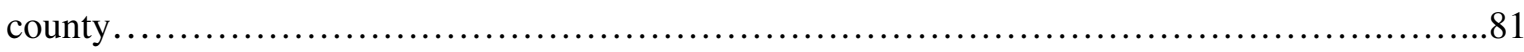

Figure 4. Proportion of patients receiving surgical staging for endometrial cancer in Ontario by

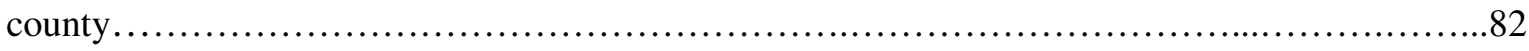




\section{List of Tables}

\section{Chapter 1}

Table 1. Risk stratification for local recurrence for Stage I and II tumors of the

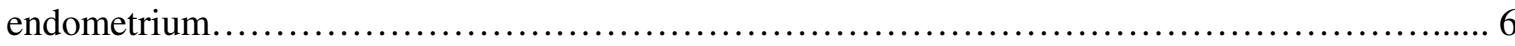

Table 2. Dimensions of access to post-operative radiation for endometrial cancer and factors potentially affecting them that can be measured by administrative data................. 22

\section{Chapter 2}

Table 1. Classification of independent variables for study of factors affecting use of adjuvant radiation for endometrial cancer in Ontario volume.

Table 2. Proportion of patients managed at hospitals with specified annual surgical

volume 38

Table 3. Pearson Correlation Coefficient Matrix for gynecologic oncologist involvement, radiation oncologist involvement and annual surgical volume for endometrial cancer.... 38

Table 4. Proportion of patients with indicated Deyo and Elixhauser comorbidity scores for the Endometrial Cancer Cohort

\section{Chapter 3}

Table 1. Characteristics of patient-, disease- and treatment-factors at Comprehensive Gynecologic Oncology Centres versus other hospitals................................. 75

Table 2. Stage distribution by age group for 2003 staged cohort...................... 76 Table 3. System-related factors affecting use of adjuvant radiation for endometrial cancer

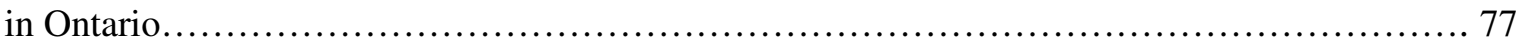

Table 4. Patient-, disease- and treatment-related factors affecting use of adjuvant radiation

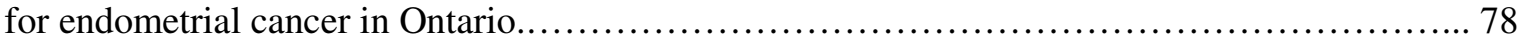

Table 5. Multivariate analysis stratified by performance of surgical staging............80 


\section{Appendix 1}

Tabe 1. Percent missing values in data set for explanatory variables.................98 


\section{Chapter 1}

\section{Chapter 1: General Introduction and Literature Review}

Though radiotherapy is an important part of the curative treatment of many cancers, access to this treatment in Ontario has been shown to be limited by factors unrelated to patient's needs. A number of patient and health system factors such as age, distance of residence from a cancer centre, neighborhood economic status, year of treatment, treating cancer centre, and

prevailing wait time may influence radiation use or practice. ${ }^{1-3}$ Radiation therapy for endometrial cancer is often part of treatment after surgery, especially for localized disease. However, it is unknown whether patient and health system factors shown in other settings to affect access to radiotherapy affect access to radiation for endometrial cancer.

Data from the past 25 years suggest radiation reduces the chance of cancer returning in the region of the original tumor. ${ }^{4-6}$ The radiation oncology community generally agrees that there are certain women with early-stage endometrial cancer whose risk of their cancer returning is so low that they should not have post-operative radiation and those whose risk is so high that they clearly should. ${ }^{7,8}$ There has, however, been some controversy regarding whether post-operative radiation has any benefit for women at intermediate risk of cancer recurrence.

A gynecological surgeon is usually the party referring patients for radiation. In Canada, there is a specific stream of gynecologic surgeon that treats only gynecologic cancer patients including endometrial cancer. They are specially trained to perform lymph node removal. This is also referred to as a lymphadenectomy or lymph node staging. Gynecologic surgeons who refer patients for radiation sometimes remove lymphatic tissue during surgery in order to assess whether a woman's cancer has spread beyond the uterus into the lymphatic system. Some oncologists will 
not use radiation for selected early stage patients if the sampled lymph nodes do not contain cancer. ${ }^{9}$ Both generalist and specialist gynecologic surgeons work in Ontario and differences in their use of lymph node staging and patterns of referral for radiation when they use lymph node staging are not known but may be very different given that a community gynecologic surgeon may only see a handful of endometrial cancer cases each year.

I hypothesize that access to post-operative radiotherapy for endometrial cancer varies across Ontario, relating to varying knowledge and practice among generalized and specialized surgeons, differences in views between treating radiation oncologists as well as differences in other patient and system factors: prevailing waiting times at regional cancer centres, patient travel distance to cancer centers, neighborhood median income quintile and patient age.

\section{Primary Objectives}

1. To describe variation in use of post-operative radiation for endometrial cancer in Ontario

2. To identify system and patient factors that may be affecting use of post-operative radiation for endometrial cancer in Ontario after controlling for covariates

\section{Contribution}

This will be the first patterns of practice study to examine system factors associated with the use of adjuvant radiation for endometrial cancer in Ontario. It will also be the first study to control for known covariates using multiple regression modeling. Endometrial cancer is a common cancer among women in Ontario and radiation is an important part of its management. ${ }^{10}$ Given this, the current study will be of importance as it will examine whether system and patient factors unrelated to patient's needs may be limiting access to radiation for endometrial cancer in Ontario. 
The factors identified will be of importance as they will be hypothesis-generating for similar studies in other provinces and countries. If any of the investigated factors are associated with less use of radiation, this study's results may fuel further investigation and exploration of means to improve access, when appropriate, through targeted provincial policies and initiatives.

\section{Overview of Endometrial Cancer}

Pathology. The most commonly diagnosed form of invasive endometrial cancer is endometrioid adenocarcinoma, accounting for 75 to $85 \%$ of cases. ${ }^{11-13}$ Nonendometrioid tumours represent a smaller proportion of neoplasms and include papillary serous adenocarcinoma and clear cell adenocarcinoma that each account for $10 \%$ and $4 \%$ of cases respectively. These are associated with two to three times the risk of advanced disease at presentation and poorer prognosis stage for stage compared to endometrial tumours. ${ }^{11,13}$

Descriptive Epidemiology. Cancers of the endometrium (uterine corpus) account for approximately $3.8 \%$ of all female neoplasms worldwide, with an estimated 142,000 new cases annually. It ranks as the $7^{\text {th }}$ most common malignancy affecting women worldwide. ${ }^{14}$ North American incidence rates are the highest in the world at 22 per 100,000 and cancer of the endometrium ranks as the $4^{\text {th }}$ most common malignancy affecting women in Canada. ${ }^{14,15}$

In Ontario, an estimated 1,550 new cases of uterine cancers are diagnosed each year. ${ }^{16}$ The projected age standardized incidence rate in Ontario for 2009 was 21 per 100,000 population. ${ }^{17}$ An estimated 320 women died of uterine corpus cancer in 2009 in Ontario, with an age-standardized mortality rate of 3 per 100,000 . 
Risk Factors. The risk for endometrial cancer rises rapidly in women over the age of 40 and declines in women after the age of 70. The major known risks for endometrial cancer are thought to be hormone-related, most of which are hypothesized to be related to unopposed estrogen exposure. These include estrogen-only hormone replacement therapy, tamoxifen for breast cancer treatment, early menarche, late menopause, nulliparity, long ovulation span, polycystic ovarian syndrome, as well as increased body mass and low-fibre, high-fat diets. ${ }^{18-32}$ Rarely, familial causes are involved. ${ }^{30-31}$ Smoking and combined birth control pill use decreases the risk of endometrial cancer. ${ }^{33}$ Overall, the population attributable risk for known risk factors is at least $50 \%{ }^{32,34}$ However, it is difficult to disentangle the confounding effects of obesity, diet and endogenous estrogens on risk of disease.

Detection and Diagnosis. Endometrial cancer presents in $80 \%$ of cases with postmenopausal bleeding. ${ }^{35}$ In premenopausal women, it may present as heavy bleeding with periods or other abnormal uterine bleeding patterns. $10 \%$ of cases have a vaginal discharge. Less commonly, patients may present with symptoms of locally advanced disease: pelvic pain, bloody urine or rectal bleeding, large bowel obstruction or renal failure. Rarely patients may present with metastatic disease. ${ }^{35}$ An endometrial biopsy may serve as a definitive diagnosis, though if this is negative and bleeding symptoms persist, a hysteroscopy, dilatation and curettage is usually definitive.

Cancer Staging. Endometrial cancer is usually surgically staged. ${ }^{36}$ Stage I cancers are confined within the body of the uterus. Stage I endometrioid adenocarcinomas can be further characterized as low-risk, intermediate-risk and high-risk, based on tumour grade, capillary space invasion with 
tumor, patient age and depth of myometrial invasion. Stage II cancers invade the cervix. Stage III and IVa cancers have spread outside the body of the uterus and cervix, including lymph nodes and direct invasion of adjacent structures. Stage IVB indicates distant metastasis. Approximately $80 \%$ of women with endometrial cancer present at an early stage, where it is confined to the uterus. Endometrioid endometrial cancer spreads first by local extension. It also commonly spreads to regional lymph nodes in the pelvis and less commonly to lymph nodes surrounding the aorta and inferior vena cava in the abdomen. Endometrial cancer may sometimes seed itself across the lining of the abdominal contents. In $3 \%$ of cases of endometrioid adenocarcinoma, spread occurs through the blood to distant organs such as the lungs, liver, bone. ${ }^{13}$

\section{Management}

Management for stage I and II cancers of the endometrium depends on their risk of recurring in the pelvis and of distant metastasis. Stage I and II endometrial cancers are divided into low-, intermediate- and high-risk of recurrence categories. Tumors are low-risk if they have none of the following features: poor differentiation, invasion of lymphatics or capillaries, serous papillary or clear cell histologies, involvement of the cervix or invasion into the outer half of the myometrium (Table 1$).^{37,38}$ Tumors that are poorly differentiated, invade capillaries or lymphatics or invade the outer half of the myometrium are categorized as intermediate-risk. Tumors that are poorly 


\begin{tabular}{|c|c|c|}
\hline Low-risk & Intermediate-risk & High-risk \\
\hline $\begin{array}{l}\text { 1. No intermediate-risk } \\
\text { or high-risk features }\end{array}$ & $\begin{array}{l}\text { 1. Poorly differentiated } \\
\text { OR Invasion of outer } \\
\text { half of myometrium } \\
\text { 2. Tumor invades } \\
\text { capillaries or } \\
\text { lymphatics }\end{array}$ & $\begin{array}{l}\text { 1. Poorly differentiated } \\
\text { AND Invasion of } \\
\text { outer half of } \\
\text { myometrium } \\
\text { 2. Serous papillary or } \\
\text { clear cell histology } \\
\text { 3. Cancer extends to } \\
\text { cervix }\end{array}$ \\
\hline
\end{tabular}

differentiated and also invade the outer half of the myometrium are high-risk. Tumors involving the cervix or are serous papillary or clear cell histologies are also high-risk tumors.

Increased age has also been considered as an additional risk factor risk of local recurrence and need for radiation. ${ }^{38}$ The GOG-99 trial characterized women at high-intermediaterisk of local recurrence if their age was 70 or above and their cancers were either poorly differentiated, invaded the outer half of the myometrium or had lymphatic or capillary invasion. If women were 50 to 69 , their tumors fell into a high-intermediate risk category if two of these three characteristics were present. If their age was 49 or less, all three characteristics had to be present to be at high-intermediate risk. ${ }^{38}$

A pelvic lymphadenectomy or pelvic lymph node dissection is a selective removal of lymph node bearing tissue from the pelvis (Figure 1). In the case of endometrial cancer, it is usually performed for diagnostic purposes. Sometimes peri-aortic lymph nodes are also sampled or dissected. Unlike obstetrician gynecologists, gynecologic oncologists are thoroughly trained to perform pelvic and peri-aortic lymphadenectomies. Gynecologic surgeons will sometimes perform a lymph node dissection and if negative, the patient may not receive radiation if there are no highrisk features for local recurrence of the cancer. If there are lymph nodes involved with cancer, the 
patient will usually receive radiation and potentially chemotherapy. The risks of lymphadenectomy include chronic leg swelling and fluid collections in the pelvis that may become infected. ${ }^{39-41}$ Sometimes suspicious looking lymph nodes are removed. This is a selective sampling of representative lymph nodes and is performed in order to minimize the morbidity of lymph node staging. This form of lymph node staging may be done by non-specialist gynecologic surgeons as well as gynecologic oncologists.

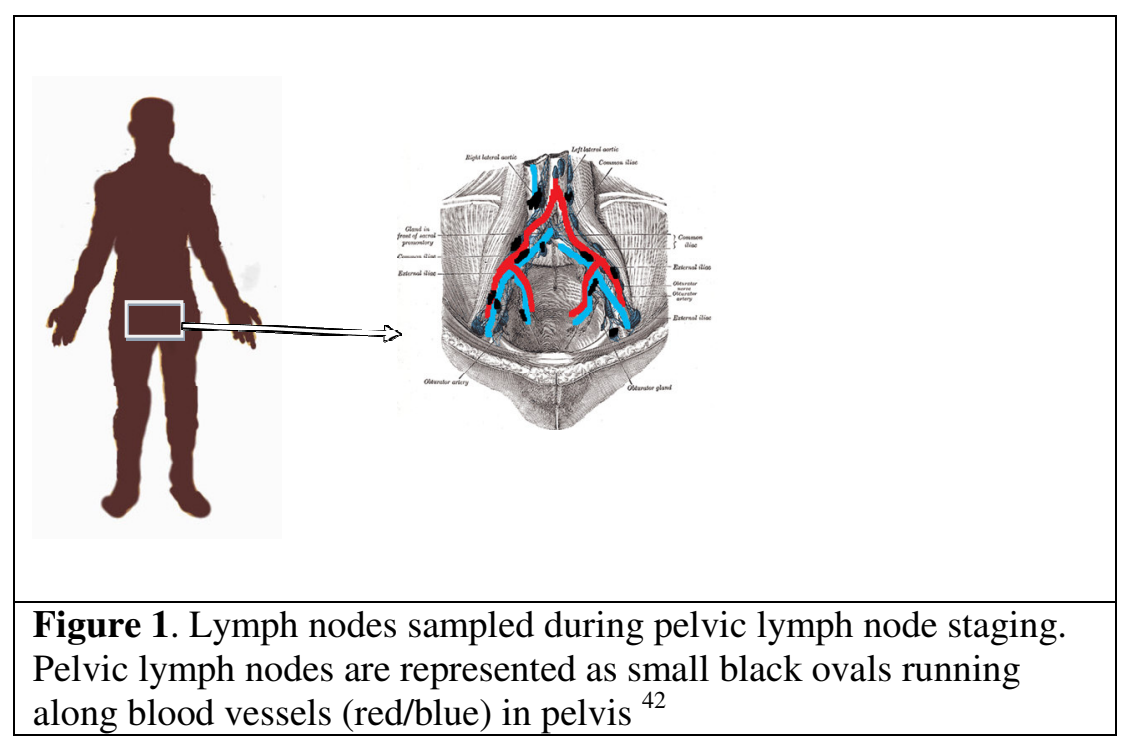

\section{Management of Low-risk Stage I Endometrial Cancer}

Patients with well-differentiated stage 1 tumors are generally treated with simple hysterectomy alone. ${ }^{43}$ It involves removal of the uterus with minimal displacement of the bladder or rectum. The ovaries may or may not be removed. Retrospective series have suggested that women with low-risk stage I cancers are at such low risk of recurrence that radiation should not be included in 
their treatment. ${ }^{43-45}$ Some women with stage I and II cancers who are poor surgical candidates are treated with radiotherapy alone. ${ }^{43}$ This is uncommon and cure rates are not as high as with surgery.

\section{Management of Intermediate-risk Stage I Endometrial Cancer}

Historical series have suggested that the risk of lymph node metastases is between 15$40 \%$ and pelvic recurrence risk is $15-30 \%$ for intermediate-risk patients treated with surgery alone. ${ }^{44,46}$ Estimates suggest that approximately two thirds of intermediate-risk stage I endometrial cancer patients whose disease returns will recur in the pelvis without distant metastasis. ${ }^{6,38}$ This local recurrence risk has been considered sufficiently high to justify additional treatment with radiation in an attempt to increase cure rates. Though randomized controlled clinical trials have found that radiation therapy after surgery for intermediate-risk patients reduces the risk of recurrence significantly, it has no impact on overall survival. ${ }^{6,38,47}$ This has led to considerable controversy regarding whether radiation is appropriate for this group of patients. Cancer Care Ontario's (CCO) guideline on the topic recommends radiation for patients at high risk of recurrence based on stage and grade of tumor and those at low risk are recommended not to receive radiation. ${ }^{8}$ CCO's guideline states that it is 'reasonable' to prescribe external beam radiation therapy (EBRT) for women at intermediate risk of recurrence.

Endometrial cancer most frequently recurs at the vaginal vault after a hysterectomy. ${ }^{6}$

Therefore, some intermediate-risk patients with stage I disease are treated with only vaginal vault brachytherapy which is a form of temporarily inserted radiation (Figure 2). It allows radiation to be given to a targeted area at the top of the vagina (vaginal vault). This is done by placing one or more thin, hollow tubes called applicators inside the vagina. Each applicator is connected to a tube that 
allows a radiation source to travel into the applicator from a shielded storage unit by being propelled at the end of a thin wire. ${ }^{48}$ Brachytherapy can be given at a low dose rate (LDR) or high dose rate (HDR). LDR requires a 2-3 day hospitalization while HDR requires one to three outpatient visits each lasting a few hours. ${ }^{43}$ The optimal role of adjuvant vaginal vault brachytherapy in treating endometrial cancer is unclear. ${ }^{8}$

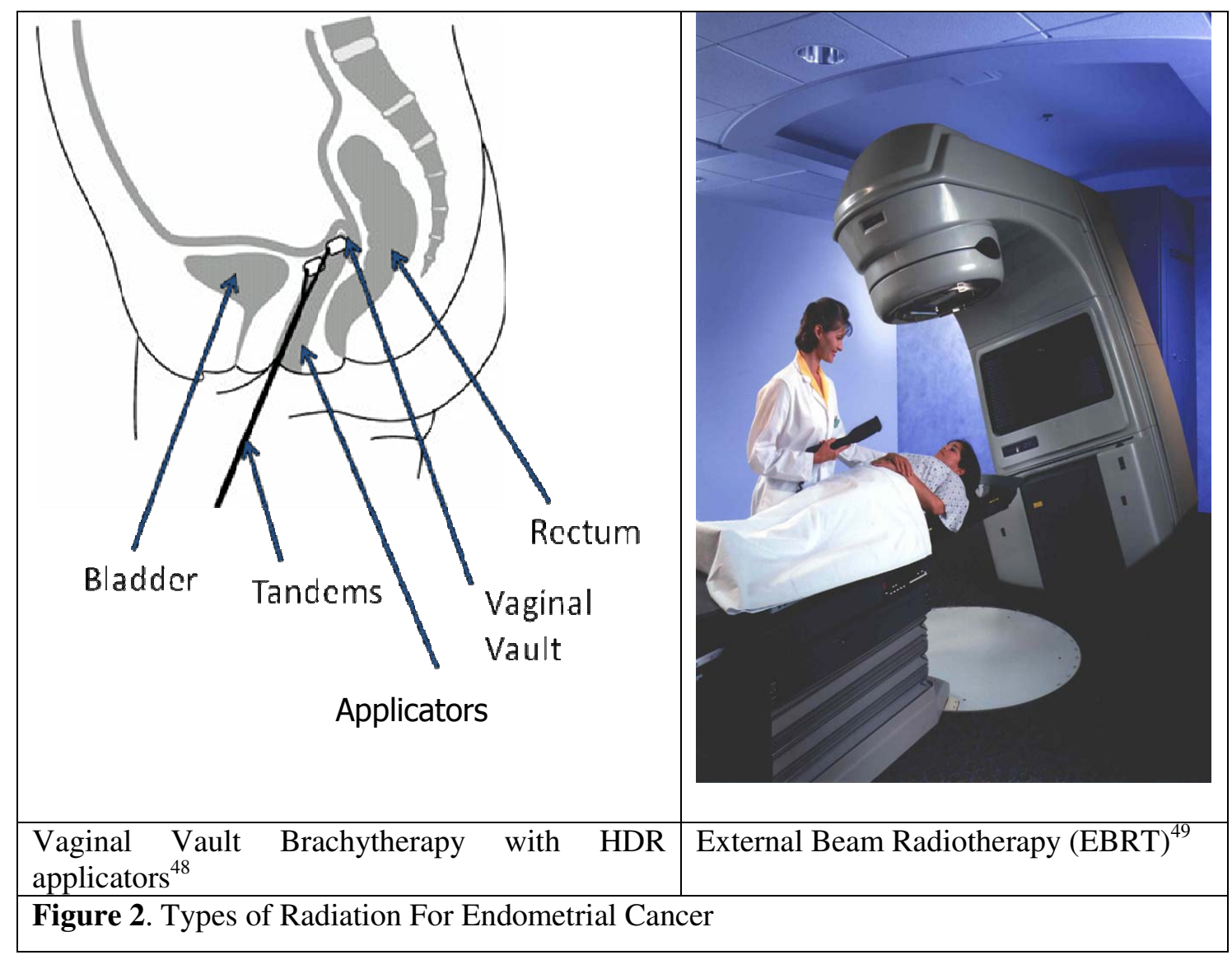




\section{Management of High-risk stage I and stage II Endometrial Cancer}

Patients with high-risk stage I and II disease are almost always offered radiation after their surgery to reduce their chance of pelvic cancer recurrence. Even with radiation, patients with Stage Ic, poorly differentiated tumors have a $13 \%$ rate of local recurrence. ${ }^{37}$ Some guidelines recommend routine lymph node staging for high-risk patients. ${ }^{50}$

Gynecologic Oncologists will sometimes treat patients with cases of endometrial cancer that are visibly spread outside the body of the uterus into the parametria or cervix with a more extensive surgery called a radical hysterectomy. As a radical hysterectomy is most likely done for aggressive cancers that have spread beyond the body of the uterus, it is much more likely that radiation will be part of the post-operative management for a given case.

As rates of distant metastasis are high for high-risk patients, being $31 \%$ for stage Ic poorly differentiated cancers, chemotherapy has been investigated as an adjuvant treatment. There have been three major studies showing no overall survival benefit for chemotherapy and one whose early results suggest a 7\% statistically significant improvement in progression-free survival but not overall survival. The role for chemotherapy in high-risk cases of endometrial cancer is hence still unclear. ${ }^{51}$ During the period under study in this thesis, chemotherapy after surgery for this group was not a standard treatment.

\section{Management of Stage III-IVa Endometrial Cancer}

Treatment of advanced cases of endometrial cancer is less well defined than for early stages and may involve surgery, often post-operative radiation and possibly chemotherapy. Radiation fields may include the whole abdomen or the peri-aortic lymph nodes in the upper abdomen given the high risk of disease recurrence in these sites. ${ }^{43}$ 
For metastatic cancer, there is some role for palliative chemotherapy and progestational agents, but response rates are in the range of $20-30 \% .{ }^{43}$ Doctors sometimes use palliative radiation to treat symptoms such as vaginal bleeding or pelvic pain caused by cancer for incurable cases. $^{43}$

\section{Prognosis}

The overall 5-year survival for endometrial cancer is $80 \% .^{52}$ As obesity, hypertension and diabetes are associated with endometrial cancer, it is perhaps not surprising that the 10 -year overall survival for endometrial cancer patients is $66 \%{ }^{6}$ Endometrial cancer is generally highly curable when it is stage I or II with a 5-year survival rate of $91 \%$ for the earliest stage cancers (Ia). ${ }^{52}$ Patients with metastatic disease (IVb) have a $20 \%$ 5-year overall survival in comparison. Survival is dependent on tumor, patient and treatment factors. Tumor factors are most notable, and poor prognostic factors include depth of myometrial invasion, high tumor grade, lymphovascular invasion, involved lymph nodes, and clear cell or serous papillary histology. ${ }^{53}$ Age is the most important patient-related prognostic factor. In one influential study, age over 70 was found to be associated with notably higher risk of cancer recurrence. ${ }^{38,43}$ Treatment factors include whether appropriate chemotherapy and radiation are administered.

\section{Patterns of Practice Studies and Oncology}

Practice variation has long been recognized within the field of medicine, though John Wennberg produced some of the first recognized studies documenting this phenomenon. ${ }^{54,55}$ Wennberg's main observations were large practice variation between groups of patients in relatively small geographic regions, medical care signatures that were stable over time and greater 
variation for procedures and conditions where there was more uncertainty and less agreement among physicians on optimal management. ${ }^{55,56} \mathrm{He}$ was one of the first to popularize populationbased, rather than hospital-based analysis utilizing computerized administrative data. ${ }^{55}$ Findings of practice variation have been noted to be an almost universal phenomenon in medicine, confirmed by numerous studies. ${ }^{54,57,58}$ This practice variation may come about by unnecessary care and hence overuse, insufficient care and hence underuse or appropriate use with varying disease rates and patient preference. ${ }^{59}$ Variation is inappropriate if it is not related to scientific knowledge or patient values, needs or wants. ${ }^{57}$ Practice variation hence matters as it can be one indicator of quality of care. ${ }^{60}$

Practice variation has been documented in radiation oncology practice in numerous studies from the province of Ontario. Dose, fractionation and use of radiation vary across the province for almost every site considered. Published site-specific studies include non-small cell lung cancer, breast cancer, bladder cancer, palliative radiation for bone metastasis, glioblastoma, Hodgkin's disease, Larynx cancer, and rectal cancer. ${ }^{1,3,61-66}$ Other studies have found variation in practice between various cancers treated with curative radiation, among patients dying of cancer or with age. ${ }^{2,67,68}$

System factors and patient related factors can affect practice. For instance, variation exists in the utilization of post-operative (adjuvant) radiotherapy for breast cancer in Ontario by geographic region, patient age and neighborhood economic status. ${ }^{1}$ A number of other factors such as life expectancy, treating cancer centre and prevailing wait time may also influence radiation use or radiation dose and fractionation., 3, 69, 70 Again using the example of breast cancer adjuvant therapy, Ashworth, Kong, Whelan and Mackillop found wide variation in choice of radiation dose fractionation for breast cancer between 1984 to $2004 .^{70}$ 
Some studies of practice variation have been completed for use of radiation for endometrial cancer. Vulto et al examined patterns of referral for endometrial cancer in the Southern Netherlands for 1988 to $1999 .^{71}$ They found a more than two-fold variation in referral for radiation for endometrial cancer between the nine hospitals studied (mean $42 \%$ range $29 \%-63 \%$ ). In a multiple logistic regression, patients diagnosed in the last four years of the study were half as likely to receive radiation as those diagnosed in the first four years. Patients at medium-sized hospitals ( 350 to 500 beds) were $50 \%$ more likely to be referred for radiation compared to patients from large hospitals ( $>500$ beds). Patients with stage II and III cancers were 3.2 and 4.2 times as likely to receive radiation compared to stage I patients. A brief survey from the U.K. found large variation among gynecological surgeons in use of radiation. ${ }^{72}$ Of those surveyed, 9\% reported using it for all patients and only $43 \%$ and $63 \%$ used information on grade and stage to make this decision respectively. Most endometrial cancer was managed by general gynecologists who saw less than five cases of endometrial cancer per year.

Though there have been numerous previous oncology patterns of practice studies in the province of Ontario, particularly for radiation oncology, this thesis project is only the second to examine endometrial cancer patterns of use of radiation. This is the first study to examine factors associated with utilization of radiation with an effort to control for covariates. Kwon et al. examined utilization of adjuvant radiation for intermediate and high-risk early stage patients in Ontario between 1996 and 2000. ${ }^{73}$ Patients who received adjuvant pelvic radiation were significantly younger, less likely to live in a poor neighborhood, less likely to have any comorbidity, less likely to have high risk disease and equally likely to have had surgical staging as those who did not receive radiation. Probably due to small numbers, this study did not attempt to control for covariates through multiple regression. 


\section{The Concept of Health Care Accessibility}

Penchansky and Thomas originally described the dimensions of access to medical care more than 25 years ago. He labeled them as availability, spatial accessibility, accommodation,

affordability and acceptability. ${ }^{74}$ The importance of awareness as an additional dimension of access has been articulated by Mackillop and also alluded to in other conceptual frameworks. ${ }^{75-77}$ Total system capacity relative to total needs reflect availability of services. Capacity relates to the total available resources as well as the efficiency in their use and flexibility in their application. Spatial accessibility reflects not only the distance one must travel to access health services, but also the time it takes to travel that distance. Accommodation refers to the hours of operation of a health service such as a cancer center or operating room as well as other special services that make utilization of the service possible once the individual is actually present at the site of service. Affordability is still an important element of accessibility to care in Canada's health care system. Indirect or ancillary costs such as pharmaceuticals, lost earnings during treatment, home care and travel costs are all factored into affordability. Acceptability can be described as 'socioorganizational accessibility'. ${ }^{74}$ Acceptability would be an issue for instance if there were a reluctance of some men to see a female physician for the treatment of prostate cancer. ${ }^{74}$ Finally, Awareness reflects both doctor and patient consciousness of health care availability and needs. The referring doctor must be aware of indications for potentially useful services and be aware that those services are available to the patient. The patient must be aware that they have an illness that needs medical attention and know how to seek the medical help that they need.

Access to treatment such as adjuvant radiation is related to the medical decision making process through the conceptual framework outlined in figure 3. The following discussion will highlight key relationships in this framework. In order for an appropriate medical decision to occur, 
it is important to follow best clinical practice. If there is no consensus, than variation in medical decision making can occur, as it probably does in the case of use of radiation for endometrial cancer for intermediate-risk early stage patients. Some treatments have a number of equally good management options. In these cases, the medical decision is especially influenced by patient preference. Low-risk prostate cancer is one example of this situation, where watchful waiting, external beam radiation, brachytherapy (radioactive seed implant) and surgery are all acceptable alternatives.

For a patient to have access to a treatment, they must in the very least be referred for it. Beyond referral, the 6 dimensions of access to treatment described by Penchansky, Thomas and Mackillop are involved. For instance, once a patient is referred for adjuvant radiation for endometrial cancer, they may choose to not attend the consultation or the recommended treatment if they cannot afford to travel for this appointment or if their working hours or family commitments are prohibitive. Both referral and access are affected by health policy. For instance, a policy mandating that all patients with cancer need to have their case discussed by a tumor board might increase referrals for cancer treatment. A policy to build more cancer centres would most likely improve geographic accessibility. Ultimately, patient and disease factors affect appropriate referral, patient preference and best clinical practice. Patients with minimal education may not advocate for appropriate referral. Elderly patients may prefer radiation treatments that are short to minimize travel time. Clinical practice often suggests that patients with multiple comoribidites are managed differently. All of these factors ultimately affect a doctor's ultimate medical decision and the treatment that each patient receives. 


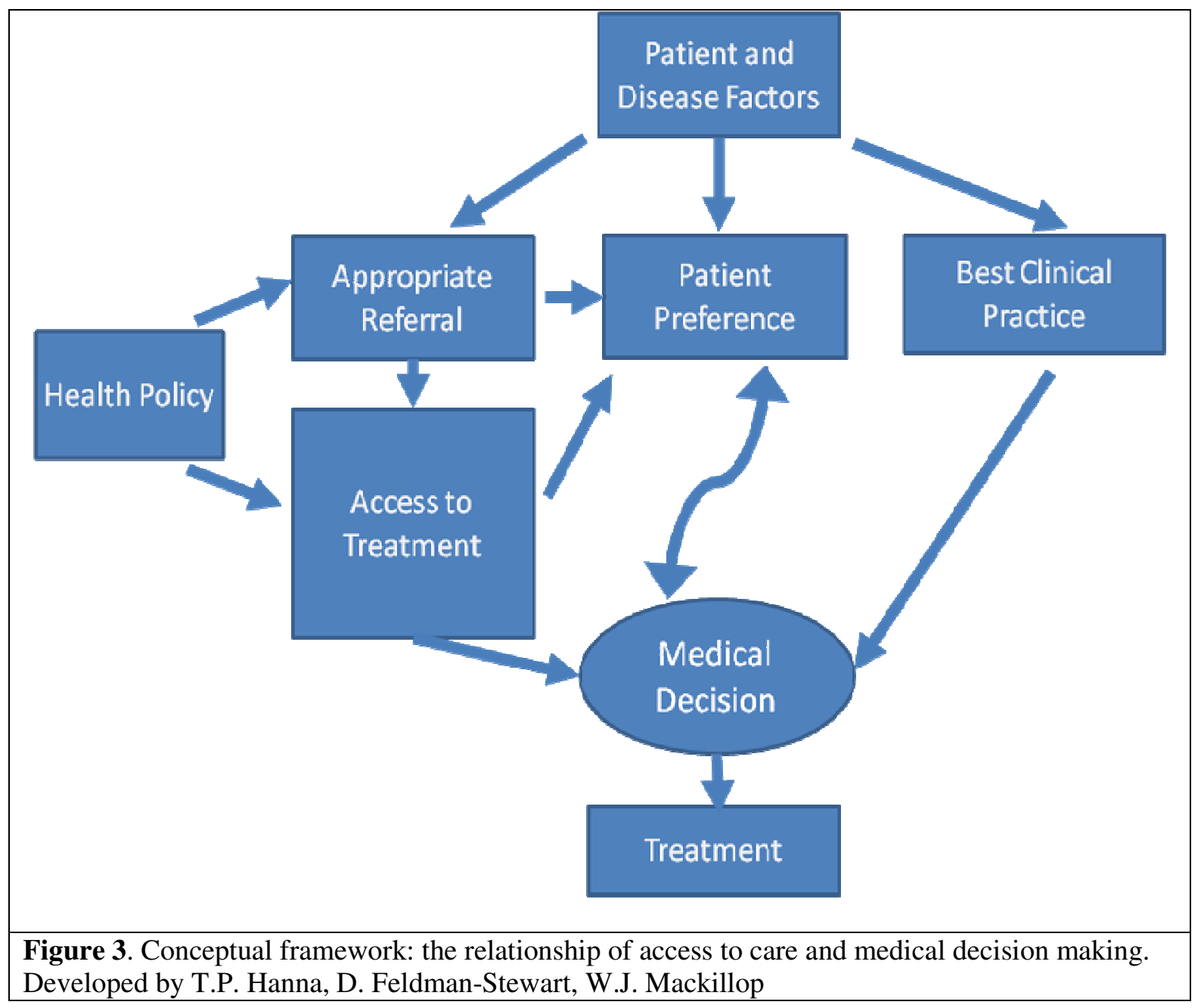

Our study will focus on how access to care affects the medical decision to treat with radiation. This conceptual framework illustrates the complexity of the relationship between access and medical decision making. Patient preference may be involved in the choice of radiation for endometrial cancer given some uncertainty in optimal treatment for intermediaterisk stage I patients. However, uncertainties in best clinical practice with radiation and surgical staging are a far wider issue and probably have a much larger impact on decision making for endometrial cancer. Our study will focus on assessing system-related and patient-related factors 
affecting use of radiation for endometrial cancer and control for known prognostic factors that are taken into account by most oncologists in treatment decisions. ${ }^{43,78}$

\section{Organization of the health care system in Ontario and management of Endometrial Cancer}

In 1931, the Ontario government struck the Royal Commission on the Use of X-Rays and Radium in the Treatment of the Sick at the recommendation of the Ontario Medical Association. ${ }^{79}$ This commission was chaired by Rev. Henry John Cody, who was then the president of the University of Toronto. The 'Cody Commission' travelled the world gathering information on the organization of cancer systems, especially in the United States and Europe. The commission observed large variations in practice in their travels. They concluded that a centralized system would be the best way to deliver cancer care in Ontario. Their recommendations have been criticized for the little time they spent in Ontario for public hearings, and their reliance on the opinions of Gordon Richards, the head of radiology at Toronto General Hospital; Richards strongly

supported a centralized system. ${ }^{79}$ At the recommendation of the Cody Commission, an independent body to coordinate cancer control in Ontario was eventually launched in 1943. It was named the Ontario Cancer Treatment and Research Foundation (OCTRF) and was replaced by Cancer Care Ontario (CCO) in 1997. All radiation therapy for endometrial cancer in Ontario during the period of this thesis was provided by 8 fully publically funded regional cancer centres and the Princess Margaret Hospital.

Against the intent of the Cody Commission, organized cancer services were largely focused on provision of radiation therapy at cancer centres rather than building true comprehensive cancer services. As a result, cancer treatments involving radiation are centralized as are much of drug therapies. However, no efforts were made by the government in coordinating surgical 
services, thus, surgical management of cancer is provided by a wide range of physicians, many of whom are not specialists in cancer management. This is certainly the case for endometrial cancer. As will be described later in this thesis, the majority of hysterectomies are performed by community surgeons.

\section{The Accessibility of Radiation Therapy in Ontario and Waiting Times}

There is evidence that barriers to accessibility exist in the provision of radiation in Ontario. It has previously been shown that variation exists in the utilization of post-operative (adjuvant) radiotherapy for breast cancer in Ontario by geographic region, patient age and neighborhood economic status. ${ }^{1}$ Greater distance to a radiation facility has also been positively associated with use of mastectomy over breast conserving surgery plus adjuvant radiotherapy in the United States. ${ }^{80}$ A number of other factors such as life expectancy, treating cancer centre and prevailing wait time may also influence radiation use or radiation dose and number of treatments. ${ }^{2}$ 3,69 It is unclear if any of these factors affect the utilization of adjuvant radiation for endometrial cancer and one of the primary objectives of this project will be to investigate this.

Wait times for medical treatments including radiation have been a significant problem across Canada. These waits have been part of the impetus for a number of high-level investigations including the Romanow Report and the Kirby Commission. ${ }^{81,82}$ In the early 1990's, waiting times for radiation in Ontario became a significant issue. For laryngeal cancer, cervical cancer, nonsmall cell lung cancer and prostate cancer, time from diagnosis to curative radiation treatment increased by $178.7 \%, 105.6 \%, 158.3 \%$, and $62.9 \%$, respectively between 1982 and $1991 .^{83}$ Wait times for radiation has been subdivided into three parts. ${ }^{83}$ The first is the wait from time of diagnosis to referral for radiation. The second is the time from receipt of referral at the cancer 
centre to the time when a patient is seen by a radiation oncologist in consultation. The third interval is the time from consultation to start of treatment.

The prevailing waiting time for a cancer centre can be quantitatively described as the median time that all patients in a defined group at the cancer center wait from date of diagnosis until treatment with radiation during a given time period. ${ }^{84}$ There is some evidence that prevailing wait times at a cancer centre are associated with choice of treatment that cancer patients receive. For instance, the number of fractions of palliative radiation delivered for bone metastases tends to be less for an individual patient when the prevailing wait time at the treating cancer center is longer. ${ }^{3}$ Elderly patients are less likely to receive post-lumpectomy radiation for breast cancer as prevailing wait times become longer. ${ }^{85}$ Huang and Mackillop did not, however, find an association between treatment choice for prostate cancer and prevailing waiting time. ${ }^{84}$

One can associate a prevailing waiting time with each patient that is part of the study group corresponding to when each patient in the study cohort first visits the cancer centre or is diagnosed with cancer. ${ }^{3}$ The period of time assessed for prevailing wait time should fall before the potential date of decision to treat with radiation so as to reflect the workload environment that would factor into a radiation oncologist or referring doctor's most recent experience, potentially affecting decision making for the patient in front of them.

\section{Measuring Access to Radiation through Administrative Data}

Various factors that can be measured through administrative data and health care databases may be associated with impaired access to radiotherapy for endometrial cancer. Table 2 provides a summary of the different dimensions of access that can be estimated with data available at the Queen's Division of Cancer Care and Epidemiology (CCE). 
Prevailing wait time can both affect and reflect the availability of treatment. Implicit rationing of radiation services may occur during times of excessive waits. ${ }^{75}$ Surgeons may be less inclined to refer patients for radiotherapy when their past experiences have suggested that patients wait excessively long. Long prevailing waiting time may also predispose radiation oncologists to choose brachytherapy when prescribing radiation as it is a shorter treatment and does not take up time on a cancer centre's external beam radiation machines where waiting times may be longer. Long prevailing wait times may also be associated with higher rates of surgical staging in an effort to lessen the need for radiotherapy.

The median income of the neighborhood in which the patient resides can serve as a measure of socioeconomic status (SES). Income quintile has been demonstrated to be associated with reduced access to radiotherapy in Ontario. ${ }^{1-3}$ SES may be associated with affordability and awareness dimensions of access. Affordability can be an issue for those with limited financial resources. The cost of gas or bus fair for the numerous cancer centre visits during radiation treatment may be prohibitive. Patients must make daily visits for five weeks or more during external beam radiation therapy for endometrial cancer. Awareness of the value of radiotherapy and the function of the medical system may mean that those of lower SES who may be less educated may not effectively advocate for themselves and pursue or demand medical treatments that may be either beneficial or desirable to them.

The distance from the treating cancer center to the patient's residence, as measured using postal code data and a SAS macro to calculate distance, serves as a measure of spatial accessibility. Patients living a long distance from a cancer centre may be less willing to travel for treatment or their surgeon may assume they know the patient's preference and make a decision on the patient's behalf. Patients living further from the cancer center may also be more likely to ask 
for and receive brachytherapy as it is a shorter treatment requiring fewer visits. Spatial accessibility includes the concept of travel time. When methods of transport apart from driving are involved in getting from home to the treatment centre, this becomes more important. For instance, a patient may either walk or use a bicycle for economic reasons or for environmental stewardship. It would take this person much longer to cover the same distance as someone in a car. For this reason, measuring distance travelled is only a crude measure of spatial accessibility.

For gynecological cancers, acceptability is harder to measure with administrative data. It is a common problem that administrative data is not well suited for measuring acceptability. Some women may not wish to be treated for their cancers by male doctors (or sometimes vice versa) and measuring the sex of a patient's gynecologist or radiation oncologist and whether the patient receives radiation or not is one possible estimator of acceptability. This information is not recorded directly in OCR. As patient preference is not specifically captured with administrative data, questionnaires and patient interviews are more suited for measuring this dimension of accessibility.

One can estimate the awareness of doctors regarding indications of treatment using electronic data. In the case of endometrial cancer, one can measure the number of hysterectomies for endometrial cancer a given hospital performs (surgical volume) in order to estimate the centre's expertise with gynecologic oncology. One can also measure whether gynecology oncologists work at the hospital a woman has her hysterectomy at. Measuring whether a given hospital has a radiotherapy department or is visited by radiation oncologists for clinics or multidisciplinary tumor boards is another means of estimating doctor awareness of indications for treatment. 
One potential measure of accessibility identifiable through administrative data is age. Older patients have been shown to be treated differently with radiation than other patients for various palliative and adjuvant indications, even after controlling for a decline in functional status. 1, 2, 64, 68 This may be due to lack of doctor awareness of the real risks and benefits of radiation for the elderly or may represent to some extent the acceptability of radiation treatment to older patients who do not wish to make daily trips to the cancer center for five weeks or more of treatment.

Table 2. Dimensions of access to post-operative radiation for endometrial cancer and factors potentially affecting them that can be measured by administrative data

\begin{tabular}{|l|l|}
\hline Access Dimension & $\begin{array}{l}\text { Factors Potentially Affecting Access to Post-operative Radiation for } \\
\text { Endometrial Cancer }\end{array}$ \\
\hline Availability & Prevailing wait time \\
\hline Spatial Accessibility & Distance from treating cancer centre \\
\hline Affordability & Income quintile \\
\hline Acceptability & Gender of treating oncologist or surgeon \\
\hline Awareness & $\begin{array}{l}\text { Income quintile } \\
\text { Gynecologic Oncology expertise at referring hospital }\end{array}$ \\
\hline
\end{tabular}

\section{Quantifying Gynecologic Expertise at the Referring Hospital: Hospital Volume}

Previous studies have suggested that high hospital surgical volume for certain procedures are associated with improved outcomes. One Ontario study found a decreased risk of death if a patient's lung, liver or breast cancer was resected at a high volume hospital. ${ }^{86}$ This same effect was not seen for other cancer surgeries considered in this study. Guller et al found high surgical volume hospitals managing breast cancer in the United States had significantly lower non-routine discharges, postoperative morbidity and mortality, shorter length of stay post-operatively and higher likelihood that the patient received breast-conserving therapy. ${ }^{87}$ This case volume effect has been observed in numerous studies, though the mediators of this effect are less clear and are 
probably disease-specific. ${ }^{88-94}$ Hébert-Croteau et al found the effect of hospital case volume on overall survival for breast cancer was mediated by hospital type. Hospitals were dichotomized into those with or without teaching, research or delivery of radiotherapy. ${ }^{88}$ Diaz-Montes et al defined a high-volume endometrial cancer hospital as those hospitals performing more than 200 surgeries over 12 years, or approximately 17 surgeries per year. This study of surgical volume found that only $7 \%$ of gynecologic surgeons in their cohort who operated on at least one case of endometrial cancer in Maryland between 1994 and 2005 operated on more than one case of

endometrial cancer per year. ${ }^{95}$ Management by high-volume surgeons was associated with a $48 \%$ decreased risk of death $(95 \%$ CI $0.26,1.00)$. A study from Japan by Ioka et al found that the fiveyear survival for endometrial cancer patients managed at high-volume hospital was $85.9 \%$ versus $54.6 \%$ at very low volume hospitals with a hazard ratio of 2.5 (95\% CI 1.9, 3.3) after controlling for covariates. ${ }^{96}$ Covariates were age, extent of disease and hospital type. As endometrial cancer is more likely to be seen first by a community obstetrician gynecologist in Ontario than a gynecologic oncologist, it was thought to be quite likely that the issue of volume and expertise might also be an important factor for referral for radiation for endometrial cancer.

\section{Measuring Socio-economic Status in Electronic Health Data}

There is evidence that ecological measures of SES do correlate with individual-level measures of SES though some studies vary regarding the degree these measures represent individual-level data and the direction of correlation. ${ }^{97-100}$ Given that conceptually the economic status of the individual and the community may be associated with health, it is possible for ecologic variables to overestimate or underestimate results obtained from individual estimators of 
SES. ${ }^{98}$ Ecological measures of SES are often more accessible for large population-level cohorts and so are often used with these data sets. ${ }^{2,75,101}$

A number of ecological measures have been examined in cancer patient cohorts. ${ }^{97,} 102$ Poverty can be measured as a dichotomous variable where households fall below the "poverty line' such as based on a defined income level. ${ }^{102}$ The proportion of poor households in a neighborhood is then specified. Median neighborhood income is another ecologic measure. ${ }^{102}$ SES categories based on median neighborhood income are often subdivided according to tertiles or quintiles. ${ }^{2,101,103}$ Median neighborhood income has been used in a number of provincial studies of oncology health services. ${ }^{2,101,103}$ It is correlated with other ecological measures of SES: poverty, education, occupation, unemployment rates, marital status, proportion of owneroccupied houses, and proportion of single parent families. ${ }^{101,102}$

\section{Measuring Comorbidity in Electronic Health Data}

Stedman`s Medical dictionary defines comorbidity as `a concomitant but unrelated pathologic or disease process; usually used in epidemiology to indicate the coexistence of two or more disease processes. ${ }^{104}$ In clinical practice, patients with multiple medical comorbidities are often managed differently than other patients. This trend holds true for cancer patients. For instance, elderly patients with rectal cancer with certain comorbidities are less likely to receive adjuvant radiotherapy. ${ }^{105} \mathrm{~A}$ Netherlands study using cancer registry data found that presence of comorbidity based on the Charlson index diminished treatment intensity for elderly colon cancer, lung cancers and non-Hodgkin's lymphoma. ${ }^{106}$ For endometrial cancer, two Canadian studies, one involving patients from Ontario, have found that patients with comorbid conditions as classified by the Charlson index were less likely to receive adjuvant radiation. ${ }^{73,107}$ Kwon et al's 
population-based study involving women with endometrial cancer in Ontario found 51.2\% of women with one or more comorbidity received adjuvant radiation versus $58.5 \%$ for women without a documented comorbidity $(\mathrm{p}=0.02){ }^{73}$

Comorbidity will be measured in our study using the Elixhauser score applied to each patient's surgical admission records. The Elixhauser score is a validated system for classifying comorbidity specifically designed for electronic data. ${ }^{108}$ Its performance characteristics have been compared with the Deyo adaption of the Charlson score and found superior in predicting inhospital mortality for cancer patients and other groups for electronic data. ${ }^{109-111}$ The Deyo adaption of Charlson score is one of the most popular adaptions allowing the use of ICD-9-CM coded data to be used to generate a Charlson comorbidity score. ${ }^{112}$ Unlike the Charlson score, the Elixhauser comorbidity index was specifically designed to be used with electronic administrative data. ${ }^{108,113}$ Though the Elixhauser score is weighted to predict mortality, it has also been shown to be predictive of health services use. Dominick et al found the Elixhauser score was predictive of the number of physician visits, number of prescriptions used and hospitalization probability for 306 patients with osteoarthritis in the Veteran's Affairs health care system. ${ }^{114}$

\section{Multi-level modeling}

Two of the key assumptions of a multiple regression model are independence of observations and equality of variances. However, in reality this is quite hard to achieve in population-level studies. Clustering of medical treatment patterns and health behaviors can be found in communities or hospitals. ${ }^{57}$ For example, most patients at hospital A may receive a tonsillectomy and few at Hospital B do, despite a similar patient population. The patients at Hospital A or B will share some likelihood of tonsillectomy related simply to the management 
philosophy of the doctors at the hospital that is not related to the patient population served. There may also be unobservable heterogeneity in patient populations between hospitals leading to predictable differences in practice style between Hospital A and B. Since it is possible to predict with some certainty whether a patient receives a tonsillectomy based on the hospital they are admitted to, observations in the data set are not truly independent.

In addition, variability in practice between hospitals can vary markedly depending on the use of and compliance with departmental treatment policies, patient preference and variability in the exposure-outcome relationship at different exposure levels. Regarding the last point, there may be more variation in management of a given medical condition the older a patient is or the more comorbidities they have.

Given that our study of factors affecting receipt of post-operative radiation involves a wide range of hospitals across the province, it is quite likely that each hospital has a predictable radiation oncology referral and receipt pattern. This would suggest data clustering at the hospital level is an issue to be described and controlled for. Without controlling for clustering, confidence intervals on estimates may improperly narrowed. Given this, we will model the data with a multilevel multiple logistic regression model to assess the effects of the clustering or grouping of data by hospital on receipt of post-operative radiation. This is a form of hierarchical modeling.

Hierarchical modeling is a complex form of regression that allows one to simultaneously control for fixed effects (individual-level effects) and random effects (group-level effects) in a model. Initial work on hierarchical modeling came from the social sciences where individual effects and group effects needed to be disentangled. ${ }^{115}$ For instance, when studying determinants of depression, there can be individual factors such as substance abuse and personal income. There can also be group-level factors such as community income quintile. It may be that wealthy individuals 
that live in impoverished communities are more likely to be depressed despite their personal wealth.

\section{References}

1. Paszat LF, Mackillop WJ, Groome PA, Zhang-Salomons J, Schulze K, Holowaty E. Radiotherapy for breast cancer in Ontario: rate variation associated with region, age and income. Clin Invest Med. Jun 1998;21(3):125-134.

2. Huang J, Zhou S, Groome P, Tyldesley S, Zhang-Solomans J, Mackillop WJ. Factors affecting the use of palliative radiotherapy in Ontario. J Clin Oncol. Jan 1 2001;19(1):137-144.

3. Kong W, Zhang-Salomons J, Hanna TP, Mackillop WJ. A population-based study of the fractionation of palliative radiotherapy for bone metastasis in Ontario. Int J Radiat Oncol Biol Phys. Nov 15 2007;69(4):1209-1217.

4. Aalders J, Abeler V, Kolstad P, Onsrud M. Postoperative external irradiation and prognostic parameters in stage I endometrial carcinoma: clinical and histopathologic study of 540 patients. Obstet Gynecol. Oct 1980;56(4):419-427.

5. Creutzberg CL. GOG-99: ending the controversy regarding pelvic radiotherapy for endometrial carcinoma? Gynecol Oncol. Mar 2004;92(3):740-743.

6. Scholten AN, van Putten WL, Beerman H, et al. Postoperative radiotherapy for Stage 1 endometrial carcinoma: long-term outcome of the randomized PORTEC trial with central pathology review. Int J Radiat Oncol Biol Phys. Nov 1 2005;63(3):834-838.

7. Greer BE, Koh W-J, Small Jr. W. Uterine neoplasms version 1.2008 2007.

8. Lukka H, Chambers A, Fyles A, et al. Adjuvant Radiotherapy in Women with Stage I Endometrial Cancer: A Clinical Practice Guideline. Vol \#4-10: Cancer Care Ontario Program in Evidence-Based Care; 2006.

9. Roland PY, Kelly FJ, Kulwicki CY, Blitzer P, Curcio M, Orr JW, Jr. The benefits of a gynecologic oncologist: a pattern of care study for endometrial cancer treatment. Gynecol Oncol. Apr 2004;93(1):125-130.

10. Canadian Cancer Society, National Cancer Institute of Canada, Statistics Canada, Provincial and Territorial Cancer Registries, Public Health Agency of Canada, Statistics Canada. Canadian Cancer Statistics 2007; Toronto: Canadian Cancer Society; 2007.

11. Tropé CG, Alektiar, KM, Sabbatini, PJ, Zaino, RJ. Corpus: Epithelial Tumors. In: Hoskins WJ, Perez CA, Young RC, Barakat RR, Markman M, Eds. Principles and Practice of Gynecologic Oncology 4th Ed. Philadelphia: Lippincott Williams \& Wilkins; 2005.

12. Creasman WT, Odicino F, Maisonneuve P, et al. Carcinoma of the corpus uteri. Int $J$ Gynaecol Obstet. Oct 2003;83 Suppl 1:79-118.

13. Creasman $\mathrm{W}$, Odicino $\mathrm{F}$, Maisonneuve $\mathrm{P}$, et al. Carcinoma of the corpus uteri. Int $J$ Gynaecol Obstet. Nov 2006;95 Suppl 1:S105-143.

14. IARC. GLOBOCAN 2002 Online World Cancer Database. http://www-dep.iarc.fr/. Lyon, France; 2002. 
15. Canadian Cancer Society, National Cancer Institute of Canada, Statistics Canada, Provincial and Territorial Cancer Registries, Public Health Agency of Canada, Statistics Canada. Canadian Cancer Statistics 2007; Toronto: Canadian Cancer Society; 2007.

16. Canadian Cancer Society, National Cancer Institute of Canada, Statistics Canada, Provincial and Territorial Cancer Registries, Public Health Agency of Canada, Statistics Canada. Canadian Cancer Statistics 2006. Toronto: Canadian Cancer Society; 2006.

17. Canadian Cancer Society's Steering Committee. Canadian Cancer Statistics 2009. Toronto: Canadian Cancer Society; 2009.

18. Hulka BS, Fowler WC, Jr., Kaufman DG, et al. Estrogen and endometrial cancer: cases and two control groups from North Carolina. Am J Obstet Gynecol. May 1 1980;137(1):92-101.

19. Paganini-Hill A, Ross RK, Henderson BE. Endometrial cancer and patterns of use of oestrogen replacement therapy: a cohort study. Br J Cancer. Mar 1989;59(3):445-447.

20. Persson I, Adami HO, Bergkvist L, et al. Risk of endometrial cancer after treatment with oestrogens alone or in conjunction with progestogens: results of a prospective study. BMJ. Jan 21 1989;298(6667):147-151.

21. Grady D, Gebretsadik T, Kerlikowske K, Ernster V, Petitti D. Hormone replacement therapy and endometrial cancer risk: a meta-analysis. Obstet Gynecol. Feb 1995;85(2):304-313.

22. Cuzick J, Powles T, Veronesi U, et al. Overview of the main outcomes in breast-cancer prevention trials. Lancet. Jan 25 2003;361(9354):296-300.

23. McPherson CP, Sellers TA, Potter JD, Bostick RM, Folsom AR. Reproductive factors and risk of endometrial cancer. The Iowa Women's Health Study. Am J Epidemiol. Jun 15 1996;143(12):1195-1202.

24. Parslov M, Lidegaard O, Klintorp S, et al. Risk factors among young women with endometrial cancer: a Danish case-control study. Am J Obstet Gynecol. Jan 2000;182(1 Pt 1):23-29.

25. Purdie DM, Green AC. Epidemiology of endometrial cancer. Best Pract Res Clin Obstet Gynaecol. Jun 2001;15(3):341-354.

26. Pillay OC, Te Fong LF, Crow JC, et al. The association between polycystic ovaries and endometrial cancer. Hum Reprod. Apr 2006;21(4):924-929.

27. Hardiman P, Pillay OC, Atiomo W. Polycystic ovary syndrome and endometrial carcinoma. Lancet. May 24 2003;361(9371):1810-1812.

28. Olson SH, Trevisan M, Marshall JR, et al. Body mass index, weight gain, and risk of endometrial cancer. Nutr Cancer. 1995;23(2):141-149.

29. Schouten LJ, Goldbohm RA, van den Brandt PA. Anthropometry, physical activity, and endometrial cancer risk: results from the Netherlands Cohort Study. J Natl Cancer Inst. Nov 3 2004;96(21):1635-1638.

30. Goodman MT, Hankin JH, Wilkens LR, et al. Diet, body size, physical activity, and the risk of endometrial cancer. Cancer Res. Nov 15 1997;57(22):5077-5085.

31. Watson P, Vasen HF, Mecklin JP, Jarvinen H, Lynch HT. The risk of endometrial cancer in hereditary nonpolyposis colorectal cancer. Am J Med. Jun 1994;96(6):516-520.

32. Hemminki K, Bermejo JL, Granstrom C. Endometrial cancer: population attributable risks from reproductive, familial and socioeconomic factors. Eur J Cancer. Sep 2005;41(14):2155-2159. 
33. Purdie DM, Green AC. Epidemiology of Endometrial Cancer. Best Practice \& Research Clinical Obstetrics and Gynaecology. 2001;15(3):341-354.

34. Parazzini F, Negri E, La Vecchia C, Bruzzi P, Decarli A. Population attributable risk for endometrial cancer in northern Italy. Eur J Cancer Clin Oncol. Oct 1989;25(10):14511456.

35. Harris EER, Wei, SJ, Chu C, Acs G. Cancer of the Uterus. In: Abeloff MD, Armitage JO, Niederhuber JE, Kastan MB, McKenna WG, Eds. Clinical Oncology 3rd Ed. Philadelphia: Elsevier; 2004.

36. Benedet JL, Bender H, Jones H, 3rd, Ngan HY, Pecorelli S. FIGO staging classifications and clinical practice guidelines in the management of gynecologic cancers. FIGO Committee on Gynecologic Oncology. Int J Gynaecol Obstet. Aug 2000;70(2):209-262.

37. Creutzberg CL, van Putten WL, Warlam-Rodenhuis CC, et al. Outcome of high-risk stage IC, grade 3, compared with stage I endometrial carcinoma patients: the Postoperative Radiation Therapy in Endometrial Carcinoma Trial. J Clin Oncol. Apr 1 2004;22(7):1234-1241.

38. Keys HM, Roberts JA, Brunetto VL, et al. A phase III trial of surgery with or without adjunctive external pelvic radiation therapy in intermediate risk endometrial adenocarcinoma: a Gynecologic Oncology Group study. Gynecol Oncol. Mar 2004;92(3):744-751.

39. Abu-Rustum NR, Alektiar K, Iasonos A, et al. The incidence of symptomatic lowerextremity lymphedema following treatment of uterine corpus malignancies: a 12-year experience at Memorial Sloan-Kettering Cancer Center. Gynecol Oncol. Nov 2006;103(2):714-718.

40. Chan JK, Kapp DS. Role of complete lymphadenectomy in endometrioid uterine cancer. Lancet Oncol. Sep 2007;8(9):831-841.

41. Franchi M, Ghezzi F, Riva C, Miglierina M, Buttarelli M, Bolis P. Postoperative complications after pelvic lymphadenectomy for the surgical staging of endometrial cancer. J Surg Oncol. Dec 2001;78(4):232-237; discussion 237-240.

42. Gray H. Anatomy of the Human Body. 20 ed. Philedelphia: Lea \& Febiger; 1918.

43. Cardenes HR, Look K, Michael H, Cerezo L. Endometrium. In: Perez CA, Brady LW, Halperin EC, Schmidt-Ullrich RK, eds. Principles and Practice of Radiation Oncology Fifth Edition. New York: Lippincott Williams \& Wilkins; 2007.

44. Morrow CP, Bundy BN, Kurman RJ, et al. Relationship between surgical-pathological risk factors and outcome in clinical stage I and II carcinoma of the endometrium: a Gynecologic Oncology Group study. Gynecol Oncol. Jan 1991;40(1):55-65.

45. Mariani A, Webb MJ, Keeney GL, Haddock MG, Calori G, Podratz KC. Low-risk corpus cancer: is lymphadenectomy or radiotherapy necessary? Am J Obstet Gynecol. Jun 2000;182(6):1506-1519.

46. Boronow RC, Morrow CP, Creasman WT, et al. Surgical staging in endometrial cancer: clinical-pathologic findings of a prospective study. Obstet Gynecol. Jun 1984;63(6):825832.

47. Blake P, Swart AM, Orton J, et al. Adjuvant external beam radiotherapy in the treatment of endometrial cancer (MRC ASTEC and NCIC CTG EN.5 randomised trials): pooled trial results, systematic review, and meta-analysis. Lancet. Jan 10 2009;373(9658):137146. 
48. UW Health. Vaginal Cuff Radiation Treatment.

http://www.uwhealth.org/servlet/Satellite?cid=1105110026830\&pagename=B_EXTRAN ET_HEALTH_INFORMATION\%2FFlexMember\%2FShow_Public_HFFY\&c=FlexGro up. Modified; Accessed January 14,2008.

49. Salina Regional Cancer Center. What is Radiation Therapy?

www.srhc.com/services/oncology/radiation.htm; Accessed January 14, 2008.

50. Kitchener H, JonesIII HW, Bertelsen K, et al. Cancer of the Corpus Uteri. In: Benedet JL, Pecorelli S, Ngan HY, et al., eds. Staging Classifications and Clinical Practice

Guidelines for Gynaecological Cancers: Elsevier; 2000.

51. Hogberg T, Rosenberg P, Kristensen G, et al. A randomized phase-III study on adjuvant treatment with radiation $(\mathrm{RT}) \pm$ chemotherapy $(\mathrm{CT})$ in early-stage high-risk endometrial cancer (NSGO-EC-9501/EORTC 55991). Journal of Clinical Oncology ASCO Meeting Abstracts. 2007;25(18S):5503.

52. Creasman WT, Odicino F, Maisonneuve P, et al. Carcinoma of the corpus uteri. FIGO 6th Annual Report on the Results of Treatment in Gynecological Cancer. Int J Gynaecol Obstet. Nov 2006;95 Suppl 1:S105-143.

53. Ludwig H. Prognostic factors in endometrial cancer. Int J Gynaecol Obstet. Jul 1995;49 Suppl:S1-7.

54. Margo CE. Quality care and practice variation: the roles of practice guidelines and public profiles. Surv Ophthalmol. May-Jun 2004;49(3):359-371.

55. Wennberg J, Gittelsohn. Small area variations in health care delivery. Science. Dec 14 1973;182(117):1102-1108.

56. Caper P. Variations in medical practice: implications for health policy. Health Aff (Millwood). Summer 1984;3(2):110-119.

57. Wennberg JE. Dealing with medical practice variations: a proposal for action. Health Aff (Millwood). Summer 1984;3(2):6-32.

58. Baker LC, Fisher ES, Wennberg JE. Variations in hospital resource use for medicare and privately insured populations in California. Health Aff (Millwood). Mar-Apr 2008;27(2):w123-134.

59. Wennberg J. Which rate is right? N Engl J Med. Jan 30 1986;314(5):310-311.

60. Brennan TA, Gawande A, Thomas E, Studdert D. Accidental deaths, saved lives, and improved quality. N Engl J Med. Sep 29 2005;353(13):1405-1409.

61. Hayter CR, Paszat LF, Groome PA, Schulze K, Mackillop WJ. The management and outcome of bladder carcinoma in Ontario, 1982-1994. Cancer. Jul 1 2000;89(1):142-151.

62. Hodgson DC, Zhang-Salomons J, Rothwell D, et al. Evolution of treatment for Hodgkin's disease: a population-based study of radiation therapy use and outcome. Clin Oncol ( $R$ Coll Radiol). Aug 2003;15(5):255-263.

63. Jackson LD, Groome PA, Schulze K, et al. Radiotherapy patterns of practice: T1N0 glottic cancer in Ontario, Canada. Clin Oncol (R Coll Radiol). Aug 2003;15(5):266-279.

64. Mackillop WJ, Dixon P, Zhou Y, et al. Variations in the management and outcome of non-small cell lung cancer in Ontario. Radiother Oncol. Aug 1994;32(2):106-115.

65. Paszat L, Laperriere N, Groome P, Schulze K, Mackillop W, Holowaty E. A populationbased study of glioblastoma multiforme. Int J Radiat Oncol Biol Phys. Sep 1 2001;51(1):100-107. 
66. Paszat LF, Brundage MD, Groome PA, Schulze K, Mackillop WJ. A population-based study of rectal cancer: permanent colostomy as an outcome. Int J Radiat Oncol Biol Phys. Dec 1 1999;45(5):1185-1191.

67. Mackillop WJ, Groome PA, Zhang-Solomons J, et al. Does a centralized radiotherapy system provide adequate access to care? J Clin Oncol. Mar 1997;15(3):1261-1271.

68. Tyldesley S, Zhang-Salomons J, Groome PA, et al. Association between age and the utilization of radiotherapy in Ontario. Int J Radiat Oncol Biol Phys. May 1 2000;47(2):469-480.

69. Denham JW. How do we bring an acceptable level of radiotherapy services to a dispersed population? Australas Radiol. May 1995;39(2):171-173.

70. Ashworth A, Kong W, Whelan T, Mackillop WJ. A population-based study of the fractionation of post-lumpectomy breast radiotherapy in Ontario. Radiother Oncol. September 2008;88(Suppl 2):s117.

71. Vulto JC, Louwman WJ, Poortmans PM, Coebergh JW. Hospital variation in referral for primary radiotherapy in South Netherlands, 1988-1999. Eur J Cancer. Nov 2005;41(17):2722-2727.

72. Rogerson L, Downes E. How do UK gynaecologists manage endometrial carcinoma? A national survey. Eur J Gynaecol Oncol. 1998;19(4):331-332.

73. Kwon JS, Carey MS, Cook EF, Qiu F, Paszat L. Patterns of practice and outcomes in intermediate- and high-risk stage I and II endometrial cancer: a population-based study. Int J Gynecol Cancer. Mar-Apr 2007;17(2):433-440.

74. Penchansky R, Thomas JW. The concept of access: definition and relationship to consumer satisfaction. Med Care. Feb 1981;19(2):127-140.

75. Mackillop WJ. Health Services Research in Radiation Oncology: Towards Achieving the Achievable for Patients with Cancer. In: Gunderson LL, Tepper JE, eds. Clinical Radiation Oncology 2nd Edition. New York: Churchill Livingstone; 2006.

76. Safer MA, Tharps QJ, Jackson TC, Leventhal H. Determinants of three stages of delay in seeking care at a medical clinic. Med Care. Jan 1979;17(1):11-29.

77. Allison P, Locker D, Feine JS. The role of diagnostic delays in the prognosis of oral cancer: a review of the literature. Oral Oncol. May 1998;34(3):161-170.

78. Lee CM, Szabo A, Shrieve DC, et al. Descriptive nomograms of adjuvant radiotherapy use and patterns of care analysis for stage I and II endometrial adenocarcinoma: A surveillance, epidemiology, and end results population study. Cancer. Nov 1 2007;110(9):2092-2100.

79. Hayter CR. Historical origins of current problems in cancer control. CMAJ. Jun 30 1998;158(13):1735-1740.

80. Schroen AT, Brenin DR, Kelly MD, Knaus WA, Slingluff CL, Jr. Impact of patient distance to radiation therapy on mastectomy use in early-stage breast cancer patients. $J$ Clin Oncol. Oct 1 2005;23(28):7074-7080.

81. Commission on the future of healthcare in Canada. Building on Values: The Future of Health Care in Canada- Final Report. Romanow, R. Commisioner 2002.

82. Standing Senate Committeeon Social Affairs, Science and Technology. The Health of Canadians- The Federal Role. Interim Report. Volume 1: The Story So Far. Ottawa: The Senate; March, 2001.

83. Mackillop WJ, Fu H, Quirt CF, Dixon P, Brundage M, Zhou Y. Waiting for radiotherapy in Ontario. Int J Radiat Oncol Biol Phys. Aug 30 1994;30(1):221-228. 
84. Huang M. The influence of waiting time on treatment choices among prostate cancer patients. Kingston: Thesis for the Department of Community Health and Epidemiology, Queen's University; 2006.

85. Zhang-Salomons J, Fourodi F, Huang J, Mackillop WJ. Health System Effects on the Use of Radiotherapy Following Surgery for Breast Cancer. Abstr Acad Health Serv Res Health Policy Meet. 2002;19:45.

86. Simunovic M, Rempel E, Theriault ME, et al. Influence of hospital characteristics on operative death and survival of patients after major cancer surgery in Ontario. Can J Surg. Aug 2006;49(4):251-258.

87. Guller U, Safford S, Pietrobon R, Heberer M, Oertli D, Jain NB. High hospital volume is associated with better outcomes for breast cancer surgery: analysis of 233,247 patients. World J Surg. Aug 2005;29(8):994-999; discussion 999-1000.

88. Hebert-Croteau N, Brisson J, Lemaire J, Latreille J, Pineault R. Investigating the correlation between hospital of primary treatment and the survival of women with breast cancer. Cancer. Oct 1 2005;104(7):1343-1348.

89. Gilligan MA, Neuner J, Zhang X, Sparapani R, Laud PW, Nattinger AB. Relationship between number of breast cancer operations performed and 5-year survival after treatment for early-stage breast cancer. Am J Public Health. Mar 2007;97(3):539-544.

90. Schrag D, Cramer LD, Bach PB, Cohen AM, Warren JL, Begg CB. Influence of hospital procedure volume on outcomes following surgery for colon cancer. JAMA. Dec 20 2000;284(23):3028-3035.

91. Schrag D, Earle C, Xu F, et al. Associations between hospital and surgeon procedure volumes and patient outcomes after ovarian cancer resection. J Natl Cancer Inst. Feb 1 2006;98(3):163-171.

92. Simunovic M, To T, Baxter N, et al. Hospital procedure volume and teaching status do not influence treatment and outcome measures of rectal cancer surgery in a large general population. J Gastrointest Surg. May-Jun 2000;4(3):324-330.

93. Skinner KA, Helsper JT, Deapen D, Ye W, Sposto R. Breast cancer: do specialists make a difference? Ann Surg Oncol. Jul 2003;10(6):606-615.

94. Urbach DR, Bell CM, Austin PC. Differences in operative mortality between high- and low-volume hospitals in Ontario for 5 major surgical procedures: estimating the number of lives potentially saved through regionalization. CMAJ. May 27 2003;168(11):14091414.

95. Diaz-Montes TP, Zahurak ML, Giuntoli RL, 2nd, Gardner GJ, Bristow RE. Uterine cancer in Maryland: impact of surgeon case volume and other prognostic factors on short-term mortality. Gynecol Oncol. Dec 2006;103(3):1043-1047.

96. Ioka A, Tsukuma H, Ajiki W, Oshima A. Influence of hospital procedure volume on uterine cancer survival in Osaka, Japan. Cancer Sci. Oct 2005;96(10):689-694.

97. Greenwald HP, Polissar NL, Borgatta EF, McCorkle R, Goodman G. Social factors, treatment, and survival in early-stage non-small cell lung cancer. Am. J. Pub. Health. 1998;88(11):1681-1684.

98. Geronimus AT, Bound J, Neidert LJ. On the validity of using census geocode characteristics to proxy individual socioeconomic characteristics. J. Am. Stat. Assoc. 1996;91(434):529-537.

99. Krieger N. Overcoming the absence of socioeconomic data in medical records: validation and application of a census-based methodology. Am. J. Pub. Health. 1992;82(5):703-710. 
100. Mustard CA, Derksen S, Berthelot JM, Wolfson M. Assessing ecologic proxies for household income: a comparison of household and neighourhood level income measures in the study of population health status. Health Place. 1999;5(2):157-171.

101. Mackillop WJ, Zhang-Salomons J, Groome PA, Paszat L, Holowaty E. Socioeconomic status and cancer survival in Ontario. Journal of clinical oncology. Vol 15; 1997:1680.

102. Zhang-Salomons J, Qian H, Holowaty E, Mackillop WJ. Associations between socioeconomic status and cancer survival: choice of SES indicator may affect results. Ann Epidemiol. Jul 2006;16(7):521-528.

103. Groome PA, Schulze KM, Keller S, et al. Explaining socioeconomic status effects in laryngeal cancer. Clin Oncol (R Coll Radiol). 2006;18(4):283-292.

104. Stedman, TL. Stedman's Medical Dictionary 28th Ed. in STAT!Ref Online Electronic Medical Library. Baltimore, MD: Lippincott Williams \& Wilkins; 2006.

105. Lemmens VE, Janssen-Heijnen ML, Verheij CD, Houterman S, Repelaer van Driel OJ, Coebergh JW. Co-morbidity leads to altered treatment and worse survival of elderly patients with colorectal cancer. Br J Surg. May 2005;92(5):615-623.

106. Janssen-Heijnen ML, Houterman S, Lemmens VE, Louwman MW, Maas HA, Coebergh JW. Prognostic impact of increasing age and co-morbidity in cancer patients: a population-based approach. Crit Rev Oncol Hematol. Sep 2005;55(3):231-240.

107. Truong PT, Kader HA, Lacy B, et al. The effects of age and comorbidity on treatment and outcomes in women with endometrial cancer. Am J Clin Oncol. Apr 2005;28(2):157164.

108. Elixhauser A, Steiner C, Harris DR, Coffey RM. Comorbidity measures for use with administrative data. Med Care. Jan 1998;36(1):8-27.

109. de Groot V, Beckerman H, Lankhorst GJ, Bouter LM. How to measure comorbidity. a critical review of available methods. J Clin Epidemiol. Mar 2003;56(3):221-229.

110. Southern DA, Quan H, Ghali WA. Comparison of the Elixhauser and Charlson/Deyo methods of comorbidity measurement in administrative data. Med Care. Apr 2004;42(4):355-360.

111. Stukenborg GJ, Wagner DP, Connors AF, Jr. Comparison of the performance of two comorbidity measures, with and without information from prior hospitalizations. Med Care. Jul 2001;39(7):727-739.

112. Deyo RA, Cherkin DC, Ciol MA. Adapting a clinical comorbidity index for use with ICD-9-CM administrative databases. J Clin Epidemiol. Jun 1992;45(6):613-619.

113. Charlson ME, Pompei $P$, Ales KL, MacKenzie CR. A new method of classifying prognostic comorbidity in longitudinal studies: development and validation. J Chronic Dis. 1987;40(5):373-383.

114. Dominick KL, Dudley TK, Coffman CJ, Bosworth HB. Comparison of three comorbidity measures for predicting health service use in patients with osteoarthritis. Arthritis Rheum. Oct 15 2005;53(5):666-672.

115. Diez-Roux AV. Multilevel analysis in public health research. Annu Rev Public Health. 2000;21:171-192. 


\title{
Chapter 2
}

\section{Methodologic Considerations: Choice and Characterization of Explanatory Variables for Thesis}

\begin{abstract}
A detailed description of the study population, source databases and statistical methods can be found in the methods section of Chapter 3. In short, the study population was all patients with endometrial cancer in Ontario who had a hysterectomy between 1992 and 2003 and had potentially curable disease and no previous cancer diagnosis. Health data on individual patients was abstracted from the Ontario Cancer Registry, Canadian Institute of Health Information (CIHI) Discharge Abstract Database and Cancer Care Ontario stage data on a subset of patients and radiotherapy records from all nine cancer centres operating during the time period under study. Univariate analysis was performed as well as a multivariate logistic regression. Available stage data was used to identify factors associated with stage that could be used to account for a portion of variation due to stage. We used a mixed multiple logistic model to assess and control for the effect of clustering due to operating hospital.

This chapter will expand on details provided in the methods section of the manuscript in Chapter 3. I will describe some of the rationale in choice and definition of explanatory and outcome variables and the work I did to characterize these. Table 1 summarizes the explanatory variables included in this study.
\end{abstract}




\begin{tabular}{|l|l|}
\hline Health System Factors & 1. Comprehensive Gynecologic Oncology Centre (CGOC) \\
\hline & 2. Prevailing waiting time at the most responsible cancer centre \\
\hline & 3. Distance to most responsible cancer centre \\
\hline & 4. Year of treatment \\
\hline & 5. Most responsible cancer centre \\
\hline Patient Factors & 1. Patient age \\
\hline & 2. Neighborhood median income \\
\hline & 3. Elixhauser comorbidity score \\
\hline Disease Factor & 1. Histology \\
\hline Treatment-related Factors & 1. Lymph node staging \\
\hline & 2. Type of hysterectomy \\
\hline & 3. Peritoneal biopsy \\
\hline $\begin{array}{l}\text { Table 1. Classification of explanatory variables for study of factors affecting use of adjuvant } \\
\text { radiation for endometrial cancer in Ontario }\end{array}$ \\
\hline
\end{tabular}

\section{Quantifying Gynecologic Oncology Expertise at the Referring Hospital}

One of the key hypotheses of this thesis was that varying gynecologic oncology expertise at the operating hospital would be associated with different rates of use of radiation. Initially I derived three separate variables to characterize this expertise: gynecologic oncologist surgeon involvement, radiation oncologist involvement at the operating hospital and surgical volume. These were highly correlated:

1. Gynecologic oncologist involvement. This was a three-level variable defined using information on the performance of radical hysterectomies at the referring hospital. As the radical hysterectomy is a specialized procedure performed only for resection of cancers, this was taken as a proxy of the presence of a trained gynecologic oncologist surgeon at the hospital. Standard obstetrician gynecology training exposes residents to the principles of this procedure, but these procedures are almost exclusively performed by fellowshiptrained gynecologic oncologists in Ontario. This categorical variable's levels were: (1) no specialty-trained gynecologic oncology expertise, (2) some gynecologic oncology expertise and (3) full gynecologic oncology hospital. Hospitals not meeting criteria for 
(2) or (3) were defined as (1). For any year that a hospital performed one or more radical hysterectomies, the hospital was defined as having some gynecologic oncology expertise. If there were four or more consecutive years with one or more radical hysterectomies performed at the hospital, the hospital was defined as being a full gynecologic oncology hospital for those years (3). If there were at least four consecutive years that met criteria for (3), a one-year gap with no radical hysterectomies performed at the hospitals was allowed. Three or more consecutive years at the end of the study period with one or more radical hysterectomy was also defined as (3). If more than five radical hysterectomies were performed in the first or last year of the study period, this was also defined as (3) for that year. In order to determine the external validity of this construct, findings were presented to two senior gynecologic oncology surgeons from Ontario (Dr. P. Bryson and Dr. B. Rosen). They corroborated findings for centres that they were familiar with. Overall, $60 \%$ of patients received their surgery at a hospital without gynecologic oncology experience, $7 \%$ received surgery at a hospital with some gynecologic oncology experience and $33 \%$ received surgery at a full gynecologic oncology centre.

2. Radiation oncologist involvement. This was defined as a three-level categorical variable: (1) no radiation oncologist involvement at the hospital, (2) some radiation oncologist involvement through means such as outreach clinics or tumor boards or (3) hospital with a radiation oncology department. This data was collected at the Queen's Division of Cancer Care and Epidemiology (CCE) through surveys of key informants from the radiation oncology community in Ontario. Kong et al found that hospitals associated with a radiation oncology department were significantly more likely to receive radiation then hospitals that were not, even after controlling for covariates $\left(31.9 \%\right.$ vs. $26.2 \%$, p<.05). ${ }^{1}$ 
There was no significant effect of a visiting radiation oncologist in this study. Given that this study did not focus on endometrial cancer, it was thought that it would be reasonable to explore whether there was any difference between category (2) and the other two categories. We found that $59 \%$ of patients received surgery at hospitals without any direct involvement of a radiation oncologist. While $11 \%$ of patients were managed at hospitals with some radiation oncologist involvement, $30 \%$ received surgery at a hospital associated with a radiation therapy department.

3. Hospital volume. This was defined as the annual number of hysterectomies for endometrial cancer performed at a hospital. Hospital volume was hypothesized to be an indicator of a hospital's experience with managing endometrial cancer and knowledge of indications for adjuvant radiation therapy. Using Diaz-Montes' definition of 200 endometrial cancer surgeries over 12 years as high endometrial cancer surgical volume, $51 \%$ of endometrial cancer patients in Ontario receive surgery at a low-volume hospital (table 2). ${ }^{2}$ There were 106 patients managed at hospitals that performed one hysterectomy per year for endometrial cancer. In 1992, 96 hospitals performed surgery for endometrial cancer in Ontario. The number of hysterectomies for endometrial cancer varied between hospitals from 1 to 52 with a median of 6.5 and an inter-quartile range of 3 to 13 . In 2003, 82 hospitals performed surgery for endometrial cancer. The number of hysterectomies varied from 1 to 99 with a median of 9.5 and an inter-quartile range of 4 to 17 . 


\begin{tabular}{|l|r|r|}
\hline $\begin{array}{l}\text { Annual } \\
\text { Surgical } \\
\text { Volume }\end{array}$ & Frequency & Percent \\
\hline$<\mathbf{4}$ & 450 & 4.8 \\
\hline $\mathbf{4 - 1 0}$ & 1893 & 20.1 \\
\hline $\mathbf{1 1 - 1 7}$ & 2474 & 26.3 \\
\hline $\mathbf{1 8 - 3 7}$ & 2231 & 23.7 \\
\hline $\mathbf{3 8 - 7 6}$ & 1876 & 19.9 \\
\hline $\mathbf{7 7 +}$ & 487 & 5.2 \\
\hline $\begin{array}{l}\text { Table 2. Proportion of patients } \\
\text { managed at hospitals with } \\
\text { specified annual surgical volume } \\
\text { for endometrial cancer }\end{array}$ \\
\hline
\end{tabular}

Exploratory analysis found a strong correlation between gynecologic oncologist involvement, radiation oncologist involvement and annual surgical volume. These relationships are summarized in table 3.

\begin{tabular}{|c|c|c|c|}
\hline & $\begin{array}{c}\text { Surgical } \\
\text { Volume }\end{array}$ & $\begin{array}{r}\text { Gynecologic } \\
\text { Oncologist } \\
\text { Involvement }\end{array}$ & $\begin{array}{r}\text { Radiation } \\
\text { Oncologist } \\
\text { Involvement }\end{array}$ \\
\hline $\begin{array}{l}\text { Surgical } \\
\text { Volume }\end{array}$ & 1.00 & 0.76 & 0.70 \\
\hline $\begin{array}{l}\text { Gynecologic } \\
\text { Oncologist } \\
\text { Involvement }\end{array}$ & & 1.00 & 0.73 \\
\hline $\begin{array}{l}\text { Radiation } \\
\text { Oncologist } \\
\text { Involvement }\end{array}$ & & & 1.00 \\
\hline \multicolumn{4}{|c|}{$\begin{array}{l}\text { Table 3. Pearson Correlation Coefficient Matrix for gynecologic } \\
\text { oncologist involvement, radiation oncologist involvement and } \\
\text { annual surgical volume for endometrial cancer. All p-values } \\
<.0001\end{array}$} \\
\hline
\end{tabular}

The above results are in keeping with Hébert-Croteau et al`s finding that the hospital volume effect was mediated in their study through hospital type. ${ }^{3}$ Hospital type was defined in part for 
their breast cancer surgical study by presence or absence of a radiation therapy department. ${ }^{3}$ Given the high correlation between these variables, as well as their lack of independent explanatory power in multivariate analysis, we explored a composite hospital type variable. As initial exploratory analysis did not suggest any meaningful difference in radiation use between patients managed at hospitals with some radiation oncologist or gynaecologic oncologist involvement, a dichotomous hospital type variable was used in the final model. Hospitals were classified according to whether or not a radiation therapy department was associated with the hospital and the gynecologic oncologist involvement category was (3). These hospitals were considered Comprehensive Gynecologic Oncology Centres (CGOC).

Findings from this process of creating a measure of physician experience with managing endometrial cancer support the hypothesis that the effect of surgical volume on outcomes may be associated with hospital type, a concept which captures a range of potential factors including teaching, research and availability of specific equipment such as a radiation oncology department in the case of cancers.

\section{Prevailing Waiting Time and Most Responsible Cancer Centre}

Prevailing wait time at the most responsible cancer centre was defined as the median time that patients requiring adjuvant radiation must wait from time of surgery to time of start of adjuvant radiation. This was measured for each patient in the endometrial cancer cohort for all patients treated for common adjuvant radiation indications at the most responsible cancer centre in the four months preceding the patient's date of surgery to two months following. This six month period for the prevailing wait time was chosen as we hypothesized that a referring surgeon's decision to refer to the regional cancer centre might depend on recent experiences with 
referral to the regional cancer centre. As many community surgeons might only see a handful of patients in a year, a broad time period was chosen to allow for this intermittent contact with the cancer centre.

As a patient's surgical stage can only be determined after assessing post-operative pathology, most referrals for radiation will be submitted after the pathology report is available from the patient's hysterectomy. We noted that the median time from admission for surgery to start of radiation was 69 days with an inter-quartile range of 55 to 92 days. As we estimated that it could take up to two months for a patient to see their surgeon in post-operative follow-up and a decision to refer for radiation to be made, we extended the period we assessed prevailing wait time to two months following the date of admission for surgery for a total of six months.

The common indications for adjuvant radiation used to measure prevailing waiting time were defined as: mastectomy, lumpectomy, cystectomy, radical abdominal hysterectomy, simple hysterectomy, colectomy, esophagectomy, laryngectomy, pneumonectomy, lobectomy, radical prostatectomy, partial/total excision of rectum, and gastrectomy. These were chosen as the common indications based on known rates of radiation for these cancer sites in Ontario. ${ }^{4}$ We used the hospital procedure codes defined by Bardell et al to identify the associated cancer surgeries for these indications for adjuvant radiation. ${ }^{5}$ Adjuvant radiation was defined as radiation within six months of admission for one of these common cancer surgeries. Of the patients who had the listed common cancer surgeries between 1992 and 2003, 624, 892 were identified. There were 47,433 identified who had radiation within six months following their surgery. These patients hence made up the cohort used to define prevailing waiting time for our study.

The most responsible cancer centre was determined for each operating hospital and was defined as the cancer centre where endometrial cancer patients who had their surgery at the 
specified hospital most often received adjuvant radiation. If hospitals had less than twenty cases receiving radiation over the study period and less than $70 \%$ of their patients were treated at the same cancer centre, the most responsible to cancer centre was defined using information on use of radiation following the common cancer surgeries previously mentioned. For those cases where no patient operated on at the hospital received adjuvant radiation for any indication, the closest cancer centre was assigned as the most responsible to cancer centre.

We found that for $87 \%$ hospitals, patients received radiation at the most responsible cancer centre $80 \%$ of the time or more (Figure 1). As figure 2 illustrates, the most responsible cancer centre tended to be geographically defined; operating hospitals tended to refer patients to the nearest cancer centre.

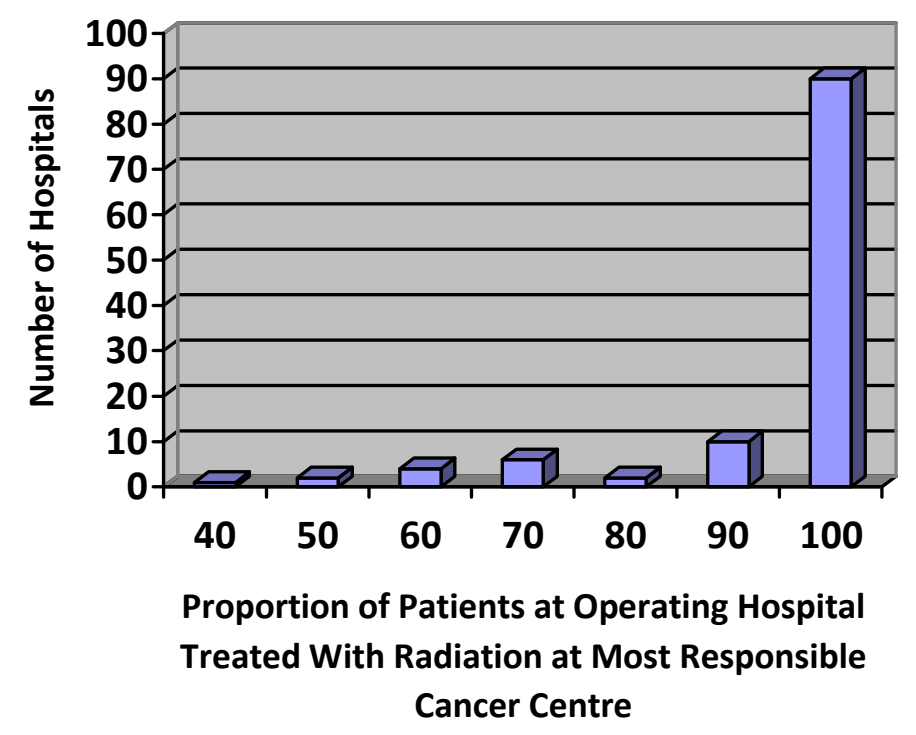

Figure 1. Number of operating hospitals with given proportions of endometrial cancer patients receiving radiation at the most responsible cancer centre. Proportion of patients is rounded to the nearest 10. 


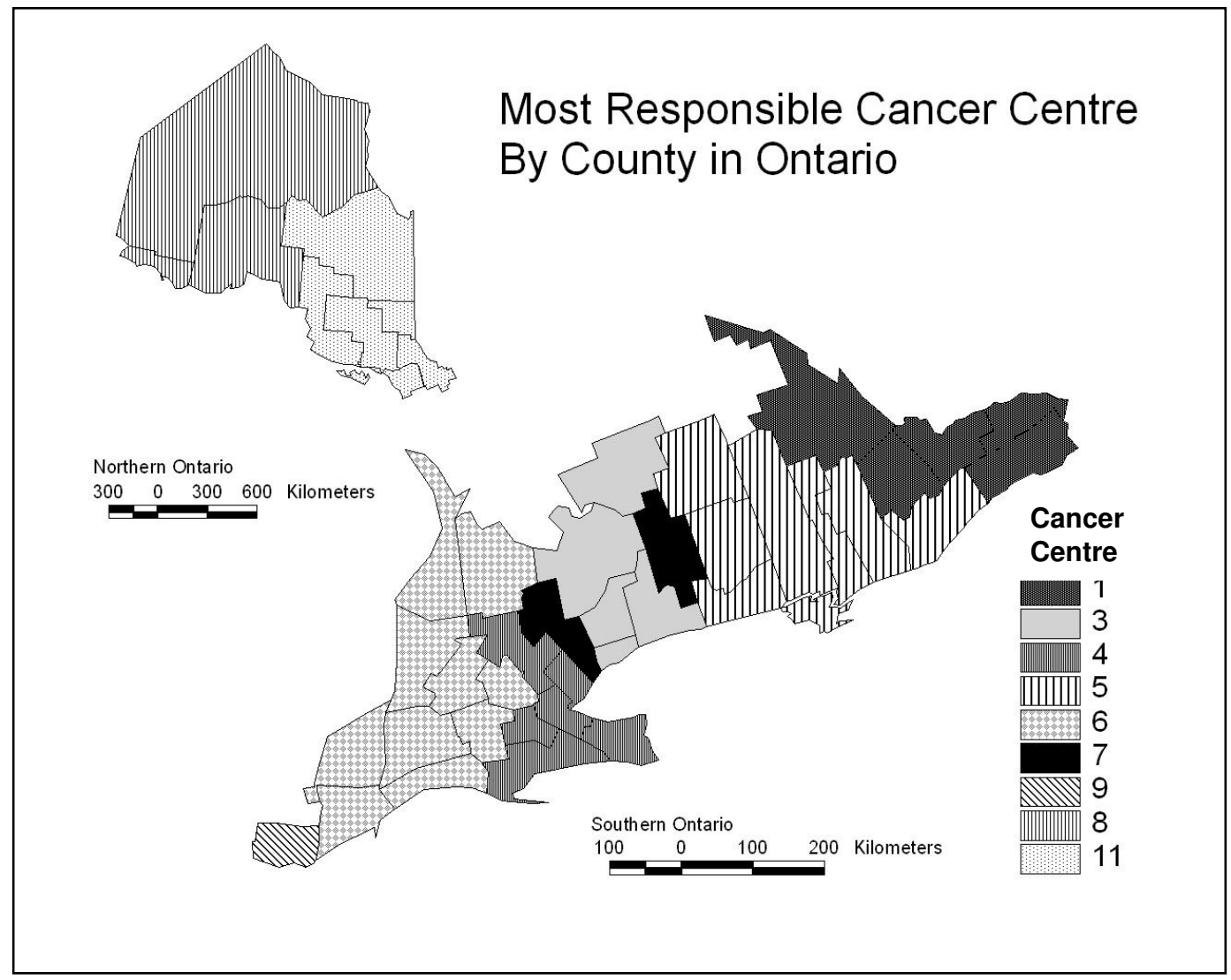

Figure 2. Most responsible cancer centre by county for endometrial cancer patients in Ontario.

\section{Distance}

Our measure of spatial accessibility was the distance from the patient's home at time of diagnosis to the most responsible cancer centre. Distance was measured using a SAS macro developed at the Queen's Cancer Research Institute's division of Cancer Care and Epidemiology as the linear distance to the most responsible cancer centre from the centre of the patient's census enumeration area if postal code was available or census subdivision if only the patient's residence code was available. This variable does not take into account travel time or road transportation 
routes but was considered to be a reasonable means of estimating the association between distance and use of radiation for endometrial cancer.

\section{Year of Diagnosis}

We included patients in the study cohort from 1992 to 2003 to maximize study power. As there had not been any major or influential clinical trials published during this time window, we hypothesized that practice patterns would not shift significantly over time. Though a shorter time window would have had adequate power to detect most differences, we expected that if prevailing waiting time had any effect on use of radiation, this effect would be quite small. In addition, as most hospitals operated on 10 patients or less per year, we decided to optimize the sample size from each hospital to adequately assess the effects of clustering on management of endometrial cancer by operating hospital using a mixed multiple logistic regression model with operating hospital as a random effects variable.

\section{Median Neighborhood Income Quintile and Socio-Economic Status}

For the purposes of our study, we estimated socio-economic status using a patient's neighborhood median income quintile compared to other regions in Ontario. Information from Statistics Canada census data on median household income of the Canadian population by region has allowed linkage of this information at CCE at the census enumeration level (mean population 700) to a patient's residential postal code as listed in OCR and at the census subdivision level (mean population $~ 10,000$ ) to a patient's residence code as listed in OCR. ${ }^{6}$ Linkage of median household income to census data was based on the census year closest in time to the patient's year of diagnosis. 
For OCR as a whole, Mackillop et al found in 1997 that $64.4 \%$ of registry cases were linked by postal code, $32.1 \%$ were linked by residence code and $3.5 \%$ could not be linked. ${ }^{6}$ There has been an increase with time in the proportion of patients in the OCR database with linkages based on postal code. The use of census subdivision data for a minority of patients may lead to some non-differential misclassification of neighborhood income quintile. Though this would bias towards the null for the odds of radiation use by neighborhood income quintile, it would not alter whether patients receive radiation or not and hence would not affect the strength of the relationship of radiation use with other exposure variables.

\section{Elixhauser versus Deyo Comorbidity for the Endometrial Cancer Database}

There are a number of challenges to using electronic data to measure comorbidity. Construct validity is one significant problem of comorbidity indices applied to electronic data, that is, how successful is the comorbidity index in adequately discriminating groups of patients into separate groups? In exploratory analyses, both the Deyo adaption of the Charlson index and the Elixhauser comorbidity were characterized for the endometrial cancer cohort data. When the scores were applied to each patient's CIHI surgical admission record, $82 \%$ of patients had no comorbidity according to the Deyo score, while $70 \%$ of patients had no comorbidity according to the Elixhauser comorbidity index.

For both measures, each uniquely identified comorbidity adds a point to the patient's comorbidity score. Both comorbidity scores were able to identify only a small handful of qualifying comorbidities, with the Elixhauser comorbidity index identifying slightly more (table 4). The slightly higher number of comorbidities identified by the Elixhauser index relates to the higher number of diagnoses that are classified as comorbidities compared to the Deyo adaption of 
the Charlson index. It is worth noting that the Charlson index was originally developed to be used with a complete prospectively collected medical record. ${ }^{7}$ The Elixhauser comorbidity index was specifically designed to be used with electronic administrative data. ${ }^{8}$

\begin{tabular}{|c|c|c|c|c|c|}
\hline \multirow[t]{2}{*}{$\begin{array}{l}\text { Comorbidity } \\
\text { Index }\end{array}$} & \multicolumn{5}{|c|}{ Comorbidity Score } \\
\hline & 0 & 1 & 2 & 3 & 4+ \\
\hline Deyo & $81.5 \%$ & $11.0 \%$ & $6.2 \%$ & $0.8 \%$ & $0.5 \%$ \\
\hline Elixhauser & $70.0 \%$ & $18.8 \%$ & $7.8 \%$ & $2.5 \%$ & $0.9 \%$ \\
\hline
\end{tabular}

The poor performance of both of these indeces in identifying all true comorbidities is highlighted by a study from the Netherlands where comorbidity information was prospectively collected as part of a cancer registry. There were $64 \%$ of patients with endometrial cancer with at least one Charlson comorbidity for those aged 65 to 79 and $77 \%$ for those 80 years and older. ${ }^{9}$ This compares to $18.5 \%$ of patients overall in our cohort with at least one comorbidity according to the Deyo adaption of the Charlson score.

The CIHI data linked to the Ontario Cancer Registry was not specifically designed to capture all comorbidities for cancer registry subjects. Only medical conditions that occur during a hospital admission are captured. Furthermore, not even all comorbidities that exist during a hospitalization will necessarily be captured as variation in documentation probably exists between hospitals. In our endometrial cancer cohort, we found that comprehensive gynecologic oncology hospitals had more patients with comorbidities, despite having a nearly identical age distribution compared to other hospitals $(\mathrm{p}=0.1426)$. One explanation of this is that these hospitals have more time and personnel to document comorbidities compared to peripheral 
hospitals. It is also possible that CGOCs manage sicker patients though one would expect at least some significant difference in age distribution in that case.

An additional issue in measuring comorbidity with electronic data is deciding which hospital information to use. The Ontario Cancer Registry contains hospitalization data that starts only at the time of the patient's diagnosis of cancer. Information from hospital admissions prior to this is not available. The Elixhauser comorbidity score is uniquely suited to this problem as it has been found to be a valid and reliable predictor of mortality without the need for information prior to the index admission. ${ }^{10}$ The Charlson score, on the other hand, has certain comorbidities that can be counted only if they occur prior to the index admission such as acute myocardial infarction. For the current study, it is reasonable to exclude admissions following the patient's admission for surgery if the Elixhauser comorbidity score is used. The focus of our study was to assess factors affecting receipt of radiation and comorbidities developing after radiotherapy are thus not relevant.

In bivariate analysis, there was a non-significant trend toward less radiation therapy for patients with more than one Elixhauser comorbidity $(\mathrm{p}=0.1106)$. In the multivariate analysis of factors affecting use of radiation of endometrial cancer to be presented in the next chapter, the Elixhauser comorbidity score was not a significant explanatory variable. Given its poor ability to identify patient comorbidity with the available CIHI data, this is perhaps not surprising. As age group and Elixhauser comorbidity are significantly associated in the Endometrial Cancer Database $(\mathrm{p}<0.0001)$, it is likely that the comorbidity information associated with age overwhelmed the limited and incomplete information provided by the Elixhauser comorbidity score in our analysis. Ultimately, more information would be needed to directly assess the 
confounding effect of medical comorbidity on receipt of radiation for endometrial cancer patients in Ontario using a comorbidity score.

\section{Identifying cases of lymph node staging}

An investigation of the most common procedures according to $\mathrm{CCP}$ procedure codes recorded in the CIHI discharge abstract database identified many different lymph node procedures. Only one CCP code clearly indicated that the procedure was a pelvic or peri-aortic lymph node staging procedure: 52.44 (radical excision of iliac lymph nodes). Most other relevant lymph node procedures were non-specific: 52.19 (simple excision of other lymphatic structure), 52.2 (regional lymph node excision), 52.81 (biopsy of lymphatic structure), 52.89 (other invasive diagnostic procedures on lymphatic structures), 52.4 (radical excision of other lymph nodes), 52.41 (radical excision of lymph nodes unqualified) and 52.49 (radical excision of other lymph nodes). We decided to consider these lymph node procedures as surgical staging if they occurred during the patient's admission for hysterectomy for endometrial cancer. Given these patients were admitted for cancer surgery, it is unlikely that these lymph node procedures would represent anything other than a staging procedure for endometrial cancer, which would be in almost all cases a pelvic lymph node dissection or sampling and/or a peri-aortic lymph node sampling or dissection. In initial exploratory analysis, we did not find sufficient associations to justify categorizing these procedures beyond the simple dichotomous relationship (surgical staging yes/no) used in the final analysis. 


\section{Peritoneal Biopsy}

My exploratory review of common procedures occurring during admission for hysterectomy identified peritoneal biopsy as a regular phenomenon. This procedure was recorded in $7.4 \%$ of cases. Bivariate analysis suggests that peritoneal biopsy was a proxy of poor prognosis. Patients with a peritoneal biopsy were more likely to have died $(21.0 \%$ vs $16.8 \% \mathrm{p}=$ 0.0048). Hospitals without gynecologic oncologist surgical expertise were only slightly less likely to perform the procedure than hospitals that had gynecologic oncology expertise $(6.3 \%$ vs $9.0 \%$ $\mathrm{p}<0.0001)$. Stage IIIC endometrial cancer patients were more likely to have had a peritoneal biopsy than stage IA patients in the limited cohort of staged patients from 2003 (28.6\% vs $16.7 \%$ $\mathrm{p}=0.2949$ ) and patients who had a peritoneal biopsy were more likely to have had radiation in univariate analysis $(35.0 \%$ vs $25.4 \% \mathrm{p}<.0001)$. In addition, patients with aggressive histologies (serous papillary and clear cell carcinoma) were also more likely to have had a peritoneal biopsy: $6.6 \%$ endometrioid adenocarcinoma versus $19.3 \%$ clear cell carcinoma and $20.8 \%$ serous papillary carcinoma $(\mathrm{p}<.0001)$. Peritoneal biopsy was performed $72.4 \%$ of the time without a lymph node staging procedure, suggesting it was performed based on concerning intra-operative findings rather than as part of routine surgical staging. As such we decided to include peritoneal biopsy as a potentially relevant treatment-related factor to control for in our analysis.

\section{The Outcome: Adjuvant Radiation for Endometrial Cancer}

This was defined as documented receipt of radiation in the radiotherapy database within six months of a hysterectomy for a pathologic diagnosis of endometrial cancer. The six-month cut-off was set using available information on timing of adjuvant and recurrence radiation treatment available for a representative subset of the data. Unfortunately the complete radiation 
therapy data set does not distinguish adjuvant treatments from primary treatment of recurrence with radiation.

Raw data from Hamilton from 1992-2003 included a unique category of radiation treatment named ' $R$ ' for treatment of recurrence. More than $75 \%$ of endometrial cancer recurrences treated with radiation in Hamilton were treated more than one year following their surgery with less than $10 \%$ being treated within 90 days of surgery. Data from Princess Margaret Hospital uniquely has an 'adjuvant' category for radiation in their database. Of patients receiving adjuvant radiation, $75 \%$ received it within 135 days of surgery. Within 195 days, $90 \%$ received it. Almost all patients had received adjuvant radiation within 1 year.

Keeping in mind the need to balance the need to exclude radiation treatments for recurrence with the need to capture as many patients as possible who truly received adjuvant radiation, we set our definition of adjuvant radiation as treatment within six months of surgery. From a clinical standpoint, it is highly unlikely that a radiation oncologist would offer adjuvant radiation any longer than this after surgery for endometrial cancer. External beam radiation and brachytherapy were both accepted as types of radiation for purposes of this study given that both are considered by many radiation oncologists to be an acceptable means of delivering radiation to selected early-stage patients.

\section{Exclusion of Patients with Previous Malignancies}

We excluded patients from our study cohort whose endometrial cancer was not their first cancer. We were concerned that patients who had received previous cancer treatments would have an altered likelihood of receiving radiation. Patients with previous cancers may have received radiation to the pelvis as part of their treatment. Cervical cancer, bladder cancer and rectal cancer 
are examples of this. In addition, if the previous cancer had not been cured, it is possible that treatment recommendations for the new endometrial cancer would be affected by this.

\section{Controlling for Clustered Surgical Data using Multi-level Modeling}

For our project, the operating hospital is the random effect parameter while the patientrelated, disease-related and other system factors are the fixed effect parameters. To model operating hospital as the random effect parameter, each hospital is assigned a random variable shared by all patients whose hysterectomy was performed there. The random variables from all hospitals will be treated as a random sample from a normal distribution with a mean zero and an unknown variance that determines the strength of correlation of likelihood of having radiation based on operating hospital and is to be estimated. If the confidence interval for the variance of the intercept includes or approaches zero and confidence intervals of the parameter estimates are not notably larger, then the random effect parameter does not have a meaningful effect. If this is the case, it would be reasonable to revert to a fixed effects regression without this random effect variable. $^{11}$

A special likelihood ratio test can be performed to confirm the statistical significance of the random effects parameter. ${ }^{12}$ The current version of SAS (9.1) does not produce enough information in its output from its GLIMMIX procedure to perform this test. ${ }^{13}$ The next available version of SAS will have this function and this statistical test will be reported in the manuscript portion of the thesis when it is submitted for publication. ${ }^{12}$ 


\section{References}

1. Kong W, Voroney J-P, Mackillop WJ. The patient's chance of receiving radiotherapy depends on the type of hospital in which the diagosis was made. Radiother Oncol. 2008;88(S1):S23.

2. Diaz-Montes TP, Zahurak ML, Giuntoli RL, 2nd, Gardner GJ, Bristow RE. Uterine cancer in Maryland: impact of surgeon case volume and other prognostic factors on short-term mortality. Gynecol Oncol. Dec 2006;103(3):1043-1047.

3. Hebert-Croteau N, Brisson J, Lemaire J, Latreille J, Pineault R. Investigating the correlation between hospital of primary treatment and the survival of women with breast cancer. Cancer. Oct 1 2005;104(7):1343-1348.

4. Mackillop WJ, Zhou S, Groome P, et al. Changes in the use of radiotherapy in Ontario 1984-1995. Int J Radiat Oncol Biol Phys. May 1 1999;44(2):355-362.

5. Bardell T, Belliveau P, Kong W, Mackillop WJ. Waiting times for cancer surgery in Ontario: 1984-2000. Clin Oncol (R Coll Radiol). Jun 2006;18(5):401-409.

6. Mackillop WJ, Zhang-Salomons J, Groome PA, Paszat L, Holowaty E. Socioeconomic status and cancer survival in Ontario. Journal of clinical oncology. Vol 15; 1997:1680.

7. Charlson ME, Pompei P, Ales KL, MacKenzie CR. A new method of classifying prognostic comorbidity in longitudinal studies: development and validation. J Chronic Dis. 1987;40(5):373-383.

8. Elixhauser A, Steiner C, Harris DR, Coffey RM. Comorbidity measures for use with administrative data. Med Care. Jan 1998;36(1):8-27.

9. Janssen-Heijnen ML, Houterman S, Lemmens VE, Louwman MW, Maas HA, Coebergh JW. Prognostic impact of increasing age and co-morbidity in cancer patients: a population-based approach. Crit Rev Oncol Hematol. Sep 2005;55(3):231-240.

10. Stukenborg GJ, Wagner DP, Connors AF, Jr. Comparison of the performance of two comorbidity measures, with and without information from prior hospitalizations. Med Care. Jul 2001;39(7):727-739.

11. Diez-Roux AV. Multilevel analysis in public health research. Annu Rev Public Health. 2000;21:171-192.

12. Jones A, Huddelston EE. SAS/STAT(R) 9.2 User's Guide. http://support.sas.com/documentation/cdl_main/index.html: SAS Institute Inc.; Accessed: July 1, 2009.

13. SAS Institute Inc. SAS/STAT(C) User's Guide: The GLIMMIX Procedure. Cary, NC: SAS Institute Inc.; 2008. 


\title{
Chapter 3
}

\section{Paper 1- For Submission to Clinical Oncology}

\section{A Population-Based Study of Factors Affecting Access to Radiotherapy for Endometrial Cancer in Ontario}

\author{
TP Hanna ${ }^{1}$, H Richardson ${ }^{2}$, P Peng ${ }^{3}$, WJ Mackillop ${ }^{1}$ \\ ${ }^{1}$ Cancer Care and Epidemiology division of the Queen's Cancer Research Institute, Cancer Centre \\ of Southeastern Ontario, Kingston, ON, Canada ${ }^{2}$ National Cancer Institute of Canada, Clinical \\ Trials Group and Cancer Care and Epidemiology division of the Queen's Cancer Research Institute \\ ${ }^{3}$ Department of Community Health and Epidemiology, Department of Mathematics and Statistics \\ and Cancer Care and Epidemiology division of the Queen's Cancer Research Institute
}

TP Hanna

Cancer Centre of Southeastern Ontario

25 King Street West, Kingston, ON, Canada K7L 5P9

W: 613.453 .2517

F: 613.544 .9708

H Richardson

National Cancer Institute of Canada (NCIC)

Clinical Trials Group

10 Stuart Street, Kingston, ON K7L 3N6

W: 613.533 .6430

F : 613.533.2941

P Peng

Department of Community Health and Epidemiology

Abramsky Hall, Queen's University, Kingston, ON Canada K7L 3N6

W: $613.533 .6000 \times 78525$

F: 613.533.6794

\section{WJ Mackillop}

Cancer Care and Epidemiology division of the Queen's Cancer Research Institute 10 Stuart St. Level 2, Kingston, ON Canada K7L 3N6

W: $613.533 .6000 \times 78509$

F: 613.533 .6794 


\section{Corresponding Address}

WJ Mackillop

Cancer Care and Epidemiology division of the Queen's Cancer Research Institute 10 Stuart St. Level 2, Kingston, ON Canada K7L 3N6

W: $613.533 .6000 \times 78509$

F: 613.533 .6794

William.Mackillop@krcc.on.ca 


\begin{abstract}
Aims: To describe use of post-operative radiation for endometrial cancer in Ontario. To identify system-related and patient-related factors affecting access to this treatment.

Materials and Methods: We performed a retrospective population-based cohort study of patients with surgically resected endometrial cancer in the Canadian province of Ontario between 19922003. Patients with evidence of incurable cancer at diagnosis or previous cancer diagnosis were excluded. We used multiple logistic regression to assess patient and system factors affecting radiation use. We controlled for disease-related and treatment-related factors: histology, surgical staging, type of hysterectomy and peritoneal biopsy. We applied a mixed model to account for clustering of data by operating hospital.
\end{abstract}

Results: 9,411 women comprised the study cohort. The median age was 63 years. $26.2 \%$ received adjuvant radiation. The proportion of patients receiving radiation varied between cancer centre catchment areas from $18.0 \%$ to $34.3 \%$ (median 26.3\%). In multivariate analysis, older patients were more likely to receive radiation up to the age of 80 ( $\mathrm{p}<.0001)$. Patients who lived further from regional cancer centres were less likely to receive radiation $(\mathrm{p}=.0210)$. Patients who had their surgery during longer prevailing wait times at regional cancer centres were less likely to receive radiation $(\mathrm{p}=.0441)$. There was a 2.7 -fold variation in the odds of radiation use between cancer centre catchments $(\mathrm{p}<.0001)$. Management at a comprehensive gynecologic oncology centre was associated with use of radiation for patients who had surgical staging of lymph nodes. Year of diagnosis and neighborhood income quintile did not significantly affect the use of radiation. Conclusions: There is wide variation in use of radiation for endometrial cancer in Ontario. There is evidence that system factors unrelated to patient's needs affect use of adjuvant radiation for endometrial cancer in Ontario. Age is a key patient-related factor affecting radiation use. 
6 Keywords: access, endometrial cancer, health services research, radiation therapy, pelvic lymph node dissection.

\section{Introduction}

Post-operative or adjuvant radiation is an important part of many endometrial cancer patient's management. Though there is controversy regarding use of radiation for intermediate-risk early-stage patients, most radiation oncologists would agree that there is a group of high-risk earlystage patients for whom radiation is indicated based on risk of local recurrence. ${ }^{1,2}$ Radiation is also important for local control in more advanced cases of endometrial cancer. ${ }^{3}$ Delaney et al estimated that between $34 \%$ to $58 \%$ of all patients with endometrial cancer will have an indication for external beam radiation at some point in their disease course, depending on population lymphadenectomy rates. ${ }^{4}$

A number of patient and health system factors such as age, distance of residence from a cancer centre, neighborhood economic status, year of treatment, life expectancy, treating cancer centre, and prevailing wait time may influence radiation use or practice. ${ }^{5-7}$ However, it is unknown whether such factors affect access to radiotherapy for endometrial cancer.

A gynecological surgeon is usually the party who refers patients for radiation for endometrial cancer. In Canada, some gynecologic surgeons specialize in gynecologic cancer whose specialty skills include training in pelvic and peri-aortic lymphadenectomy. Oncology groups will not send selected patients for radiation if the lymph node samples do not reveal cancer. ${ }^{8}$ Both generalist and specialist gynecologic surgeons work in Ontario and differences in their use of lymph node staging and patterns of referral for radiation are not known but may be very different 
given that a community gynecologic surgeon may only see a handful of endometrial cancer cases each year at most.

The objectives of this study are to describe variation in use of post-operative radiation for endometrial cancer in Ontario and to identify factors that may be affecting its use. We hypothesize that access to post-operative radiotherapy varies across Ontario, relating to varying knowledge and practice among generalist and specialist surgeons as well as to differences in patient and system factors unrelated to patient's needs: patient travel distance to regional cancer centers, prevailing waiting times at regional cancer centres, practice variation between cancer centre catchment areas, neighborhood median income quintile, and patient age.

\section{Materials and Methods}

Study Population. This study was a retrospective population-based cohort study of all cancer patients in Ontario diagnosed with endometrial cancer between 1992 and 2003 who had a simple or radical hysterectomy. Only patients with adenocarcinoma, clear cell carcinoma or serous papillary carcinoma by ICD-0 criteria were included: Adenocarcinoma 8140/3, 8210/3, 8380/3, 8570/3, Clear Cell Carcinoma 8005/3, 8310/3, and Serous Papillary 8460/3, 8461/3. Patients whose first radiation after their primary surgery was palliative were excluded, as were patients with any previous malignancy or distant metastatic cancer at diagnosis. Cases of endometrial cancer diagnosed by autopsy or death certificate were excluded. Patients dying within 90 days of surgery were excluded as they had not lived long enough to ascertain whether they would have received post-operative radiation had they lived longer. Patients with ovarian metastases were not excluded. 
Ontario Cancer Registry - The Cancer Care Ontario (CCO) Ontario Cancer Registry (OCR) contains data on every cancer diagnosed in the province with a high level of accuracy and $95 \%$ completeness for all sites combined. ${ }^{9}$ OCR data includes date of birth, postal code, histologic diagnosis in ICD-O format, date of cancer diagnosis and body site identified with ICD-9, ICD-9CM or ICD-10 code. The OCR database is linked to the provincial death registry, providing highly complete documentation of date of death. OCR data on individuals are formed through a series of probabilistic linkages from four different sources: cancer centre records, Canada Institute of Health Information (CIHI) discharge data, pathology records and death certificates. ${ }^{10}$ Unique cases are assigned a Group ID number and all contributing source data are assigned this Group ID, as are all relevant CIHI source files for that case. This allows linkage and cross-referencing of information of data from cancer centre records, CIHI discharge abstract data, pathology records and death certificates.

Canada Institute of Health Information (CIHI) Discharge Abstract Database Information - The CIHI database supplies hospitalization information including discharge diagnoses in ICD 9 or 10 code, most responsible diagnosis for admission, admission and discharge dates as well as documentation of all procedures in the form of Canadian Classification of Diagnostic, Therapeutic and Surgical Procedures (CCP) code.

Radiotherapy Database - This database was assembled at the Queen's Division of Cancer Care and Epidemiology (CCE) with permission from all nine provincial cancer centres open during the period under study. Information includes body site treated with radiation, treatment intent 
(palliative or curative), dose of radiation, fractionation of radiation and dates of all treatments. The centres have kept electronic radiation therapy records since 1982.

Stage data. Staging data for this study was available for patients treated in 2003. Stage information is documented by clinicians at the province's regional cancer centres and reported to Cancer Care Ontario. Since stage is reported from cancer centres on patients seen there, any patient not seen at a cancer centre will not have electronic stage information. For endometrial cancer, this is a large group as most women will not have radiation at a regional cancer centre or have a surgery performed by a gynecologic oncologist. Data sources and their associated variables are summarized in figure 1 . The OCR, CIHI and radiotherapy data have been previously linked through unique identifiers (Group ID) for each patient.

\section{Classification of Independent Variables.}

Health System Factors (1) Comprehensive Gynecologic Oncology Centre (CGOC). This was defined as a hospital with gynecologic oncology surgical expertise based on evidence from the CIHI discharge abstract database of performance of at least one radical hysterectomy per year at the hospital and presence of a radiation therapy treatment centre. The Ontario Ministry of Health and Long Term Care (MOHLTC) master numbering system assigns unique hospitals codes to each hospital. We used the April 1, 2006 MOHLTC codex to identify hospital amalgamations and name changes. ${ }^{11}$ (2) Prevailing waiting time at the most responsible cancer centre. The concept of prevailing waiting time was first described by Huang et al. ${ }^{12}$ For the purposes of this study, it was defined as the median time that all patients requiring adjuvant radiation for a defined group had to wait from time of surgery to time of start of adjuvant radiation at a defined point in time. This was 
measured for each patient in the endometrial cancer cohort for all patients treated with postoperative radiation at the most responsible cancer centre in the four months preceding the selected endometrial cancer patient's date of surgery to two months following. Surgeries were identified using CCP surgical codes specified by Bardell et al. ${ }^{13}$ The most responsible cancer centre was determined for each operating hospital and was defined as the cancer centre where endometrial cancer patients most commonly received adjuvant radiation. If hospitals had less than twenty patients receiving radiation over the study period and less than $70 \%$ of their patients received radiation at the same cancer centre, the most responsible cancer centre was defined using information on radiation use following other common cancer surgeries using CCP surgical codes specified by Bardell et al. ${ }^{13}$ For any cases where no patient from that hospital had ever received adjuvant radiation for any indication, the closest cancer centre was assigned as the most responsible to cancer centre. The concept of the most responsible cancer centre's prevailing waiting time allows a prevailing waiting time to be associated with each endometrial cancer patient even if they did not receive radiation, in order to determine whether long waiting time was a factor explaining why they did not receive radiation. (3) Distance to the most responsible cancer centre. This was the linear distance to the most responsible cancer centre from the centre of the patient's census enumeration area if postal code was available or from the centre of the patient's census subdivision if only the patient's residence code was available. Distance was measured using a SAS macro developed at CCE. (4) Year of treatment. (5) Most responsible cancer centre. Patient Factors (1) Patient age. (2) Neighborhood median income was used as an ecologic measure of socioeconomic status. Information from Statistics Canada on median household income for the Canadian population by region has allowed linkage of this information at $\mathrm{CCE}$ at the census enumeration level to a patient's residential postal code and at the census subdivision level to a patient's 
residence code. ${ }^{14}$ The median income of the population comprising the patient's neighborhood was ordered by quintile compared to all other regions of Ontario. (3) Comorbidity. Comorbidity was measured using the Elixhauser comorbidity score for each patient's surgical admission record. The Elixhauser score is a validated scoring system for comorbidity data extracted from electronic records. ${ }^{15-17}$ Its performance characteristics have been compared with the Deyo adaption of the Charlson score and found superior in predicting in-hospital mortality for cancer patients and other patient populations. ${ }^{15-18}$ Disease Factors (1) Histology was defined according to ICD-O morphological categories as documented in OCR. Treatment-related Factors (1) Surgical staging. CCP procedure codes $52.19,52.2,52.4,52.41,52.44,52.49,52.81$ or 52.89 were defined as surgical staging if coded during the patient's admission for hysterectomy. (2) Type of hysterectomy. Patients were subdivided using $\mathrm{CIHI}$ procedure data into those receiving a simple hysterectomy (CCP codes 80.3, 80.4) or radical hysterectomy (CCP codes 80.5, 80.6). (3) Peritoneal biopsy. CCP procedure code 66.82 was used to identify cases of peritoneal biopsy.

The dependent variable was adjuvant radiation for endometrial cancer defined as documented receipt of radiation in the radiotherapy database within six months of a hysterectomy for a pathologic diagnosis of endometrial cancer. The six-month cut-off was chosen using available information on timing of adjuvant radiation and recurrence treatment available for a representative subset of the data. External beam radiation and brachytherapy were both accepted as types of radiation for the purposes of this study.

Homogeneity of Stage. Stage and grade strongly affect treatment for endometrial cancer. Though stage and grade information was not available for most patients in the cohort of interest, stage information was available from CCO for patients seen at most cancer centers in 2003. When present, pathologic stage information was used with precedence over clinical stage information. If 
T, N, M information was recorded then this was used to derive the stage. Clinical M category was taken as sufficient to assign pathologic $\mathrm{M}$ category if missing.

As previous studies have suggested that age and SES are strong predictors of stage for endometrial cancer, we assessed whether these or other available factors in the endometrial cancer database could be used to control for stage for the entire cohort. ${ }^{19,}{ }^{20}$ Using the 2003 staged cohort, we performed a multivariate logistic regression to identify factors associated with intermediate and advanced stage, defined as stage 1c and above. This data was used to identify factors that could serve as proxies of stage for the whole data set and assess homogeneity of stage among subgroups.

\section{Statistical Analysis}

All statistical analysis was performed using SAS Version 9.1. Univariate relationships between independent variables and the use of radiation were assessed using chi-square statistics. Exploration of confounding and effect modification was performed using stratified contingency tables and logistic regression. The strength of association between use of radiation and independent variables was estimated using logistic regression. Both crude and adjusted odds ratios were computed to examine the probability of radiation use for each factor of interest. A priori identified independent variables were included in the multivariate logistic model: Comprehensive Gynecologic Oncology Centre (CGOC), Prevailing wait time at the most responsible cancer centre, Distance to most responsible cancer centre, Year of treatment, Most responsible cancer centre, patient age, neighborhood median income, and Elixhauser comborbidity score.

Stepwise selection was used to identify the most parsimonious model with Schwartz's Criterion and Akaike's Information Criterion used as further discriminating criteria. The significance level for inclusion in the final model was 0.05. Histology, surgical staging, type of 
hysterectomy and peritoneal biopsy as well as a priori identified independent variables and all first order interaction terms were included in the stepwise selection process.

We used multi-level multiple logistic regression to assess and control for the potential effects of data clustering by operating hospital. We assessed the confidence interval of the variance of the intercept for the random effects parameter in the multi-level model, in this case, the operating hospital. A confidence interval centered near zero for this measure indicates that the random effects parameter is not statistically significant, and there is not a detectable effect of clustering on the multivariate model. If the random effects parameter is not significant and confidence intervals of the odds ratios are not notably different, a model with only fixed effects parameters as in fixed-effects multiple logistic regression is appropriate. Give a sample size of 9411, our cohort was adequately powered to perform the fixed effects multiple logistic regression undertaken in this analysis. $^{21}$

\section{Results}

Of all patients in the cohort, $26.2 \%$ (2461) received adjuvant radiation therapy. Patient Characteristics. There were 15,291 patients with endometrial cancer diagnosed between January 1, 1992 and December 31, 2003 in Ontario. Of these, 2,314 were excluded as they did not have a hysterectomy for their endometrial cancer. In addition, 447 were excluded for receiving first-course palliative radiation. No patients beyond these were excluded due to diagnosis by autopsy or death certificate or diagnosis of metastatic cancer. Additionally, 410 were excluded as they died within 90 days of surgery and 936 were further excluded as they had a previous malignancy. Of the remaining patients, 1,773 with uterine sarcoma or other histology were excluded. 9,411 patients comprised the study cohort. Of patients diagnosed in $2003,83 \%$ who received radiation were 
completely staged. Hospital Characteristics. Characteristics of CGOCs and other hospitals are summarized in table 1 .

Multivariate Analysis. Results for the fixed effects multiple logistic regression model are presented in tables 3 and 4 . There was good fit of the fixed effects model according to the Hosmer and Lemeshow Goodness-of-Fit Test ( $\mathrm{p}=0.7932)$. The Likelihood Ratio Test $(\mathrm{p}<.0001)$ confirmed the predictive value of the model.

The mixed model with operating hospital as the random effects parameter showed little difference from the fixed effects regression model in magnitude of regression parameters. The width of confidence limits for odds ratios changed by no more than $12 \%$ in comparison to the fixed effects model. The variance of the intercept for the random effects parameter was 0.02730 (95\% CI $-0.00306,0.05766)$. This would suggest that the clustering of patients at operating hospitals had no significant effect on the overall findings of this study. Results presented in tables 3 and 4 hence report the fixed effects multiple logistic regression rather than the mixed model.

System Factors and Use of Radiation. Table 3 summarizes the proportion of patients receiving radiation according to system factors. There were $27.7 \%$ of patients treated at Comprehensive Gynecologic Oncology Centres (CGOCs). There was a small but significantly greater use of radiation at CGOCs compared to other hospitals in univariate analysis though this did not persist in multivariate analysis. There was wide variation in use of radiation between CGOCs and also between other hospitals (Figure 2). In our model selection process, we found an interaction between hospital type and performance of surgical staging that did not meet our model inclusion criteria (Schwartz Criterion). To explore the loss of significance of the CGOC's effect on 
use of radiation in multivariate analysis, we performed a stratified multiple logistic regression based on surgical staging in order to gain insights into differences between factors affecting use of radiation between groups. Table 5 summarizes the findings of this stratified analysis. Most notably, if the hospital is a Comprehensive Gynecologic Oncology Centre the odds of radiation are significantly increased when patients received surgical staging.

One quarter of patients had their hysterectomies during prevailing waiting times for radiation of $<78$ days. Those whose hysterectomies occurred during prevailing waiting times of $\geq 78$ days showed little difference in use of radiation in univariate analysis compared to those whose surgery occurred during prevailing waiting times of $<78$ days (Table 3 ). However, those where hysterectomy occurred during prevailing waiting times of $\geq 78$ days were less likely by a small but significant margin to receive radiation after controlling for other factors in multivariate logistic regression (OR 0.853, 95\% CI 0.730, 0.996).

The median distance from the patient's home to the most responsible cancer centre was $26.9 \mathrm{~km}$ (inter-quartile range $8.5 \mathrm{~km}, 68.8 \mathrm{~km}$ ). In univariate analysis, patients living within $15 \mathrm{~km}$ of their regional cancer centre were $14.6 \%$ more likely to receive radiation than those living $>180$ $\mathrm{km}$ away. There was a clear trend to less use of radiation with increasing distance to the regional cancer centre in multivariate analysis (Table 3). There was no discernible change in use of radiation with year of diagnosis in univariate or multivariate analysis (Table 3).

The proportion of patients in each cancer centre's catchment receiving radiation varied from $18.0 \%$ to $34.3 \%$ with a median of $26.3 \%$. Most regional cancer centres' rate of radiation use was approximately $26 \%$ with one centre having a comparably low rate $(18.0 \%)$ and another centre a comparably high rate $(34.3 \%)$. This pattern remained in multivariate analysis with a statistically 
significant 2.7-fold variation in the odds of use of radiation between regional cancer centres (Table $3)$.

The median proportion of patients radiated in each county was $25.6 \%$ (interquartile range (IQR) $22.0 \%, 30.4 \%$ ), varying from $11.8 \%$ to $40.3 \%$. Figure 3 illustrates the proportion of patients receiving radiation by county. The proportion of patients from each hospital that received adjuvant radiation varied from $0 \%$ to $100 \%$ with a median of $24.3 \%$ and an inter-quartile range of $17.2 \%$ to $30.7 \%$.

Patient Factors and Use of Radiation. The median patient age was 63 years. There was a linear trend in use of radiation with increasing age in univariate analysis up to age 80 (Table 4). Use increased from $16.7 \%$ for patients 40 or less to $30.4 \%$ for patients $71-80(\mathrm{p}<.0001)$. This trend in increasing radiation use with increasing age persisted in the multivariate analysis. For instance, compared to patients 40 or less, the odds for patients aged 51-60 receiving radiation was 1.66 (95\% CI 1.15, 2.41) and for patients aged $71-80$ the odds of receiving radiation was 2.16 (95\% CI $1.49,3.13)$

There was a slight predominance of patients living in poorer neighborhoods in the cohort: $20.7 \%$ lived in lowest income quintile neighborhoods, $18.9 \%$ lived in neighborhoods in the second highest income quintile and $17.7 \%$ of patients lived in highest income quintile neighborhoods $(\mathrm{p}<.0001)$. There was no discernable trend in use of radiation with patient's neighborhood income quintile in either univariate or multivariate analysis.

We found that $70.0 \%$ of patients were classified as having no comorbidity by the Elixhauser comorbidity score. There was not a clear trend in use of radiation with increased 
comorbidity in univariate analysis. In multivariate analysis, there was not a significant association.

Disease-Related Factors and Use of Radiation. The most common tumour histology was adenocarcinoma (94.3\%). Clear cell histology was found in $1.5 \%$ of cases and $4.1 \%$ were serous papillary carcinoma. One quarter of patients with adenocarcinomas received radiation in univariate analysis, compared with $50.3 \%$ of patients with clear cell carcinoma and $46.4 \%$ of patients with serous papillary carcinoma $(\mathrm{p}<.0001)$. The odds of receiving radiation for patients with clear cell or serous papillary carcinoma were respectively 2.71 (95\% CI 1.93, 3.80) and 2.19 (95\% CI 1.77, 2.71) compared to adenocarcinoma (table 4).

To assess temporal and geographic variation in intermediate and advanced stage (1c and above) we first performed a multiple logistic regression on the staged subset of patients from 2003 to identify factors associated with intermediate and advanced stage. Factors assessed were hospital type, wait time, income quintile, distance, age 70 or greater, histology, hysterectomy type, surgical staging, peritoneal biopsy, year of diagnosis, Elixhauser comorbidity score, and death within 1 year of diagnosis. Using a stepwise model selection algorithm with a 0.05 significance level for inclusion, we found that a model with two variables was most predictive and parsimonious. This model included death within 1 year of endometrial cancer diagnosis (OR 9.03, 95\% CI 2.04, 40.10) and age 70 or greater (OR 1.86, 95\% CI 1.27, 2.72). Table 2 demonstrates the association between age and stage distribution in more detail.

Geographic and temporal variation for the two identified stage proxies were acceptable. The median proportion of patients dying within one year by county was $1.9 \%$ (IQR $0.3 \%, 3.0 \%$, range $0.0 \%, 11.1 \%$ ). For counties with $>100$ patients, the median proportion of patients above the 
age of 70 was $32.0 \%$ (IQR $26.5 \%, 33.7 \%$, range $20.7 \%$ to $42.5 \%$ ). This provides indirect evidence for an acceptably low level of geographic variation in stage. The median proportion of death within 1 year of diagnosis by diagnosis year was $2.4 \%$ (IQR $2.0 \%, 2.8 \%$, range $0.9 \%, 3.9 \%$ ) and for age, the median was $31.2 \%$ (IQR $28.5 \%, 33.2 \%$, range $27.8 \%, 35.0 \%$ ). This suggests acceptably low levels of temporal variation in stage.

Treatment-Related Factors and Use of Radiation. Surgical staging was done in $11.8 \%$ of patients. Figure 4 illustrates the proportion of patients receiving surgical staging by county. The median proportion of patients receiving surgical staging in each county was 7.9\% (IQR 4.7\%, 16.6\%) with a range of $0 \%$ to $51.9 \%$. Nodal staging was done at non-CGOCs in $29 \%$ (325 patients) of cases. CGOCs performed surgical staging as part of 30.1\% (95\% CI 28.3\%, 31.8\%) of their hysterectomies versus $4.8 \%$ (95\% CI 4.3\%, 5.3\%) at other hospitals. Patients whose lymph nodes were staged were more likely to receive radiation than those whose lymph nodes were not in univariate (34.5\% vs $25.0 \%$ ) and multivariate analysis (OR 1.45, 95\% CI 1.23, 1.70) (Table 4). Simple hysterectomy was performed in $98.3 \%$ of cases and $1.7 \%$ received a radical hysterectomy. Patients who had a radical hysterectomy were more likely to receive radiation in univariate $(40.7 \%$ vs $25.9 \%$ p<.0001) and multivariate analysis (OR1.66, 95\% CI 1.18, 2.33) (Table 4).

Peritoneal biopsy was performed in $7.4 \%$ of patients. These patients were more likely to receive radiation in univariate $(35.1 \%$ vs $25.4 \% \mathrm{p}<.0001)$ and multivariate analysis $(\mathrm{OR} 1.48,95 \%$ CI 1.24, 1.76) (Table 4). 


\section{Discussion}

In this study, we identified a number of system factors associated with use of adjuvant radiation for endometrial cancer in Ontario. Patients who have their surgery during longer prevailing waiting times at regional cancer centres, live at greater distances from regional cancer centre or have surgeries within certain referral networks are less likely to receive radiation. In addition, age is a strong patient-related factor affecting use of radiation for endometrial cancer in Ontario.

There are a number of strengths and limitations to this study. The databases used for this study contained information on almost all cases of endometrial cancer in Ontario for the whole of the study period. We were hence able to avoid the biases inherent in hospital-based case series. The OCR database is known to be a highly complete and accurate source of health information. As linkages between the databases of interest have already been established, this represents a rich and accessible source of research information. Because we had highly complete information on almost all cases of endometrial cancer diagnosed in Ontario, we are able to comment on under-use of services rather than simply inappropriate over-use of radiation services at certain cancer centres. ${ }^{22,23}$

A limitation of the available data is the absence of cancer stage and grade information for all patients. A major assumption of this study is that patient's cancer stage and grade is evenly distributed geographically and temporally in Ontario. As mentioned, the limited stage information that is available suggests that vital status following endometrial cancer diagnosis and age are useful proxies for stage. We found only minor geographic variation in these variables.

As referral information was not available for all patients in the cohort, we used receipt of radiation as a proxy to referral. It is hence unknown whether patients who did not receive radiation 
were either not referred by their surgeon or did not receive radiation based on their consultation with a radiation oncologist. The role of patient preference in this medical decision is also unknown and cannot be described with the available electronic health data.

In our study we found that $26 \%$ of women in our cohort with surgically resected endometrial cancer received adjuvant radiation therapy and $12 \%$ received surgical staging. Delaney et al estimated that in populations with surgical staging rates of $10 \%$ that $58 \%$ of patients with endometrial cancer would have an indication for external beam radiation at some point in their disease course. ${ }^{4}$ Inclusion of recurrence treatments and palliative radiation in Delaney's et al's study and exclusion of brachytherapy indications make it difficult to directly compare our findings to this estimate. However, it is a useful first-order approximation since few patients with endometrial cancer ultimately develop cancer recurrence or metastases. ${ }^{4} \mathrm{We}$ found that the median proportion of patients radiated in each county was $25.6 \%$ (IQR $22.0 \%, 30.4 \%$ ), varying from $11.8 \%$ to $40.3 \%$. This would raise the question of whether under-utilization of radiation for endometrial cancer is occurring in Ontario.

What radiation use rate is right for endometrial cancer in Ontario? As figure 2 illustrates, there is a wide range of radiation use rates among patients whose surgeries were at provincial CGOCs, making determination of a provincial benchmark rate of radiation problematic. At a minimum, it can be said that patients surgically managed at CGOCs in Ontario receive radiation no less than $22 \%$ of the time and there were 49 out of 127 operating hospitals where a lower proportion of patients than this receive radiation.

We found that management at a CGOC was associated with a significantly higher use of radiation compared to other hospitals only for patients who had surgical staging (OR $1.53,95 \% \mathrm{CI}$ $1.12,2.09)$. Given most surgical staging procedures at non-CGOCs were probably not performed 
by surgeons with extensive training in radical pelvic and peri-aortic lymph node dissection, it is quite possible that these lymph node procedures performed outside of CGOCs were for incidental or suspicious intra-operative findings that might not lead to an indication for radiation. On the other hand, surgical staging is more likely to be part of routine management at CGOCs for patients with poor prognostic features where radiation is indicated. In keeping with this hypothesis, we did observe higher rates of high risk histology (clear cell carcinoma and serous papillary) and more advanced stage in patients who had surgery at CGOCs (Table 1). Complete stage information would help clarify our observation regarding use of radiation at CGOCs in patients who received surgical staging.

Utilization of post-operative radiation varies markedly among the regions served by the different cancer centres. There is a 2.7 -fold difference in the odds of use of radiation among most responsible cancer centres after controlling for other factors. Again, this may either represent variation in referral for radiation or regional variation in the prescription of radiation once the patient is referred. On comparison of the regression model with and without prevailing waiting time, we did not find evidence that this variation was due to prevailing waiting time. In addition, we controlled for referring hospital type which should minimize any effect of referring doctor. This would suggest variation between most responsible cancer centres is due to other potential factors other than hospital type or waiting times. These factors may include departmental policies or treating radiation oncologist preferences. It would also suggest that the wait time phenomenon is a distinct phenomenon rather than a signature in the data for specific cancer centres.

Prevailing waiting times have been associated with use of radiation in some but not all studies. Kong et al previously found that prevailing waiting time affected patterns of palliative radiation prescription in Ontario. ${ }^{7}$ Patients treated at times of high prevailing waiting times 
received radiation treatments with fewer fractions for their bone metastases. Similarly, elderly patients were less likely to receive post-lumpectomy radiation for breast cancer as prevailing wait times increased in Ontario. ${ }^{24}$ Huang and Mackillop did not find an association between treatment choice for prostate cancer and prevailing waiting time. ${ }^{12}$ The results of our study suggest that longer prevailing waiting times in radiotherapy departments is associated with reduced utilization of adjuvant radiation for endometrial cancer. This may be due to either lower rates of referral when prevailing wait times are longer or less frequent prescription of radiation following referral.

The further a patient lives from the most responsible cancer centre, the less likely she is to receive adjuvant radiation therapy. This trend may be related to patient preference, referring doctor or treating radiation oncologist opinion regarding the benefits of radiation. It may be both too expensive and too inconvenient for patients at long distances to travel 2 or more hours in a car daily for five weeks or more. For intermediate-risk stage I patients, the appropriate use of radiation is debated. One might hypothesize that distance-related variation is due to these debatable cases. It will be important to determine if alternatively this distance effect is in fact related to poor referral pathways or lack of understanding of accepted indications for radiation therapy for patients with endometrial cancer in Ontario.

It is noteworthy that patients are more likely to receive radiation the older they are, up to into their 70's. Previous studies in use of radiation with increasing age have shown the opposite. ${ }^{5}$, ${ }^{25}$ For instance, women receiving radiation for breast cancer following surgery $>80$ years old had an odds of receiving radiation of $0.09(95 \%$ CI $0.08,0.11)$ compared to the $<40$ reference category. ${ }^{5}$ Advanced age is a known poor prognostic factor for patients with endometrial cancer. ${ }^{326}$ This is certainly true for our cohort. For ages $<41,41-50,51-60,61-70,71-80,>80$, the proportion of highrisk histologies in each age group were respectively $1.8 \%, 1.5 \%, 3.7 \%, 6.8 \%, 7.9 \%, 9.9 \%$. Using 
disease stage 1a as a marker for favorable prognostic disease, the proportion of these patients decreased with age in our staged cohort. Rates were $28.6 \%, 31.8 \%, 14.9 \%, 11.3 \%, 6.9 \%$ and $10.0 \%$ for the above age categories. This would suggest that the poor prognostic value of age in endometrial cancer is probably responsible for our findings regarding age and use of radiation.

\section{Conclusion}

In conclusion, this study provides evidence that factors unrelated to patient's needs are involved in use of adjuvant radiation for endometrial cancer in Ontario between 1992 and 2003. Patients who have their surgery during high prevailing waiting times at regional cancer centres, live further from regional cancer centres, or who are managed in certain cancer centre catchments are less likely to receive radiation. This study provides new insight into factors that may be limiting access to radiation treatment for endometrial cancer in Ontario. It also highlights wide variation in use of radiation. Further work will need to clarify the population-level impact on outcome and morbidity of this phenomenon. In addition, age is an important patient-related factor in radiation use for endometrial cancer in Ontario.

As further studies emerge defining the need for radiation for intermediate-risk endometrial cancer patients, patterns of practice will probably change. This study provides a baseline assessment of radiation use for operable cases of endometrial cancer in Ontario. Stage information for a greater proportion of patients will become available with time given current provincial initiatives. This will enhance future projects. Ultimately, appropriate geographic and temporal allocation of resources will be needed to address the barriers to access identified in this study. 


\section{Acknowledgements}

Canadian Institute of Health Research (CIHR) Fellowship in Policy and Health Services Research

Queen's University and CIHR Transdisciplinary Training Program in Cancer Research Fellowship

CIHR New Emerging Team (NET) Grant

Cancer Care Ontario (CCO)

Ontario Cancer Registry (OCR) 


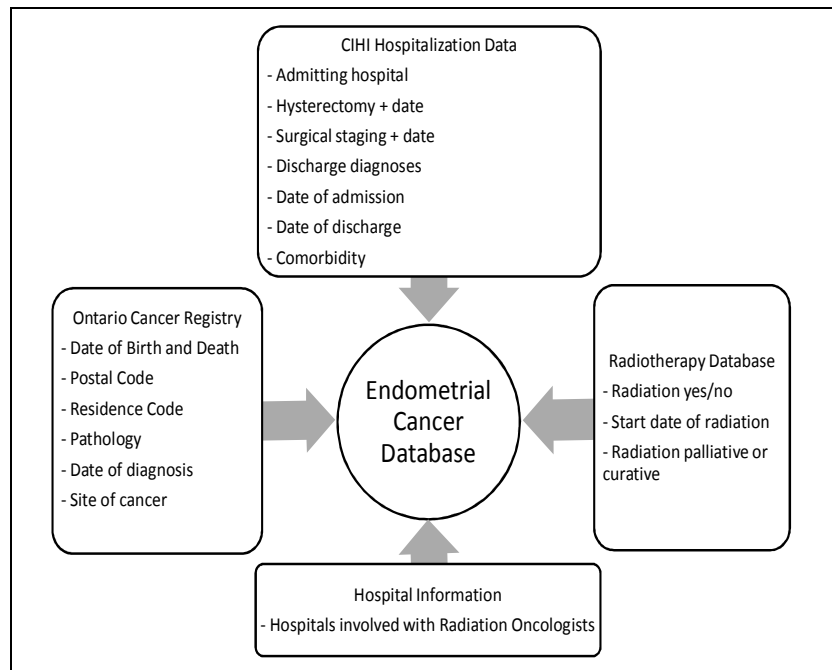

Figure 1. Data linkage relationships for Endometrial Cancer Database 


\begin{tabular}{|c|c|c|}
\hline Characteristics & CGOC (n=2605) & Other hospital ( $n=6806)$ \\
\hline \multicolumn{3}{|l|}{ Age (years) } \\
\hline$\leq 60$ & $42.7 \%$ & $41.0 \%$ \\
\hline $61-70$ & $29.6 \%$ & $30.7 \%$ \\
\hline$>70$ & $27.7 \%$ & $28.2 \%$ \\
\hline \multicolumn{3}{|l|}{ Stage (\%)‡ } \\
\hline 1 & $71.4 \%$ & $80.3 \%$ \\
\hline $1 a$ & $24.6 \%$ & $15.0 \%$ \\
\hline $1 b$ & $47.6 \%$ & $57.9 \%$ \\
\hline $1 c$ & $27.8 \%$ & $27.1 \%$ \\
\hline 2 & $12.6 \%$ & $11.9 \%$ \\
\hline $2 a$ & $34.8 \%$ & $43.6 \%$ \\
\hline $2 b$ & $65.2 \%$ & $56.4 \%$ \\
\hline 3 & $12.1 \%$ & $6.1 \%$ \\
\hline $3 a$ & $50.0 \%$ & $55.6 \%$ \\
\hline $3 b$ & $5.0 \%$ & $16.7 \%$ \\
\hline $3 c$ & $45.0 \%$ & $27.8 \%$ \\
\hline 4 & $3.9 \%$ & $1.7 \%$ \\
\hline High-risk histology (\%)* & $10.2 \%$ & $4.0 \%$ \\
\hline Peritoneal biopsy (\%)* & $9.8 \%$ & $6.5 \%$ \\
\hline Surgical staging (\%)* & $30.1 \%$ & $4.8 \%$ \\
\hline Radiation * & $29.3 \%$ & $25.0 \%$ \\
\hline $\begin{array}{l}\text { Patients who were surgically } \\
\text { managed at hospital type who } \\
\text { died by end of study period }(\%)^{*}\end{array}$ & $19.9 \%$ & $16.0 \%$ \\
\hline \multicolumn{3}{|c|}{$\begin{array}{l}\text { Table 1. Characteristics of patients managed at Comprehensive Gynecologic Oncology Centres } \\
\text { versus other hospitals. High-risk histology refers to patients with serous papillary or clear cell } \\
\text { histology } \ddagger \text { Stage distribution tested by chi square test with } p \text {-value of } 0.0340 \text {. Stage refers to the } \\
\text { cohort of patients in } 2003 \text { who were seen at a regional cancer centre and staged. There were } 182 \\
\text { staged patients who had surgery at CGOCs and } 345 \text { from other hospitals. Substage information } \\
\text { was not available for } 22 \text { records. * Statistically significant at } p<.0001 .\end{array}$} \\
\hline
\end{tabular}




\begin{tabular}{|l|l|l|l|l|l|l|}
\hline & \multicolumn{6}{|c|}{ Proportion Stage by Age Group (total) } \\
\cline { 2 - 7 } & $\begin{array}{l}0-40 \\
(n=6)\end{array}$ & $\begin{array}{l}40-49 \\
(n=41)\end{array}$ & $\begin{array}{l}50-59 \\
(n=166)\end{array}$ & $\begin{array}{l}60-69 \\
(n=153)\end{array}$ & $\begin{array}{l}70-79 \\
(n=108)\end{array}$ & $\begin{array}{l}80+ \\
(n=38)\end{array}$ \\
\hline $1 A$ & 33 & 34 & 16 & 12 & 7 & 11 \\
\hline $1 B$ & 33 & 20 & 51 & 44 & 44 & 26 \\
\hline $1 C$ & 0 & 5 & 16 & 27 & 26 & 29 \\
\hline 2 & 17 & 20 & 10 & 12 & 11 & 16 \\
\hline 3 & 17 & 17 & 7 & 3 & 8 & 11 \\
\hline 4 & 0 & 5 & 1 & 1 & 4 & 8 \\
\hline
\end{tabular}

Table 2. Stage distribution by age group for staged cohort of patients from 2003. Substage information was not available for eight patients with stage 1 disease.

Chi-square test $p<.0001$. 


\begin{tabular}{|c|c|c|c|}
\hline System Factors & Number & $\begin{array}{l}\text { Use of } \\
\text { Radiation } \\
\%\end{array}$ & $\begin{array}{r}\text { Multivariate } \\
\text { Logistic Regression Estimate OR (95\% } \\
\text { Confidence Limit)* }\end{array}$ \\
\hline \multicolumn{4}{|l|}{ Hospital Type § } \\
\hline Other hospital & 6806 & 24.95 & 1 \\
\hline $\begin{array}{r}\text { Comprehensive Gynecologic Oncology } \\
\text { Centre }\end{array}$ & 2605 & 29.29 & $1.00(0.89,1.13)$ \\
\hline \multicolumn{4}{|l|}{$\begin{array}{l}\text { Prevailing Wait Time at Most } \\
\text { Responsible Cancer Centre (days) }\end{array}$} \\
\hline$<78$ & 2326 & 25.96 & 1 \\
\hline$\geq 78$ & 7085 & 26.74 & $0.853(0.730,0.996)$ \\
\hline \multicolumn{4}{|l|}{$\begin{array}{l}\text { Distance to Most Responsible Cancer } \\
\text { Centre (km) }\end{array}$} \\
\hline $\begin{array}{rr}0.15 .0 \\
\end{array}$ & 3629 & 27.20 & 1 \\
\hline $16-60$ & 3027 & 25.27 & $0.99(0.88,1.11)$ \\
\hline $61-120$ & 1723 & 26.70 & $0.85(0.74,0.99)$ \\
\hline $121-180$ & 599 & 25.21 & $0.76(0.61,0.94)$ \\
\hline$>180$ & 337 & 23.74 & $0.76(0.56,1.02)$ \\
\hline NA & 96 & 18.75 & $0.61(0.36,1.06)$ \\
\hline \multicolumn{4}{|l|}{ Year of Diagnosis } \\
\hline 1992 & 650 & 28.62 & 1 \\
\hline 1993 & 715 & 29.65 & $1.05(0.83,1.34)$ \\
\hline 1994 & 709 & 26.80 & $0.91(0.71,1.16)$ \\
\hline 1995 & 670 & 28.36 & $0.94(0.73,1.19)$ \\
\hline 1996 & 766 & 24.67 & $0.76(0.60,0.97)$ \\
\hline 1997 & 809 & 24.47 & $0.79(0.62,1.01)$ \\
\hline 1998 & 778 & 25.84 & $0.89(0.70,1.14)$ \\
\hline 1999 & 809 & 26.70 & $0.90(0.71,1.15)$ \\
\hline 2000 & 884 & 23.30 & $0.78(0.61,1.00)$ \\
\hline 2001 & 850 & 26.82 & $0.99(0.78,1.26)$ \\
\hline 2002 & 880 & 24.32 & $0.79(0.62,1.01)$ \\
\hline 2003 & 891 & 25.93 & $0.88(0.69,1.12)$ \\
\hline \multicolumn{4}{|l|}{ Most Responsible Cancer Centre $\S$} \\
\hline e & 2494 & 26.06 & 1 \\
\hline 1 & 845 & 27.57 & $0.89(0.73,1.09)$ \\
\hline 4 & 1494 & 18.01 & $0.56(0.47,0.66)$ \\
\hline 5 & 715 & 26.43 & $1.04(0.83,1.30)$ \\
\hline 6 & 1416 & 34.25 & $1.51(1.29,1.76)$ \\
\hline 7 & 1610 & 25.71 & $0.93(0.79,1.08)$ \\
\hline 8 & 144 & 27.08 & $1.00(0.67,1.51)$ \\
\hline 9 & 243 & 26.34 & $0.94(0.69,1.29)$ \\
\hline 11 & 450 & 26.22 & $1.12(0.85,1.46)$ \\
\hline \multicolumn{4}{|c|}{$\begin{array}{l}\text { Table 3. System-related factors affecting use of adjuvant radiation in Ontario. } \S p<0.0001 \text { in univariate } \\
\text { analysis. *Fixed effects multivariate logistic regression controlling for hospital type, prevailing wait time at } \\
\text { most responsible cancer centre, distance from residence to most responsible cancer centre, year of diagnosis, } \\
\text { most responsible cancer centre, age at diagnosis, neighborhood median income quintile, Elixhauser } \\
\text { comorbidity score, histology, surgical staging, type of hysterectomy and peritoneal biopsy at time of surgery. }\end{array}$} \\
\hline
\end{tabular}




\begin{tabular}{|c|c|c|c|}
\hline Patient Factors & Number & $\begin{array}{l}\text { Use of } \\
\text { Radiation } \\
\%\end{array}$ & $\begin{array}{r}\text { Multivariate } \\
\text { Logistic Regression Estimate OR (95\% } \\
\text { Confidence Limit)* }\end{array}$ \\
\hline \multicolumn{4}{|l|}{ Patient Age $\S$} \\
\hline $0-40$ & 221 & 16.74 & 1 \\
\hline $41-50$ & 893 & 19.60 & $1.23(0.83,1.83)$ \\
\hline $51-60$ & 2791 & 24.58 & $1.66(1.15,2.41)$ \\
\hline $61-70$ & 2863 & 27.84 & $1.92(1.32,2.77)$ \\
\hline $71-80$ & 2096 & 30.44 & $2.16(1.49,3.13)$ \\
\hline$>80$ & 547 & 23.40 & $1.46(0.97,2.21)$ \\
\hline \multicolumn{4}{|l|}{ Neighborhood Income Quintile } \\
\hline 1 (Poorest) & 1950 & 26.36 & 1 \\
\hline 2 & 2102 & 25.69 & $0.98(0.85,1.13)$ \\
\hline 3 & 1904 & 27.84 & $1.09(0.94,1.26)$ \\
\hline 4 & 1778 & 24.75 & $0.93(0.80,1.09)$ \\
\hline 5 (Richest) & 1668 & 26.02 & $0.98(0.83,1.15)$ \\
\hline \multicolumn{4}{|l|}{ Elixhauser Comorbidity } \\
\hline 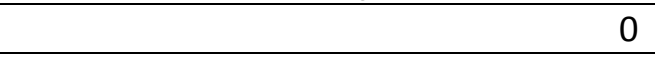 & 6587 & 25.84 & 1 \\
\hline 1 & 1771 & 28.18 & $1.04(0.98,1.11) \ddagger$ \\
\hline 2 & 730 & 25.34 & \\
\hline 3 & 234 & 25.21 & \\
\hline $4+$ & 89 & 17.98 & \\
\hline \multicolumn{4}{|l|}{$\begin{array}{l}\text { Disease- and Treatment-Related } \\
\text { Factors }\end{array}$} \\
\hline \multicolumn{4}{|l|}{ Histology $\S$} \\
\hline Endometrioid & 8876 & 24.86 & 1 \\
\hline Clear Cell & 145 & 50.34 & $2.71(1.93,3.80)$ \\
\hline Serous Papillary & 390 & 46.41 & $2.19(1.77,2.71)$ \\
\hline \multicolumn{4}{|l|}{ Surgical Staging $\S$} \\
\hline None & 8303 & 25.04 & 1 \\
\hline Staged & 1108 & 34.48 & $1.45(1.23,1.70)$ \\
\hline \multicolumn{4}{|l|}{ Hysterectomy $\S$} \\
\hline Simple hysterectomy & 9249 & 25.89 & 1 \\
\hline Radical hysterectomy & 162 & 40.74 & $1.66(1.18,2.33)$ \\
\hline \multicolumn{4}{|l|}{ Peritoneal Biopsy $\S$} \\
\hline No & 8715 & 25.44 & 1 \\
\hline Yes & 696 & 35.06 & $1.48(1.24,1.76)$ \\
\hline \multicolumn{4}{|c|}{$\begin{array}{l}\text { Table 4. Patient-related, disease-related and treatment-related factors affecting use of adjuvant radiation } \\
\text { in Ontario. ‡ Elixhauser comorbidity was modeled as a continuous variable. } \S p<0.0001 \text { in univariate } \\
\text { analysis. . *Fixed effects multivariate logistic regression controlling for hospital type, prevailing wait time at } \\
\text { most responsible cancer centre, distance from residence to most responsible cancer centre, year of } \\
\text { diagnosis, most responsible cancer centre, age at diagnosis, neighborhood median income quintile, } \\
\text { Elixhauser comorbidity score, histology, surgical staging, type of hysterectomy and peritoneal biopsy at } \\
\text { time of surgery. }\end{array}$} \\
\hline
\end{tabular}




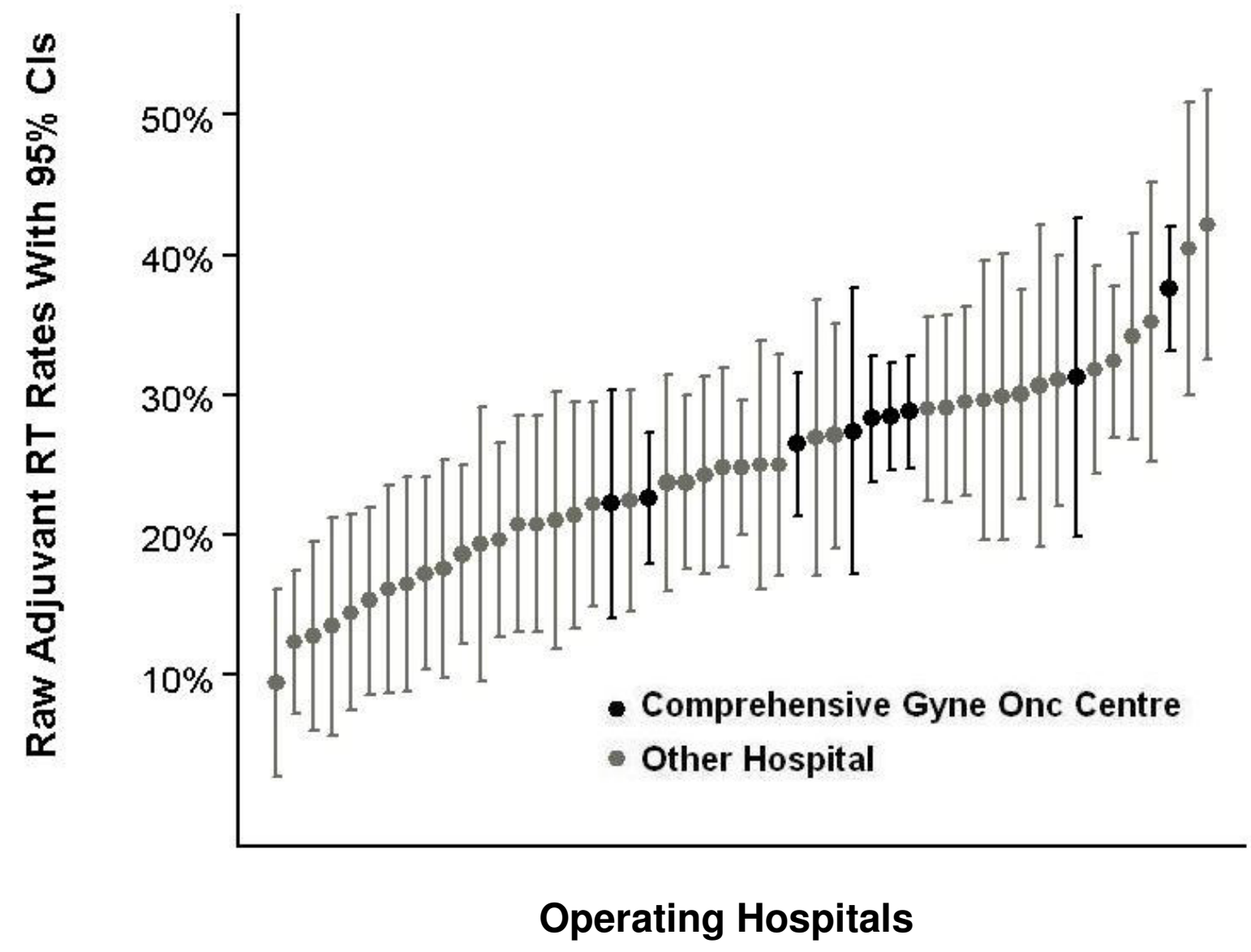

Figure 2. Adjuvant radiation rates for endometrial cancer by operating hospital. Comprehensive Gynecologic Oncology Centres are black points and other hospitals are grey points. Hospitals operating on more than 60 cases of endometrial cancer over the study period (on average 5 cases per year) were included. For the two hospitals that were CGOCs for only part of the study period, rates of use of radiation were calculated using years that the hospitals were CGOCs. 


\begin{tabular}{|c|c|c|c|c|c|c|}
\hline & \multicolumn{3}{|c|}{ Surgical Staging $\ddagger$} & \multicolumn{3}{|c|}{ No Surgical Staging } \\
\hline & Number & $\begin{array}{l}\text { Use of } \\
\text { XRT \% }\end{array}$ & OR $(95 \% \mathrm{Cl})^{*}$ & Number & $\begin{array}{l}\text { Use of } \\
\text { XRT \% }\end{array}$ & OR $(95 \% \mathrm{Cl})^{*}$ \\
\hline \multicolumn{7}{|l|}{ Hospital type } \\
\hline Other Hospital & 325 & 28.31 & 1 & 6481 & 24.78 & 1 \\
\hline Comprehensive Gyne Onc Centre & 783 & 37.04 & $1.53(1.12,2.09)$ & 1822 & 25.96 & $0.94(0.82,1.07)$ \\
\hline
\end{tabular}

Table 5. Multivariate Analysis stratified by performance of surgical staging. ¥ Proportion of patients receiving radiation varies significantly between hospital types in the surgical staging stratum in univariate analysis (p<.01). *Multivariate Regression controls for hospital type, prevailing waiting time at most responsible cancer centre, distance, year of diagnosis, most responsible cancer centre, age at diagnosis, histology and peritoneal biopsy. Surgery type was not included in the model as it is highly correlated with surgical staging in clinical practice. 


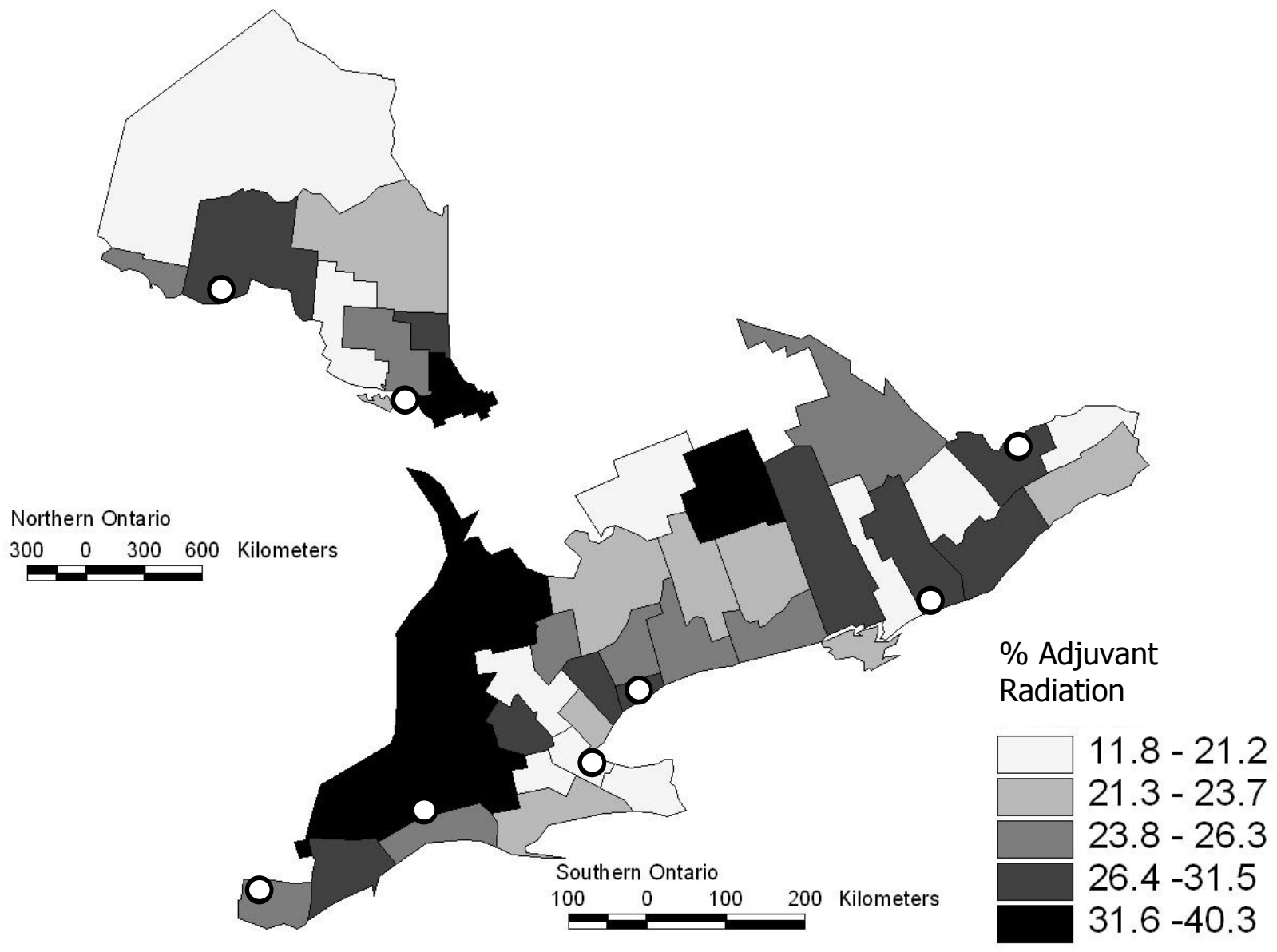

Figure 3. Proportion of patients receiving adjuvant radiation for endometrial cancer in Ontario by county. Frequencies divided into quintiles. Circles indicate locations of regional cancer centres. 


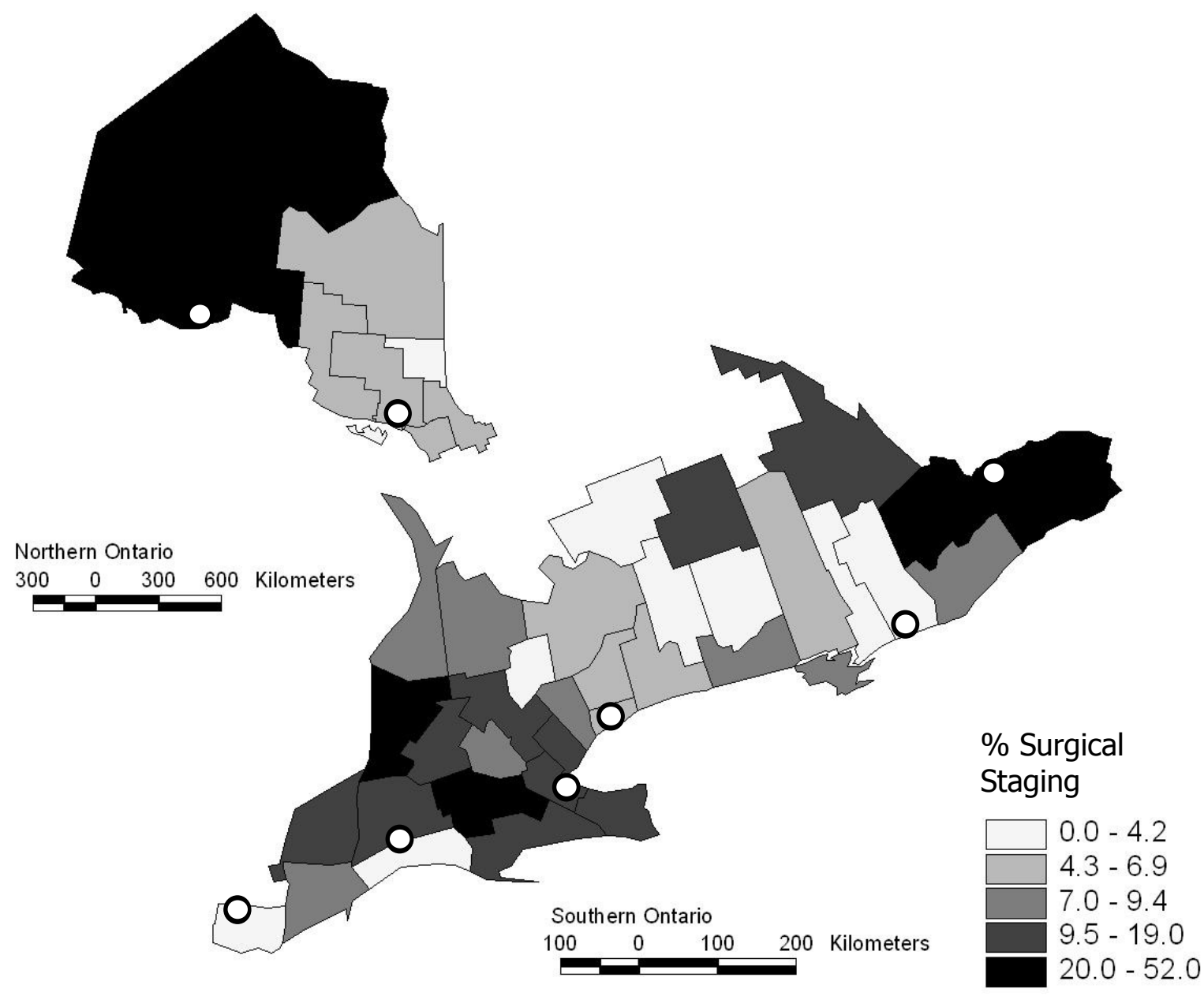

Figure 4. Proportion of patients receiving surgical staging for endometrial cancer in Ontario. Frequencies divided into quintiles. Circles indicate locations of regional cancer centres. 


\section{References}

1. Greer BE, Koh W-J co-Chairs. NCCN Clinical Practice Guidelines in Oncology- Uterine neoplasms volume 2.2009: National Comprehensive Cancer Network; 2009.

2. Lukka H, Chambers A, Fyles A, et al. Adjuvant Radiotherapy in Women with Stage I Endometrial Cancer: A Clinical Practice Guideline. Vol \#4-10: Cancer Care Ontario Program in Evidence-Based Care; 2006.

3. Cardenes HR, Look K, Michael H, Cerezo L. Endometrium. In: Perez CA, Brady LW, Halperin EC, Schmidt-Ullrich RK, eds. Principles and Practice of Radiation Oncology Fifth Edition. New York: Lippincott Williams \& Wilkins; 2007.

4. Delaney G, Jacob S, Barton M. Estimation of an optimal radiotherapy utilization rate for gynecologic carcinoma: part II - carcinoma of the endometrium. Cancer. Aug 15 2004;101(4):682-692.

5. Paszat LF, Mackillop WJ, Groome PA, Zhang-Salomons J, Schulze K, Holowaty E. Radiotherapy for breast cancer in Ontario: rate variation associated with region, age and income. Clin Invest Med. Jun 1998;21(3):125-134.

6. Huang J, Zhou S, Groome P, Tyldesley S, Zhang-Solomans J, Mackillop WJ. Factors affecting the use of palliative radiotherapy in Ontario. J Clin Oncol. Jan 1 2001;19(1): 137-144.

7. Kong W, Zhang-Salomons J, Hanna TP, Mackillop WJ. A population-based study of the fractionation of palliative radiotherapy for bone metastasis in Ontario. Int J Radiat Oncol Biol Phys. Nov 15 2007;69(4):1209-1217.

8. Roland PY, Kelly FJ, Kulwicki CY, Blitzer P, Curcio M, Orr JW, Jr. The benefits of a gynecologic oncologist: a pattern of care study for endometrial cancer treatment. Gynecol Oncol. Apr 2004;93(1):125-130.

9. Robles SC, Marrett LD, Clarke EA, Risch HA. An application of capture-recapture methods to the estimation of completeness of cancer registration. J Clin Epidemiol. 1988;41(5):495-501.

10. Clarke EA, Marrett LD, Kreiger N. Cancer registration in Ontario: a computer approach. IARC Scientific Publications. 1991(95):246-257.

11. Ministry of Health and Long Term Care Finance \& Information Management Branch Information Management Unit. Ministry of Health and Long Term Care Master Numbering System (CIHI Institution Numbers). Ontario; 2006.

12. Huang M. The influence of waiting time on treatment choices among prostate cancer patients. Kingston: Department of Community Health and Epidemiology, Queen's University; 2006.

13. Bardell T, Belliveau P, Kong W, Mackillop WJ. Waiting times for cancer surgery in Ontario: 1984-2000. Clin Oncol (R Coll Radiol). Jun 2006;18(5):401-409.

14. Mackillop WJ, Zhang-Salomons J, Groome PA, Paszat L, Holowaty E. Socioeconomic status and cancer survival in Ontario. J Clin Oncol. Apr 1997;15(4):1680-1689.

15. Elixhauser A, Steiner C, Harris DR, Coffey RM. Comorbidity measures for use with administrative data. Med Care. Jan 1998;36(1):8-27.

16. Southern DA, Quan H, Ghali WA. Comparison of the Elixhauser and Charlson/Deyo methods of comorbidity measurement in administrative data. Med Care. Apr 2004;42(4): 355-360. 
17. Stukenborg GJ, Wagner DP, Connors AF, Jr. Comparison of the performance of two comorbidity measures, with and without information from prior hospitalizations. Med Care. Jul 2001;39(7):727-739.

18. de Groot V, Beckerman H, Lankhorst GJ, Bouter LM. How to measure comorbidity. a critical review of available methods. J Clin Epidemiol. Mar 2003;56(3):221-229.

19. Jolly $\mathrm{S}$, Vargas CE, Kumar T, et al. The impact of age on long-term outcome in patients with endometrial cancer treated with postoperative radiation. Gynecol Oncol. Oct 2006;103(1):87-93.

20. Madison T, Schottenfeld D, James SA, Schwartz AG, Gruber SB. Endometrial cancer: socioeconomic status and racial/ethnic differences in stage at diagnosis, treatment, and survival. Am J Public Health. Dec 2004;94(12):2104-2111.

21. Vittinghoff $\mathrm{E}, \mathrm{McCulloch} \mathrm{CE}$. Relaxing the rule of ten events per variable in logistic and Cox regression. Am J Epidemiol. Mar 15 2007;165(6):710-718.

22. Chassin MR, Kosecoff J, Park RE, et al. Does inappropriate use explain geographic variations in the use of health care services? A study of three procedures. JAMA. Nov 13 1987;258(18):2533-2537.

23. Leape LL, Park RE, Solomon DH, Chassin MR, Kosecoff J, Brook RH. Does inappropriate use explain small-area variations in the use of health care services? JAMA. Feb 2 1990;263(5):669-672.

24. Zhang-Salomons J, Fourodi F, Huang J, Mackillop WJ. Health System Effects on the Use of Radiotherapy Following Surgery for Breast Cancer. Abstr Acad Health Serv Res Health Policy Meet. 2002;19:45.

25. Tyldesley S, Zhang-Salomons J, Groome PA, et al. Association between age and the utilization of radiotherapy in Ontario. Int J Radiat Oncol Biol Phys. May 1 2000;47(2):469-480.

26. Creutzberg CL, van Putten WL, Koper PC, et al. Surgery and postoperative radiotherapy versus surgery alone for patients with stage-1 endometrial carcinoma: multicentre randomised trial. PORTEC Study Group. Post Operative Radiation Therapy in Endometrial Carcinoma. Lancet. Apr 22 2000;355(9213):1404-1411. 


\section{Chapter 4}

\section{Summary and Conclusions}

\section{Major findings and expanded discussion}

This thesis provides evidence that there are factors unrelated to patient's needs involved in the use of adjuvant radiation for endometrial cancer in Ontario, limiting access to an important part of the management of this common cancer. We found that patients who had their surgeries during periods of longer prevailing waiting times at regional cancer centres were less likely to receive radiation. This provides evidence that access to adjuvant radiation for endometrial cancer in Ontario may be limited by the availability of this treatment. Patients who lived further from regional cancer centres were less likely to receive adjuvant radiation. This provides some evidence that access may also be limited by spatial accessibility. The likelihood of use of radiation also varied widely between most responsible cancer centres. We did not find evidence to support the hypothesis that awareness issues limit access to radiation for endometrial cancer. Radiation use did not vary between hospitals with differing levels of gynecologic oncology expertise and our ecologic measure of socioeconomic status (median neighborhood income quintile) was not associated with variation in use of radiation.

Of additional note, we found increasing age is an important patient-related factor associated with the use of radiation up to the ninth decade of life. Previous work by Kwon et al identified some patient factors associated with use of radiation in a univariate analysis. These were lower patient age, wealthier neighborhood income, and presence of comorbidity by the Deyo score. One tumor factor was also identified: intermediate risk of cancer recurrence in the pelvis. In this study, there was no multivariate analysis. ${ }^{1}$ Our study examined similar patient 
factors controlling for covariates and focused on a number of potential system factors affecting access. Unlike Kwon et al's findings, our multivariate analysis found increased used of radiation with age after controlling for covariates up to the ninth decade of life. We did not find the effect of comorbidity to be statistically significant after controlling for covariates. Our findings regarding neighborhood income were in keeping with Kwon et al's.

As mentioned in the discussion section of the last chapter, there is notable variation in the use of radiation among patients whose surgeries are at different Comprehensive Gynecologic Oncology Centres (CGOCs). For adjuvant radiation for breast cancer, the use rates for counties that have radiotherapy units follow a similar trend with wide variation among these counties. ${ }^{2}$ Also similar to the breast cancer data are the large number of counties whose use rates fall below the lowest use rates for counties with cancer centres. ${ }^{2}$

In multivariate analysis, we found that the operating hospital did not have a significant effect on use of radiation. On the other hand, the odds of radiation varied widely by cancer centre catchment area even after controlling for other variables including patient age. The fact that we controlled for prevailing waiting time and found very similar odds of radiation by most responsible cancer centre before and after controlling for waiting time suggests that differences in radiation use between most responsible cancer centre regions are not due primarily to waiting times. We found similar rates of use of radiation among most responsible cancer centre regions except for two of the nine radiotherapy regions open during this time in Ontario. One had comparably high rates of radiation and the other comparably low rates. These two regions both had relatively high rates of surgical staging and are geographically situated side by side (Chapter 3, Figure 3). We controlled for surgical staging in our multivariate analysis and there is little change in the magnitude of the odds ratios after controlling for surgical staging in multivariate 
analysis. We also examined variation in proxies of stage (age and death within one year of endometrial cancer diagnosis) which were unable to explain regional radiation use patterns.

We would hypothesize that other factors are involved in variation in use of radiation by most responsible cancer centre that we were not able to measure. There are probably differences in radiation treatment policies at these most-responsible centres. For instance, the low-use centre may have a policy that it will not treat patients with high-grade stage 1 cancers unless the cancer invades deeply into the muscle of the uterus. The high-use most responsible cancer centre probably has a specific policy which supports routine use of surgical staging for a large proportion of patients and if their sampling is more thorough than other regions, they may detect more patients with positive lymph nodes that would not have otherwise required radiation.

It is notable that for the large group of patients that were not surgically staged, having a surgery at a CGOC did not affect a patient's likelihood of receiving radiation. This would support the hypothesis that the experience of the referring surgeon with gynecologic cancers is not a factor in determining whether patients ultimately receive radiation. Based on our observed variations in use of radiation by most responsible cancer centre, particularly at two of the nine most responsible cancer centres, it seems that it is most likely that variation in use of radiation is more affected by the decision making of radiation oncologists rather than the referring doctor. As there are referral networks of various forms between comprehensive gynecologic oncology centres and regional hospitals in Ontario, it may be that these communication links have helped to ensure that patients who have surgeries at peripheral hospitals are properly referred in most cases. ${ }^{3}$ These cancer referral networks may also explain why neighborhood income quintile, our indicator of socioeconomic status (SES), was not associated with use of radiation as it was in a previous study of use of radiation for breast cancer in Ontario. ${ }^{4}$ A well defined referral and 
communications network with community surgeons provides a way for patients who may not be able to advocate for themselves as well as others to get the treatment that they need.

Overall, we found that $26 \%$ of women in our cohort received adjuvant radiation therapy. For a population with similar rates of lymph node staging to ours, Delaney et al estimated that $58 \%$ of patients with endometrial cancer would have an indication for external beam radiation at some point in their disease course. ${ }^{5}$ As previously mentioned, the Delaney et al's estimate included indications for radiation for local recurrence and distant metastasis, which would produce a higher estimate of use of radiation than had it not. Reviewing this study's methodology, the magnitude of overestimation would probably be about an absolute difference of $10 \%$. However, the observed rates of radiation in Ontario are still low compared to Delaney et al's estimate even after taking this into account.

One additional piece of evidence suggesting under-utilization of radiation and hence impaired access to radiation in Ontario for endometrial cancer is the radiation use rates for patients with high-risk endometrial cancer histologies (serous papillary and clear cell carcinoma). We found that $48 \%$ of patients with these high-risk histologies received radiation following curative surgery. Cancer Care Ontario guidelines do not address these high-risk histologies and the major randomized controlled trials either exclude these patients based on their high risk of recurrence (GOG-99) or have low numbers of them (PORTEC: 5/714 patients, ASTEC/EN-5: 94/905 patients).$^{6-9}$ Generally, in the absence of surgical staging, these patients are usually offered radiation if their cancer is localized. Consensus clinical practice guidelines and some case series would suggest that among patients who have surgical staging there are many who could still potentially benefit from radiation. ${ }^{10-12}$ In fact, Delaney et al estimated that $100 \%$ of patients 
with high-risk histologies should receive radiation for either adjuvant, definitive or palliative indications. $^{5}$

Given all patients in our cohort had curative surgery and all efforts were made to exclude non-curative cases of endometrial cancer, it seems surprising that there were not more patients with high-risk histology who received radiation. Though the optimal radiation use rate is probably not $100 \%$ for patients in our cohort with high-risk histology, it is quite likely that it is higher than the observed $48 \%$. We unfortunately lack direct stage and grade information for most patients in our cohort. In the future, the proportion of patients with stage information in Ontario will probably increase. Without stage information it is difficult to know the true extent of underutilization that is occurring for endometrial cancer patients in Ontario. Stage information would allow clear identification of patients where radiation therapy use is not debatable, such as Stage 1c grade III patients with endometrioid adenocarcinoma.

Among patients who received surgical staging, there was a trend toward decreased use of radiation with longer prevailing waiting times (38.0\% for $<78$ days vs $33.3 \%$ for $\geq 78$ days $\mathrm{p}=0.17)$. There was not a similar trend for patients who did not receive surgical staging $(25.2 \%$ for $<78$ days vs $25.0 \%$ for $\geq 78$ days $\mathrm{p}=0.84$ ). It may be that some women with lower risk of cancer recurrence who have had lymph node staging are not offered radiation during longer prevailing wait times as the managing physicians deem the balance of risk sufficient to forgo radiation. However, this seems an inadequate justification if it is the case since it might suggest that some patients are receiving un-needed radiation following surgical staging during times of shorter prevailing waiting times. An alternative and perhaps more concerning explanation is that some patients are not receiving needed radiation when regional cancer centres have longer prevailing waiting times. 
The further a patient lives from the most responsible cancer centre, the less likely she is to receive adjuvant radiation therapy. This would suggest that use of radiation for endometrial cancer in Ontario may be limited by spatial accessibility. There may be a number of reasons for our observations regarding use of radiation with increased distance and they are not mutually exclusive. A patient may not be able to afford travel to the nearest cancer centre, especially if a car is not available, gas is expensive or the time of travel means prohibitive loss of income. Travelling long distances daily for five or six weeks for radiation may be sufficiently inconvenient to affect patient decision making when the doctor communicates ambivalence regarding the benefits of a treatment. This can certainly occur for adjuvant radiation for endometrial cancer where there is still debate regarding intermediate-risk stage I patients. Our results would support the hypothesis that the treating radiation oncologist and their tumor board exert a greater influence on radiation use than referring doctors do. It may be that for certain patients, the treating radiation oncologist is sufficiently ambivalent about the benefits of treatment and so sway patients who are themselves hesitant to embark on treatment for various reasons.

\section{Strengths and Limitations}

The largest limitation of this study is the lack of stage and tumor grade information for all patients. A number of strategies were employed to minimize confounding and exclusion criteria to limit variability in cohort member's patient and tumour characteristics and control for proxies of stage. Though lack of full stage information limits the accuracy of our estimates, our study does provide some evidence that warrants further investigation. In addition, explanations of associations were limited by the lack of information on registration at regional cancer centres. For patients who did not receive radiation, we could not know for our whole cohort whether they 
were seen or not at a cancer centre. This makes it uncertain, for instance, if decreased use of radiation with increased prevailing waiting times was due to either referring doctors, consulting doctors or both.

This study is unique in its large sample size and the completeness of information on diagnosis and management of patients with endometrial cancer in Ontario. The information provided through linkages between OCR, CIHI and radiotherapy data allowed us to control for numerous covariates known to affect use of adjuvant radiation for endometrial cancer. This comprehensive patient information allowed us to examine potential underuse of radiation. Use of hospital case series from radiation oncology departments would not have permitted this. As mentioned, previous work by Kwon et al identified some patient factors associated with use of radiation in a univariate analysis. ${ }^{1}$ There was no control for covariates through a multivariate analysis. ${ }^{1}$ Our study examined some similar patient factors controlling for covariates and expanded the previous work by examining a number of potential system factors affecting access.

\section{Public health and Policy Implications and Recommendations}

The wide variation in radiation use observed between most responsible cancer centres probably relates to differing treatment policies for endometrial cancer at certain cancer centres in Ontario. With new cancer centres opening after the time of this study, this variation between regions of the province will probably widen. Provincial consensus in management of endometrial cancer with radiation is needed. An investigation into the treatment policies at the two mostresponsible cancer centres we identified with highest and lowest utilization rates of radiation will be an important step in identifying ways to harmonize radiation use rates. This would help to 
identify key treatment policy elements that could be responsible for the difference in their radiation use rates compared to other regions.

The CCO clinical practice guideline for stage I endometrial cancer offers recommendations supported by clinical trial evidence and has little to say about topics where such evidence is lacking. A comprehensive clinical practice guideline on endometrial cancer with expert opinion on topics where there is not strong randomized clinical trial evidence may help harmonize practice across the province. Compared to Delaney et al's findings, there is evidence suggesting global under-use of radiation in Ontario and a comprehensive clinical practice guideline would either justify current practice or provide clear incentive to change it.

There are some questions not answered yet by randomized clinical trials where there may not be consensus. Chemotherapy may be of use in advanced-stage and high-risk stage I and II endometrial cancer. It is uncertain how radiation should be used when chemotherapy is given, especially if a lymph node dissection is done and it is negative. Randomized clinical trials will hopefully soon address this topic, but till that time, it would be helpful to have a consensus statement on these issues to help reduce variation in practice.

Developing ways with minimal morbidity to identify patients who would benefit from radiation is also important and could help minimize practice variation. Sentinel lymph node biopsy is now commonly used for identification of patients with other forms of cancer such as breast cancer who have lymph node metastasis while minimizing the surgical morbidity of full lymph node staging. ${ }^{13}$ This method has been investigated for endometrial cancer and has shown some promise and could conceivably reduce the morbidity of lymph node staging. ${ }^{14}$ Improvements in non-invasive radiologic techniques such as MRI or PET scan may also lead to reliable ways to save more women the morbidity of a full pelvic lymph node dissection. ${ }^{14}$ 
It will be important to repeat this study in a few years to assess whether the opening of new cancer centres in the province improve use of radiation and reduce the association between distance from the most responsible cancer centre to the patient's home and use of radiation. It is important to emphasize that our findings suggest that simply opening more cancer centres will not in itself eliminate all practice variation for radiation for endometrial cancer. For instance, we found an association between variation in use of radiation and the most responsible cancer centre. If variation in practice between cancer centres persists or widens with the opening of new cancer centres, it is conceivable that proportionately less women will receive needed treatments for their endometrial cancers than at present.

As mentioned in Chapter 1, waiting lists are a form of implicit rationing. ${ }^{15}$ Decisions regarding treatment should be made explicit, and guidelines should be clear regarding who needs radiation when surgical staging is or is not performed. Our finding regarding less use of radiation when prevailing waiting times are longer is a concerning one and deserves careful investigation.

An analysis similar to the one presented in this thesis using data on registration at regional cancer centres for regions where full data on registration exist would help clarify whether it was the referring doctor or the consulting physician(s) who are most responsible for changes in use of adjuvant radiation use with high prevailing waiting times. If the referring physician is responsible, this would suggest that mechanisms such as mandated tumor board review of all cancer diagnoses in the cancer centre's catchment area would help reduce waiting time-related under-use of radiation. Whether the waiting time effect is more to do with the referring doctor or the consulting doctor, clear comprehensive provincial guidelines would probably help to address this problem. 
Given that advanced age is a poor prognostic factor for endometrial cancer, it is probably appropriate that larger proportions of patients receive radiation with increasing age. The drop in use of radiation after the age of 80 is probably also appropriate as normal patient life expectancy and comorbidity need to be taken into account in adjuvant treatment decisions. The fact that economic status did not affect radiation use after controlling for covariates such as age and comorbidity is reassuring; other patterns of practice studies have suggested alterations in practice patterns for patients from poorer neighborhoods that were unrelated to their needs. ${ }^{1,4}$

Finally, the limitations of the current electronic health data have been highlighted in some of the shortcomings of this study. For example, the lack of stage information has been highlighted in the discussion of our study results. As endometrial cancer cases are often completely managed by community surgeons, there is no opportunity to ever collect stage information on these patients through the current cancer centre-based mechanisms. This could be an argument for all cases of cancer in the province to be discussed and staged at a multi-disciplinary tumor board. Alternatively, community surgeons could be mandated to submit stage information to CCO on all cancer patients that they do not refer on to a cancer centre.

\section{Future Research}

In the future, stage information will probably be available for a larger proportion of women diagnosed with endometrial cancer in Ontario. Repeating this study when this information is available will produce more informative results, especially if stage information is available for patients who were not referred to cancer centres. As mentioned, we will need to examine a subset of the data where cancer centre registration information is available in order to determine the extent our findings relate to the referring doctor or the consulting doctor(s). 
Developing validated indicators of outcomes, quality and access to radiation will be an important endeavour in the process of improving cancer care for Ontario. For instance, measuring limitations in awareness of the indications of radiation by measuring hospital type is only an indirect measure of physician awareness. A more direct means such as direct doctor surveys have not been explored for this purpose.

A benchmark rate of radiation use in Ontario has not yet been determined. This would be a very achievable short term goal for further research using our cohort. In addition, we have not yet described dose and fractionation of radiation therapy for endometrial cancer and variation in use of brachytherapy versus external beam radiation therapy for endometrial cancer in Ontario.

We hope to repeat this study in three to five years using current data as a baseline. By this time, we will have information on treatments at newly opened cancer centres in the province. In addition, we expect practice patterns to change given new clinical trials regarding intermediaterisk endometrial cancer, surgical staging for endometrial cancer and chemotherapy for endometrial cancer.

We also plan to examine the effect of radiation use on outcomes. It will be important to determine if geographic regions and time periods with high or low use of radiation are associated with different survival or treatment-related morbidity. Mortality data for cancer patients is available to us through the Ontario Cancer Registry. Morbidity that is associated with hospital stays can be identified through the Canadian Institute of Health Information (CIHI) Discharge Abstract Database. 


\section{Conclusion}

This thesis provides evidence that there are factors unrelated to patient's needs involved in the use of adjuvant radiation for endometrial cancer in Ontario. We identified issues limiting availability and spatial accessibility of adjuvant radiation for endometrial cancer. We found that longer distance to regional cancer centres and higher prevailing waiting times were associated with less use of radiation as was having a surgery within the catchment of certain most responsible cancer centres. We also found increased age was an important patient-related factor associated with the use of radiation.

We recommend further research to gain insights into the mechanisms of these effects. In addition, building provincial consensus on management of endometrial cancer where clinical trial evidence does not exist may reduce practice variation. Developing novel means to clearly identify patients who would benefit from radiation for endometrial cancer will also be important. This study serves as a baseline for further work that will assess changes in use of radiation for endometrial cancer as the provincial cancer system evolves. Developing mechanisms to gather stage information on community surgeon-managed cancer patients will enrich future studies and ensure patients who need radiation for endometrial cancer receive it. Finally, using the defined cohort of endometrial cancer patients, we also plan to assess the effect of high and low radiation use patterns with treatment morbidity and survival.

\section{References}

1. Kwon JS, Carey MS, Cook EF, Qiu F, Paszat L. Patterns of practice and outcomes in intermediate- and high-risk stage I and II endometrial cancer: a population-based study. Int J Gynecol Cancer. Mar-Apr 2007;17(2):433-440. 
2. Kerba M, Miao Q, Zhang-Salomons J, Mackillop W. Defining the need for breast cancer radiotherapy in the general population: a criterion-based benchmarking approach. Clin Oncol (R Coll Radiol). Sep 2007;19(7):481-489.

3. Gagliardi A, DePetrillo D, Elit L. Referral patterns for gynaecologic cancers and precancerous conditions. J Obstet Gynaecol Can. Jul 2002;24(7):553-558.

4. Paszat LF, Mackillop WJ, Groome PA, Zhang-Salomons J, Schulze K, Holowaty E. Radiotherapy for breast cancer in Ontario: rate variation associated with region, age and income. Clin Invest Med. Jun 1998;21(3):125-134.

5. Delaney G, Jacob S, Barton M. Estimation of an optimal radiotherapy utilization rate for gynecologic carcinoma: part II - carcinoma of the endometrium. Cancer. Aug 15 2004;101(4):682-692.

6. Lukka H, Chambers A, Fyles A, et al. Adjuvant Radiotherapy in Women with Stage I Endometrial Cancer: A Clinical Practice Guideline. Vol \#4-10: Cancer Care Ontario Program in Evidence-Based Care; 2006.

7. Creutzberg CL, van Putten WL, Koper PC, et al. Surgery and postoperative radiotherapy versus surgery alone for patients with stage-1 endometrial carcinoma: multicentre randomised trial. PORTEC Study Group. Post Operative Radiation Therapy in Endometrial Carcinoma. Lancet. Apr 22 2000;355(9213):1404-1411.

8. Keys HM, Roberts JA, Brunetto VL, et al. A phase III trial of surgery with or without adjunctive external pelvic radiation therapy in intermediate risk endometrial adenocarcinoma: a Gynecologic Oncology Group study. Gynecol Oncol. Mar 2004;92(3):744-751.

9. Blake P, Swart AM, Orton J, et al. Adjuvant external beam radiotherapy in the treatment of endometrial cancer (MRC ASTEC and NCIC CTG EN.5 randomised trials): pooled trial results, systematic review, and meta-analysis. Lancet. Jan 10 2009;373(9658):137146.

10. Cardenes HR, Look K, Michael H, Cerezo L. Endometrium. In: Perez CA, Brady LW, Halperin EC, Schmidt-Ullrich RK, eds. Principles and Practice of Radiation Oncology Fifth Edition. New York: Lippincott Williams \& Wilkins; 2007.

11. Greer BE, Koh W-J co-Chairs. NCCN Clinical Practice Guidelines in Oncology-Uterine neoplasms volume 2.2009: National Comprehensive Cancer Network; 2009.

12. BC Cancer Agency. Cancer Management Guidelines- Gynecology- 3. Endometrium http://www.bccancer.bc.ca/HPI/CancerManagementGuidelines/Gynecology/Endometriu m/Mngmt.htm. Accessed May 10,2009; Document published 2008.

13. Quan ML, McCready D. The evolution of lymph node assessment in breast cancer. $J$ Surg Oncol. Nov 192008.

14. Selman TJ, Mann CH, Zamora J, Khan KS. A systematic review of tests for lymph node status in primary endometrial cancer. BMC Womens Health. 2008;8:8.

15. Mackillop WJ. Health Services Research in Radiation Oncology: Towards Achieving the Achievable for Patients with Cancer. In: Gunderson LL, Tepper JE, eds. Clinical Radiation Oncology 2nd Edition. New York: Churchill Livingstone; 2006. 


\section{Appendix 1}

\section{Percent Missing Values in Data Set}

\begin{tabular}{|l|l|l|}
\hline & Variable & $\%$ Missing Value \\
\hline System/Treatment factors & Hospital type & $0 \%$ \\
\hline & (Operating hospital) & $0 \%$ \\
\hline & Prevailing wait time & $0 \%$ \\
\hline & (Year of diagnosis) & $0 \%$ \\
\hline & (Date of admission for surgery) & $0 \%$ \\
\hline & Distance & $0 \%$ \\
\hline & (County of residence) & $0.03 \%$ \\
\hline & Most Responsible Cancer Centre & $0 \%$ \\
\hline Patient factors & Age & $0 \%$ \\
\hline & Neighborhood Income Quintile & $0.09 \%$ \\
\hline & (Vital status) & $0 \%$ \\
\hline Disease factors & Histology & $0 \%$ \\
\hline & Surgery type & $0 \%$ \\
\hline & Surgical staging & $0 \%$ \\
\hline & Peritoneal biopsy & $0 \%$ \\
\hline $\begin{array}{l}\text { Table 1. Percent missing values in data set. Variables in parenthesis were used to derive values of } \\
\text { independent variables. 96 (1.02\%) of patients did not have a distance to the regional cancer centre } \\
\text { and were assigned a distance category of 'Not Available'. }\end{array}$ \\
\hline
\end{tabular}


Appendix 2

\title{
Ethics Approval
}

\author{
QUEEN'S UNIVERSITY HEALTH SCIENCES \& AFFILIATED TEACHING \\ HOSPITALS RESEARCH ETHICS BOARD \\ December 4, 2007 \\ December 4, 2007 \\ Mr. Timothy Hanna \\ Department of Community Health and Epidemiology \\ Queen's University \\ Dear Mr. Hanna, \\ A Population-Based Study of Post-Operative Radiotherapy Utilization in \\ Ontario for Endometrial Cancer \\ Dr. Harriet Richardson and Dr. Bill Mackillop \\ Co-Investigators: \\ This Ethics Application was subject to:

$\begin{array}{ll}\square \quad & \text { Full Board Review } \\ \text { Meeting Date: } \\ \square \quad \text { Expedited Review }\end{array}$

I am writing to acknowledge receipt of your recent ethics submission. We have examined the protocol for your project (as stated above) and consider it to be ethically acceptable. This approval is valid for one year from the date of the Chair's signature below. This approval will be reported to the Research Ethics Board. Please attend carefully to the following list of ethics requirements you must fulfill over the course of your study:

$>$ Reporting of Amendments: If there are any changes to your study (e.g. consent, protocol, study procedures, etc.), you must submit an amendment to the Research Ethics Board for approval. (see http://www.queensu.ca/vpr/reb.htm).

$>$ Reporting of Serious Adverse Events: Any unexpected serious adverse event occurring locally must be reported within 2 working days or earlier if required by the study sponsor. All other serious adverse events must be reported within 15 days after becoming aware of the information.

$>$ Reporting of Complaints: Any complaints made by participants or persons acting on behalf of participants must be reported to the Research Ethics Board within 7 days of becoming aware of the complaint. Note: All documents supplied to participants must have the contact information for the Research Ethics Board.

$>$ Annual Renewal: Prior to the expiration of your approval (which is one year from the date of the Chair's signature below), you will be reminded to submit your renewal form along with any new changes or amendments you wish to make to your study. If there have been no major changes to your protocol, your approval may be renewed for another year.

Yours sincerely,
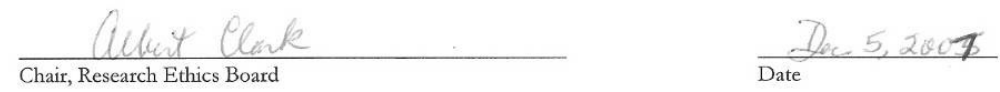

ORIGINAL TO INVESTIGATOR - COPY TO DEPARTMENT HEAD- COPY TO HOSPITAL(S) /P\&I (If APpropriate) - FILE COPY

Study Code: EPID-254-07

$>\quad$ Investigators please note that if your trial is registered by the sponsor, you must take responsibility to ensure that the registration information is accurate and complete 
QUEEN'S UNIVERSITY HEALTH SCIENCES \& AFFILIATED TEACHING HOSPITALS RESEARCH ETHICS BOARD

The membership of this Research Ethics Board complies with the membership requirements for Research Ethics Boards as defined by the Tri-Council Policy Statement; Part C Division $\mathbf{5}$ of the Food and Drug Regulations, OHRP, and U.S DHHS Code of Federal Regulations Title 45, Part 46 and carries out its functions in a manner consistent with Good Clinical Practices.

Federalwide Assurance Number : \#FWA00004184 \#IRB00001173

Current membership of the Queen's University Health Sciences \& Affiliated Teaching Hospitals Research Ethics Board

Dr. A.F. Clark

Dr. H. Abdollah

Rev. T. Deline

Dr. M. Evans

Prof. L. Keeping-Burke

Dr. J. Low

Dr. W. Racz

Dr. H. Richardson

Dr. B. Simchison

Dr. A.N. Singh

Dr. E. Tsai

Rev. J. Warren

Ms. K. Weisbaum

Ms. S. Wood
Emeritus Professor, Department of Biochemistry, Faculty of Health Sciences, Queen's University (Chair)

Professor, Department of Medicine, Queen's University

Community Member

Community Member

Assistant Professor, School of Nursing, Queen's University

Emeritus Professor, Department of Obstetrics and Gynaecology, Queen's University and Kingston General Hospital

Emeritus Professor, Department of Pharmacology \& Toxicology, Queen's

Assistant Professor, Department of Community Health \& Epidemiology Project Coordinator, NCIC CTG, Queen's University

Assistant Professor, Department of Anesthesiology, Queen's University

WHO Professor in Psychosomatic Medicine and Psychopharmacology Professor of Psychiatry and Pharmacology

Chair and Head, Division of Psychopharmacology, Queen's University

Director \& Chief of Psychiatry, Academic Unit, Quinte Health Care,

Belleville General Hospital

Assistant Professor, Department of Paediatrics and Office of Bioethics, Queen's University

Community Member

LL.B. and Adjunct Instructor, Department of Family Medicine (Bioethics)

Associate Director, Office of Research Services (Ex-Officio) 